\title{
Principales yacimientos marinos de interés para el patrimonio paleontológico en la Península Ibérica e Islas Baleares
}

\author{
Eustoquio Molina | Dpto. de Ciencias de la Tierra e IUCA, U. de Zaragoza \\ Miguel Company | Dpto. de Estratigrafía y Paleontología, U. de Granada \\ María Eugenia Dies | Dpto. de Didáctica de las Ciencias Experimentales e IUCA, \\ U. de Zaragoza \\ José Sandoval | Dpto. de Estratigrafía y Paleontología, U. de Granada \\ Francisco J. Sierro | Dpto. de Geología, Universidad de Salamanca
}

URL de la contribución <www.iaph.es/revistaph/index.php/revistaph/article/view/4197>

\section{RESUMEN}

Se describen los principales yacimientos marinos de interés para el patrimonio paleontológico situados en la Península Ibérica y en las Islas Baleares. Estos yacimientos son relevantes principalmente por distintas razones. Unos por haber servido para la definición de estratotipos de pisos o de límites; otros por su excelente registro fósil que ha permitido definir nuevas especies; así como otros por su buen desarrollo estratigráfico que ha permitido realizar estudios de alta resolución sobre distintos eventos de extinción y evolución. Muchos de estos yacimientos han sido protegidos por su gran interés patrimonial. Las secciones más relevantes del Paleozoico son: Murero, Río Luna, Arnao, Cabañeros, Checa, Sierra Norte de Sevilla, Demués y Las Llacerías. Las secciones más relevantes del Mesozoico son: Sierra de Lúgar, Agua Larga, Cúber, Fuentelsaz, Puerto Escaño, Cañada Luenga, Río Argos, Organyà y Olazagutía. Las secciones más relevantes del Cenozoico son: Caravaca, Zumaya, llerdiense, Arguis, Gorrondatxe, Fuente Caldera, Navazuelo, Sorbas-Níjar, Casa del Pino, Andaluciense y EsteponaSan Pedro.

\section{Palabras claves}

Baleares | Cenozoico | Estratotipos | Eventos | Mesozoico | Paleontología | Paleozoico | Patrimonio | Península Ibérica | Registro de fósiles | Yacimientos marinos | 


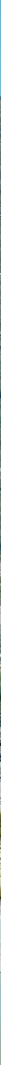

Sección de Arguis. Formaciones Margas de Arguis, Belsue-Atarés y Campodarbe | foto Eustoquio Molina 


\section{INTRODUCCIÓN}

En la Península Ibérica y en las islas Baleares, principalmente en Mallorca, existe una serie de yacimientos, generalmente llamados cortes o secciones cuando están formados por sedimentos marinos, que son muy interesantes para el estudio y conservación del patrimonio paleontológico. Los cortes principales son aquellos que tienen un buen registro fósil y han permitido aplicarlo a la solución de problemas geológicos (datación y reconstrucción paleoambiental) y biológicos (evolución y extinción). Algunos de estos cortes fueron descritos en 2008 por distintos autores en una publicación del Instituto Geológico y Minero de España, editada por Ángel García-Cortés.

A diferencia de los yacimientos continentales, los marinos suelen tener una mayor extensión y un diferente valor patrimonial. Los continentales pueden tener una extensión que varía desde una cueva a un lago y casi siempre su

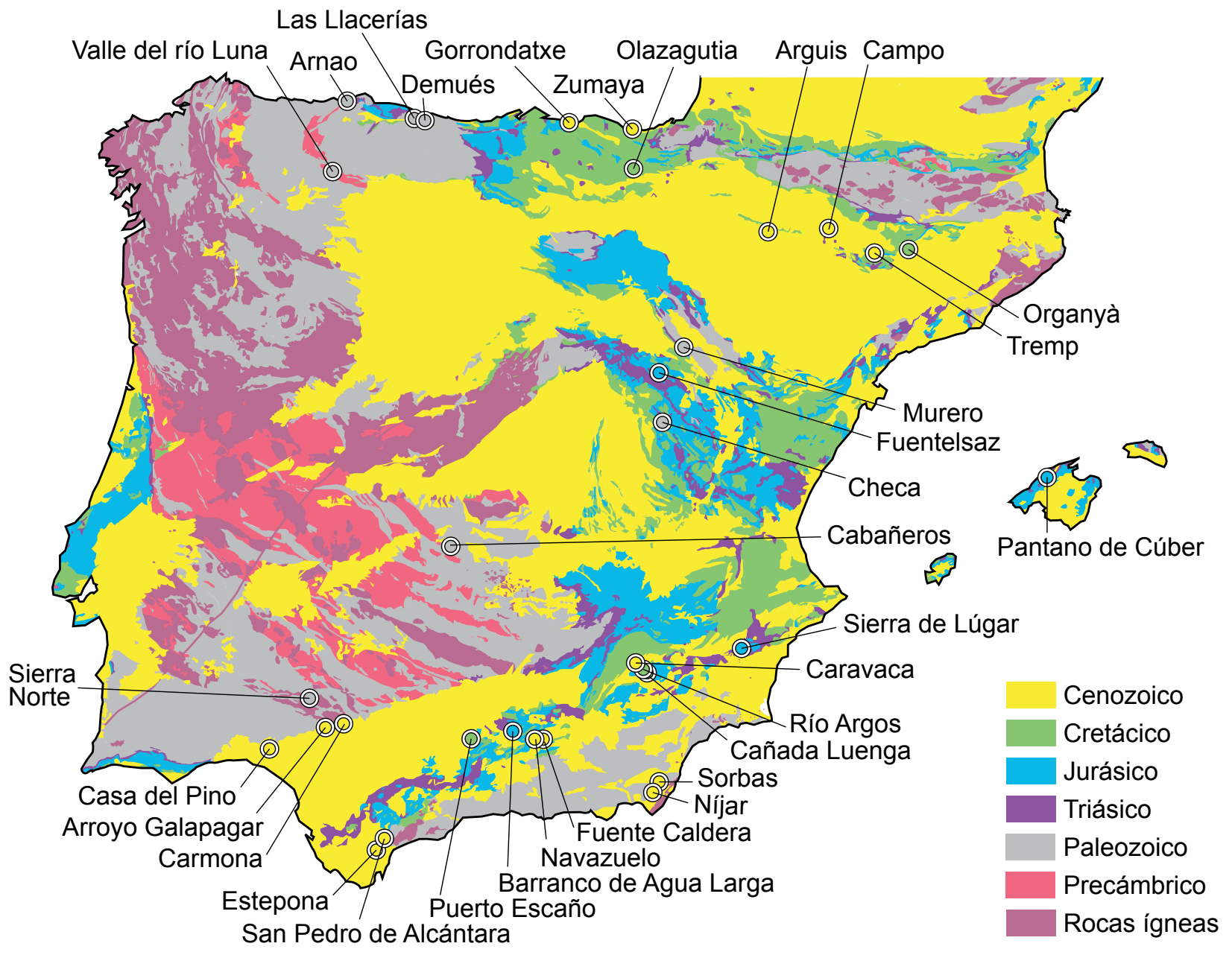


extensión suele estar limitada a un sitio más reducido dentro de ellos. Estos pueden tener valor enorme como ocurre con los yacimientos de homínidos o dinosaurios. Por el contrario, los marinos pueden variar desde un ambiente restringido costero a un ambiente oceánico profundo, los fósiles suelen estar muy diseminados y no tener tanto valor por sí mismos. En consecuencia, los yacimientos marinos suelen tener un valor patrimonial más aplicado que la simple recolección de fósiles y este interés puede variar desde la definición de estratotipos a la creación de parques geológicos.

El objetivo de este trabajo es describir los principales yacimientos marinos de la Península Ibérica e Islas Baleares, destacando las excelentes características de las distintas secciones para el estudio del patrimonio paleontológico y promocionando su conocimiento y protección.

\section{YACIMIENTOS PALEOZOICOS}

Son numerosos los puntos de interés paleontológico que muestran registro paleozoico a lo largo y ancho del territorio peninsular. En Gutiérrez-Marco, Rábano, Liñán et ál. (2008) se seleccionan y describen con detalle dentro de este patrimonio siete puntos de interés geológico para el Paleozoico Inferior y Medio de los que pasaremos a hacer un resumen. Estos son el yacimiento de Murero (Zaragoza), la sección estratigráfica del valle del río Luna (León), el arrecife y plataforma del Devónico de Arnao (Asturias), el Cámbrico y Ordovícico del Parque Nacional de Cabañeros (Ciudad RealToledo), los depósitos glaciomarinos y yacimiento paleontológico de Checa (Guadalajara), el Paleozoico del sinclinal del Valle (Sevilla) y el Silúrico de Salas de la Ribera (León). Cabe además añadir a estos lugares el yacimiento del Cámbrico del Cerro del Hierro, también en la provincia de Sevilla (MIRAS, 1990; MAYORAL; LIÑÁN; GÁMEZ VINTANED et ál., 2008) y los yacimientos carboníferos asturianos de Las Llacerías y Demúes (MARQUíNEZ; MÉNDEZ; MENÉNDEZ-ÁLVAREZ, 1982; SÁNCHEZ DE POSADA; VILLA; MARTÍNEZ CHACÓN et ál., 1999).

\section{Sección de Murero (Zaragoza)}

El yacimiento de Murero se encuentra a $1 \mathrm{~km}$ de la localidad homónima, en la Rambla de Valdemiedes, a unos $80 \mathrm{~km}$ al sur de Zaragoza. Aparece citado por primera vez en 1862 por el naturalista francés Edouard de Verneuil donde señala haber descubierto allí restos de la fauna primordial (nombre con que se conocían los fósiles más antiguos, especialmente pertenecientes al grupo de los trilobites). Desde entonces se cuentan por cientos las publicaciones realizadas sobre el yacimiento y su contenido fosilífero. Además, ha sido estudiado en varias tesis doctorales. Su importancia es tal que en 1997 fue el primer yacimiento paleontológico español protegido por ley bajo la figura de bien de interés cultural. La litología del yacimiento 

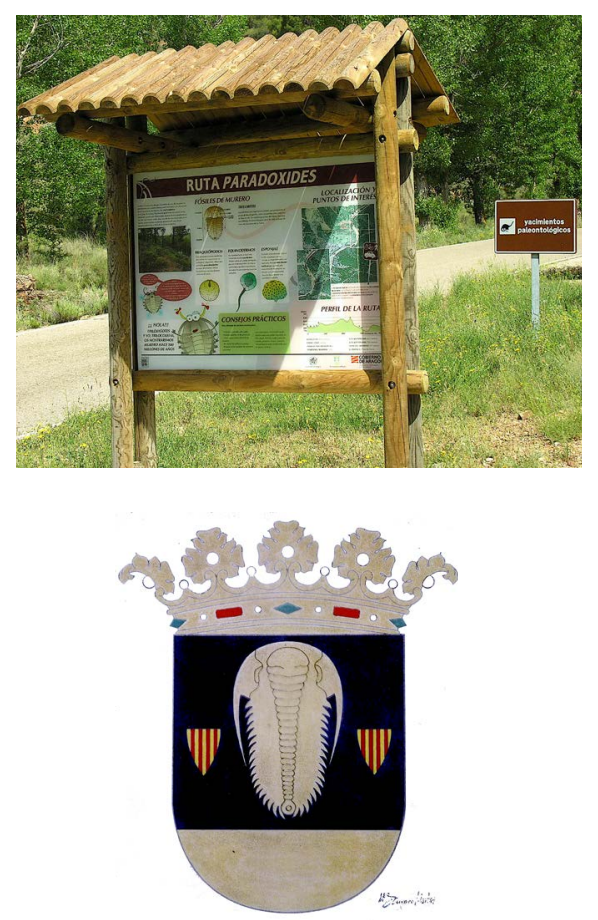

Cartel explicativo de la sección de Murero y escudo del municipio con trilobites | foto M. ${ }^{a}$ Eugenia Dies es mayoritariamente silicicláscica con algunos nódulos carbonatados, en su mayoría degradados. Aquí se definieron el techo del piso Bilbiliense (final del Cámbrico Inferior) y el piso Caesaraugustiense (Cámbrico Medio). Murero presenta tres características fundamentales que lo hacen único y especial.

Una de ellas es que muestra, de manera ininterrumpida, una secuencia estratigráfica de más de 200 metros que abarca unos 10 millones de años de edad Cámbrico Inferior y Medio, y en la que se han encontrado más de 70 especies de trilobites (LIÑÁN; GOZALO, 1986), que pueden ser estudiadas desde un punto de vista filogenético al estar registradas en continuidad. En total se conocen unas 100 especies de invertebrados pertenecientes no sólo a los trilobites sino también a otros grupos como equinodermos, braquiópodos (calcíticos y fosfáticos), crustáceos, hiolítidos u organismos sin partes mineralizadas de diversos tipos, algas o gran variedad de icnofósiles. Gracias a esta continuidad en el registro se pudo realizar uno de los primeros estudios sobre dimorfismo sexual en trilobites (GOZALO; LIÑÁN; DIES, 2003). La segunda característica fundamental del yacimiento tiene que ver con los citados organismos sin cuerpo mineralizado, que raramente suelen fosilizar y que hacen de este lugar un verdadero yacimiento de conservación excepcional (konservatlagerstätte) al haberse encontrado gusanos paleoescolécidos, esponjas sin espículas (demospongia), onicóforos o las nombradas algas. Por último, en Murero se registra un evento de extinción en los niveles del final del Cámbrico Inferior (Bilbiliense) en el que toda la fauna de trilobites se ve renovada, desapareciendo la totalidad de las especies existentes hasta ese momento y siendo reemplazadas por nuevos grupos en la base del Cámbrico Medio.

La importancia internacional de Murero la ha hecho sede de varios congresos en los que especialistas de todo el mundo han visitado el lugar (LIÑÁN; GOZALO; DIES ÁLVAREZ et ál., 2008). Los fósiles en él encontrados han permitido la correlación con lugares tan distintos como Marruecos, Cerdeña, Alemania o Turquía. En los últimos años, se ha llevado a cabo una serie de mejoras en el yacimiento para su visita turística como la colocación de carteles explicativos de aspectos geológicos y paleontológicos que además guían una serie de recorridos o rutas. Para terminar, además de señalar la gran concienciación existente entre los vecinos en relación con la protección del patrimonio paleontológico, no podemos olvidarnos de que Murero es uno de los pocos lugares del mundo que muestra en su escudo un trilobites.

\section{Sección del Valle del Río Luna (León)}

Al noroeste de la provincia de León, en el entorno al municipio de Los Barrios de Luna, se encuentra una sucesión que contiene materiales que abarcan casi 250 millones de años repartidos en unos 5.000 metros de serie estrati- 
gráfica bastante continua. Esta localidad se conoce desde 1860 cuando, De Prado por un lado, y Verneuil y Barrande por otro, citaron la presencia de la fauna primordial en ella. La zona está dividida en 22 formaciones geológicas con composiciones tanto de tipo siliciclástico como carbonatado. La sección comienza en una discordancia sobre rocas precámbricas y continúa mostrando rocas depositadas desde el Cámbrico al Carbonífero.

El contenido fosilífero es abundante y variado (se han definido 18 especies nuevas) y está conformado por trilobites cámbricos y ordovícicos, icnofósiles, palinomorfos continentales silúrico-devónicos, braquiópodos, equinodermos, corales devónicos. La riqueza paleontológica de Los Barrios de Luna ha permitido la apertura de un centro de interpretación que facilita la comprensión de la zona de forma didáctica. Así, Cantabrana Cortés, NúñezLahuerta, Gámez Vintaned et ál. (2014) describen con detalle las características del Centro de Interpretación de la explosión de la vida en el Cámbrico abierto en Miñera de Luna. Además, la situación al lado del embalse de Los Barrios de Luna suma un aspecto lúdico a la zona con abundancia de oferta para senderistas y amantes de la naturaleza y la cultura histórica.
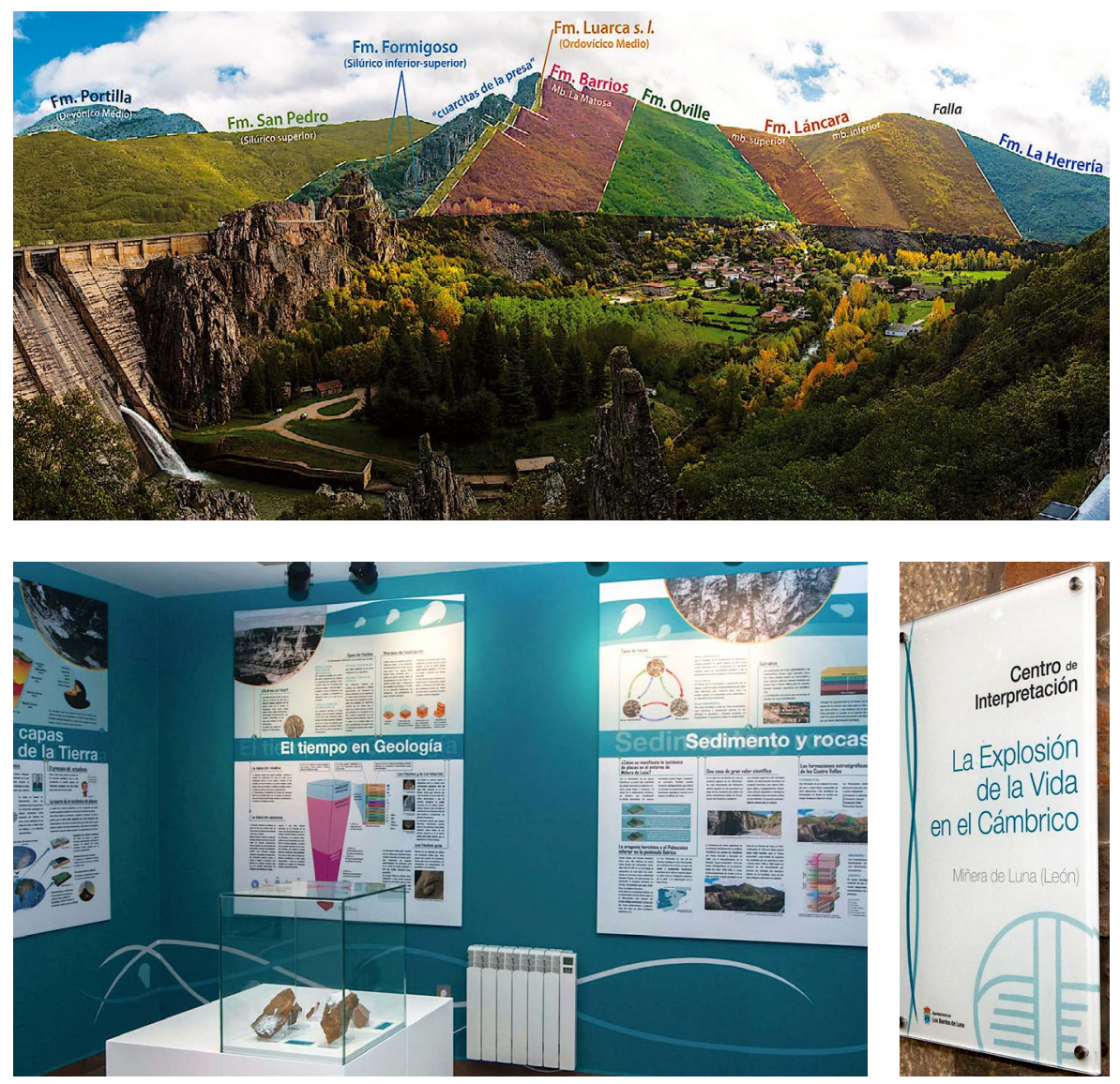

Sección del Valle del Río Luna. Esquema de las formaciones geológicas y Centro de Interpretación | fotos modificadas a partir de CANTABRABA CORTÉS; NÚÑEZ-LAHUERTA; GÁMEZ VINTANED et ál., 2014 


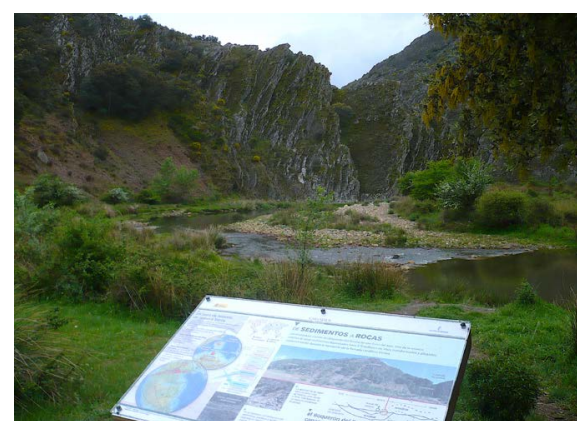

Sección de Cabañeros, vista de la ruta del Boquerón de Navas de Estena | foto modificada a partir de GUTIÉRREZ-MARCO; RÁBANO; BARRÓN, 2011

\section{Sección de Arnao (Asturias)}

Arbizu y Méndez Bedia (2006) califican esta zona costera del municipio de Castrillón, en el Principado de Asturias, como "auténticos museos paleontológicos" al aire libre que precisan de herramientas de protección que eviten que siga sometiéndose al deterioro continuo que su fácil accesibilidad y fama le están provocando. Los estratos afloran entre las playas de Santa María del Mar y Salinas y en ellos puede verse un arrecife devónico formado por corales de diversos tipos (rugosos solitarios, coloniales, tabulados) y estromatopóridos de unos 150 metros de espesor, así como su evolución en el tiempo. Además, también se registran briozoos, braquiópodos, bivalvos, gasterópodos, crinoideos, trilobites e incluso vertebrados pisciformes. Completan el yacimiento los sedimentos correspondientes a la llamada Plataforma de Arnao (ARBIZU; MÉNDEZ-BEDIA; SOTO, 1995) cuya preservación permiten estudiar la evolución de diversas comunidades marinas y su relación con las variaciones del nivel del mar.

\section{Sección de Cabañeros (Ciudad Real)}

Situado en los Montes de Toledo (entre la provincia homónima y la de Ciudad Real), que ha sido protegido como Parque Nacional de Cabañeros, registra más de 250 especies pertenecientes a taxones de trilobites, braquiópodos, cefalópodos, bivalvos, graptolitos, equinodermos. En especial, cabe destacar la importancia de los restos fósiles de edad Ordovícico Inferior y Medio, que hacen de esta sección una de las más representativas del oeste de Europa.

Desde un punto de vista de la geología estructural, es uno de los lugares donde puede observarse la discordancia Toledánica en la que, sobre los materiales plegados del Neoproterozóico y Cámbrico Inferior, se depositan los citados sedimentos del Ordovícico en un episodio relacionado con una bajada del nivel del mar de esta edad (SAN JOSÉ LANCHA; GUTIÉRREZMARCO; RÁBANO, 1997; GUTIÉRREZ-MARCO; SAN JOSÉ LANCHA; PIEREN et ál., 2007). El interés por la zona queda ya demostrado en la publicación de Gómez de Llarena y Pou (1914), donde describen con detalle una excursión geológica a Navas de Estena en la que ya figura su importancia paleontológica.

En 2011, Gutiérrez-Marco, Rábano y Barrón, dentro de la XIX Bienal de la Real Sociedad Española de Historia Natural, describen detalladamente la Ruta del Boquerón de Estena (a lo largo del río del mismo nombre), resaltando la gran geodiversidad y biodiversidad de la zona. Señalan la presencia de mesas de interpretación y señalizaciones que facilitan la visita. En la sucesión estratigráfica figurada destacan la presencia de diversos icnogéneros, como Cruziana, Skolithos o espectaculares galerías de más de 11 metros de longitud y 25 centímetros de diámetro producidas por gusanos gigantes. 


\section{Sección de Checa (Guadalajara)}

En Checa (provincia de Guadalajara) existen unos depósitos glaciomarinos de edad Ordovícico terminal, que Gutiérrez-Marco, Rábano, Liñán et ál. (2008) indican que afloran visiblemente al este de esta localidad manchega y en la carretera que la une con Orea (provincia de Guadalajara). En este contexto se registran conodontos contenidos en los fragmentos de roca formados previamente a la glaciación y arrastrados durante ella. En el tránsito Ordovícico-Silúrico se encuentra un depósito cuarcítico de potencia irregular, seguido de unas pizarras de gran potencia y llamativo contenido en graptolitos, con más de 60 tipos distintos, y que permiten correlacionar con Alemania, Cerdeña, Reino Unido o el norte de Europa, Norteamérica e incluso Australia, además de ver cómo evolucionan a lo largo del extenso tramo sedimentado. También existe registro de conodontos, moluscos, trilobites y euriptéridos. En la actualidad, el yacimiento se encuentra incluido en el Geoparque de la comarca de Molina y Alto Tajo y se puede visitar, aunque ha habido una protección con vallado de los puntos de mayor interés científico.

\section{Secciones de la Sierra Norte (Sevilla)}

El sinclinal del valle incluido en el Geoparque de la Sierra Norte de Sevilla, los depósitos paleozoicos cercanos a Cazalla de la Sierra, representan un periodo que abarca desde el Ordovícico al Devónico. Si bien su descubrimiento se produjo a mitad del siglo XX, su relevancia ha hecho que ya haya sido visitado por la Subcomisión Internacional de Estratigrafía del Silúrico y el grupo de trabajo de Graptolitos de la Asociación Paleontológica Internacional (GUTIÉRREZ-MARCO; RÁBANO; LIÑÁN et ál., 2008). Su importancia reside en la abundancia de fósiles de ambiente pelágico, especialmente graptolitos, que ha posibilitado la delimitación de 25 biozonas que permiten la correlación precisa con otras áreas del mundo, además de la identificación de eventos globales como el calentamiento y posterior glaciación del final del Ordovícico o la posterior radiación y extinción silúrica.

El yacimiento del Cerro del Hierro, también dentro del Geoparque de la Sierra Norte de Sevilla, en el término de San Nicolás del Puerto, se encuentra un yacimiento singular de edad Cámbrico Inferior situado en una antigua zona minera (MIRAS, 1990). Se trata de un espectacular paisaje paleokárstico con gran abundancia de registro fósil entre el que cabe destacar los trilobites en los materiales siliciclásticos y los biohermos de arqueociatos en las calizas karstificadas. La peculiaridad del enclave se centra en que representa una karstificación intracámbrica rellenada posteriormente por más materiales de esta misma edad. Mayoral, Liñán, Gámez Vintaned et ál. (2008) proponen una serie de recorridos para su visita que clasifican en función del interés del visitante.

\section{Secciones de Demués y las Llacerías (Asturias)}

Según Sánchez de Posada, Martínez Chacón y Villa (2002) la excepcionalidad de los yacimientos carboníferos de la Zona Cantábrica reside en que, 

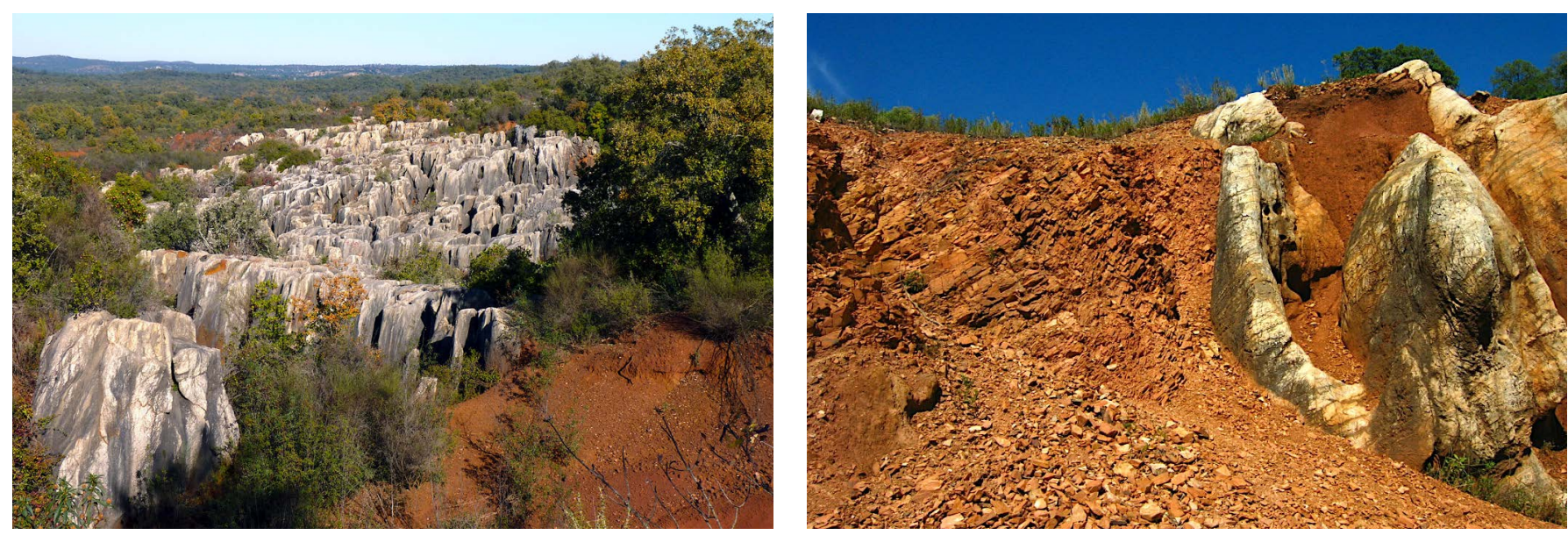

Sección de la Sierra Norte de Sevilla. Vista general del Paleokarst y detalle de las lutitas que rellenan el karst | fotos modificadas a partir de MAYORAL LIÑ̃́N; GÁMEZ VINTANED et ál., 2008

al contrario que en otras zonas del oeste de Europa, están formados por sedimentos mayoritariamente marinos o con alguna intercalación de depósitos continentales. La sección de Las Llacerías se sitúa cerca de Covadonga (Asturias), está formada por unos $1.100 \mathrm{~m}$ de calizas con conodontos y foraminíferos que facilitan la datación de los estratos que los contienen y permiten establecer asociaciones de faunas típicas de la edad a pesar de no ser una sección continua y estar interrumpida por vegetación (MARQUÍNEZ; MÉNDEZ; MENÉNDEZ-ÁLVAREZ, 1982).

Sánchez de Posada, Villa y Martínez Chacón (1999) indican que la sección de Demués (Asturias) se extiende a lo largo de unos $200 \mathrm{~m}$ en forma de sedimentos siliciclásticos y carbonatados, con alguna intercalación de niveles de carbón. Entre los grupos fósiles registrados se encuentran ejemplares de braquiópodos (de los que se han descrito nuevas especies), espongiarios, moluscos, crinoideos, corales, foraminíferos y ostrácodos. Como curiosidad negativa, los conodontos son muy poco frecuentes en esta sección.

\section{YACIMIENTOS MESOZOICOS (JURÁSICOS)}

Los afloramientos de materiales jurásicos están ampliamente distribuidos tanto en la España peninsular (cordilleras Cantábrica, Ibérica, Litoral Catalana y Bética) como en Baleares, principalmente en Mallorca, Ibiza y Cabrera (OLÓRIZ; LINARES; GOY et ál., 2002; VERA; ARIAS; GARCÍAHERNÁNDEZ et ál., 2004). La gran cantidad de afloramientos con interés paleontológico patrimonial hace difícil elegir aquellos que puedan considerarse más representativos. Como más significativos se han elegido los de sierra de Lúgar (cordillera Bética, provincia de Murcia), barranco de Agua Larga (cordillera Bética, provincia de Jaén), pantano de Cúber (sierra de Tramuntana, Mallorca) y Fuentelsaz (cordillera Ibérica, provincia de Guadalajara). 


\section{Sección de la sierra de Lúgar (Murcia)}

Las sierras de Quípar, Lúgar y Corque, situadas en el sector oriental del subbético externo (cordillera Bética) presentan afloramientos jurásicos de gran relevancia patrimonial (ROMERO; SANDOVAL; CARACUEL, 2004). Entre las diversas secciones que afloran en estas sierras cabe destacar la denominada Sierra Lúgar 1. La sección de Lúgar 1 es la más representativa del Jurásico de todo el Subbético Externo. Esta sección aflora a $\sim 6 \mathrm{~km}$ al NO de Fortuna (provincia de Murcia) y aproximadamente $1 \mathrm{~km}$ al oeste de la carretera que une Fortuna y La Garrapacha. Desde mediados del siglo XX (FALLOT, 1945) la sierra de Lúgar ha sido objeto de númerosos estudios. Esta sección incluye gran parte del Jurásico, extendiéndose desde el Jurásico Inferior hasta el Tithoniense Superior. Entre los macrofósiles, los ammonites son muy abundantes y bien preservados en diferentes intervalos de la sección, pero otros invertebrados, especialmente braquiópodos (BAEZA-CARRATALÁ, 2008; BAEZA-CARRATALÁ; GARCÍA-JORAL; SANDOVAL, 2014) y belemnites, también son comunes en algunos tramos. Los microfósiles, foraminíferos bentónicos y planctónicos, radiolarios, calpionélidos, etc., son asimismo muy significativos en varios intervalos. La buena exposición de la sección, junto a la abundancia, diversidad y buena preservación de los fósiles que contiene, hace que la misma pueda considerarse bien de interés del patrimonio paleontológico. En la sección de la sierra de Lúgar se observa una serie de discontinuidades estratigráficas, que limitan las distintas formaciones estratigráficas, ligadas a las cuales aparecen las concentraciones fósiles de mayor interés.

La sección (Jurásico Inferior) comienza con una potente serie carbonatada (más de $200 \mathrm{~m}$ ) de dolomías (parte basal) y de calizas micríticas y oolíticas (parte superior) típicas de plataforma marina carbonatada. Estas calizas acaban en una discontinuidad estratigráfica, ligada a la cual aparecen niveles condensados ( $10 \mathrm{~cm}$ a $1,6 \mathrm{~m}$ ) de calizas amarillentas, verdosas 0 rojizas con abundantes macrofósiles que forman una lumaquela de ammonites y braquiópodos a los que se unen belemnites, bivalvos y gasterópodos (SEYFRIED, 1978; BRAGA, 1983; BAEZA-CARRATALÁ, 2008). Los microfósiles, especialmente foraminíferos bentónicos, son también abundantes y están bien preservados. La excelente exposición de estos niveles junto a la buena preservación de sus fósiles hace que los mismos tengan alto interés patrimonial y científico. La parte superior del Jurásico Inferior ( 20 $\mathrm{m}$ de espesor) son margas y margocalizas, primero, y calizas margosas, después, que contienen ammonites bioestratigráficamente representativos (SEYFRIED, 1978), pero de menor interés patrimonial.

Sobre una segunda discontinuidad con hard ground y costras ferruginosas, existe un nuevo nivel condensado (escala decimétrica) de calizas nodulosas amarillentas, rojas o violáceas, con abundantes ammonites (de edad Aaleniense Tardío-Bajociense Temprano), belemnites y braquiópodos

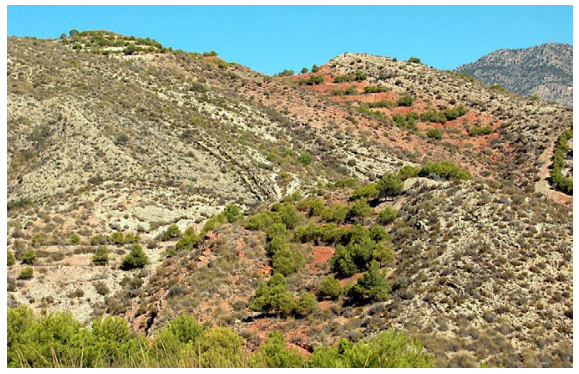

Sección de sierra de Lúgar. Vista general del Jurásico Medio/Superior | foto Luis O'Dogherty y José Sandoval 

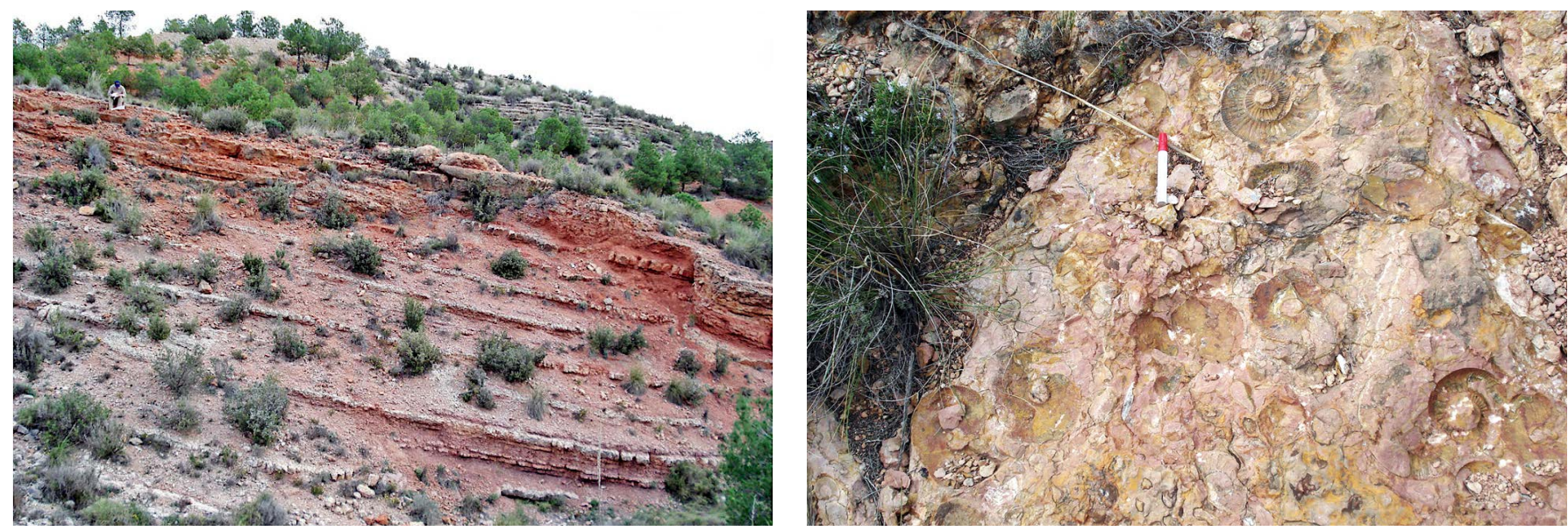

Sección de Lúgar. A la izquierda, corte del

Bathoniense; a la derecha, discontinuidad del

Calloviense inferior | fotos Gregorio Romero y José Sandoval
(SEYFRIED, 1978; BAEZA-CARRATALÁ; GARCÍA-JORAL; SANDOVAL, 2014), que corona al Jurásico Inferior.

El resto del Jurásico Medio comienza con $\sim 25 \mathrm{~m}$ de calizas micríticas, a veces con nódulos de sílex, que finalizan en una discontinuidad, ligada a la cual existe nivel condensado calizo verdoso, con costras ferruginosas y abundantes ammonites de la base del Bajociense Superior (SANDOVAL, 2016). La sección continúa con calizas micríticas grisáceas con sílex ( 7,5 m de espesor) con escasos ammonites y belemnites y con abundantes radiolarios y bivalvos de concha fina. Éstas pasan gradualmente a calizas nodulosas con intercalaciones de margas $(\sim 3 \mathrm{~m})$ que pasan de gris o blanco a violeta o amarillento. Los ammonites, abundantes y diversificados, datan Bajociense Superior (SANDOVAL, 2016). Además, existen frecuentes belemnites y braquiópodos (BAEZA-CARRATALÁ; GARCÍA-JORAL; SANDOVAL, 2014). Hacia arriba en la sección, los bivalvos pelágicos (Bositra) llegan a ser muy abundantes y los radiolarios son progresivamente más escasos. En el Bathoniense ( $\sim 9 \mathrm{~m})$ dominan las calizas nodulosas y las margas con nódulos calcáreos de color violeta a rojizo. En la parte inferior predominan las margas $y$, hacia el techo, dominan las calizas con estratos calcáreos más gruesos y compactos. El Bathoniense culmina en una nueva discontinuidad estratigráfica fácilmente observable sobre el terreno por la presencia de costras ferruginosas, abundantes concreciones ovoides de Fe-Mn, y porque las conchas de ammonites aparecen a veces corroídas y truncadas (SANDOVAL; CHECA, 2002; SANDOVAL, 2016). Los ammonites, abundantes y diversificados en la transición Bajociense-Bathoniense y en todo el Bathoniense, permitieron obtener una bioestratigrafía detallada (SEYFRIED, 1978; BAEZA CARATALÁ; GARCÍA-JORAL; SANDOVAL, 2014; SANDOVAL, 2016). Esto conlleva, a su vez, a que se haya podido correlacionar la escala bioestratigráfica con las escalas de estratigrafía isotópica (SANDOVAL; O'DOGHERTY; BILL et ál., 2011) y paleomagnética (OSETE, 1999). Sierra Lúgar 1 representa 


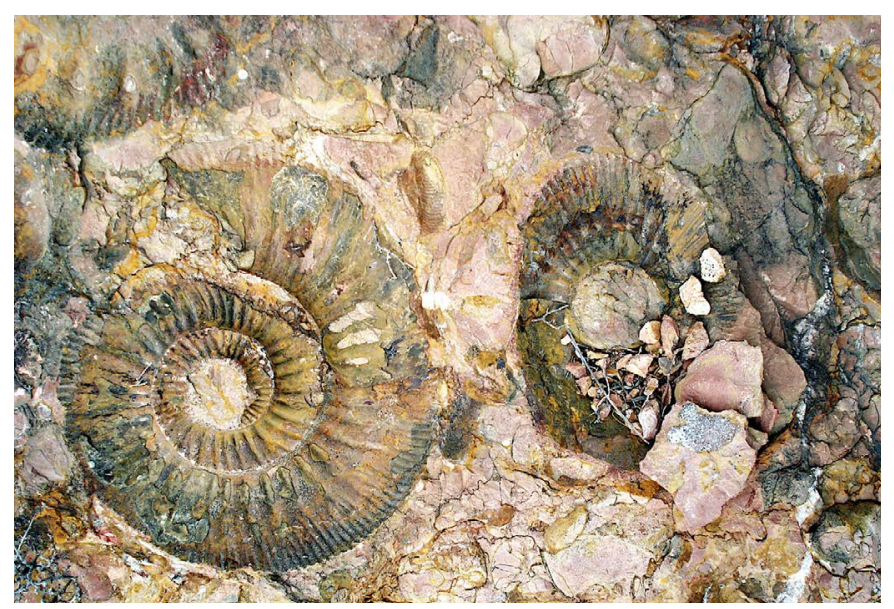

la localidad más apropiada para el estudio del límite inferior del Bathoniense en el dominio mediterráneo, el cual viene marcado por la primera aparición del género Morphoceras que sustituye a Dimorphinites y por el reemplazamiento de Nannolytoceras polyhelictum por N. tripartitum (SANDOVAL, 2016). El holotipo (género tipo) de un género nuevo y una especie nueva de ammonites (Lugariceras lugarensis), definidos por Schlögl, Elmi, Rakús et ál. (2006), procede del Bathoniense Inferior de esta sección, la cual es, por tanto, su localidad tipo y las calizas nodulosas del Bathoniense Inferior el estratotipo del nuevo taxón.

La transición Jurásico Medio-Jurásico Superior (Calloviense-Oxfordiense Inferior) se caracteriza por la presencia de discontinuidades, hiatos asociados, y por un espesor estratigráfico extremadamente reducido $(\sim 1 \mathrm{~m})$. Los macrofósiles, especialmente ammonites, son abundantes y bien preservados en Calloviense Inferior donde frecuentemente aparecen corroídos. Muchos de los fósiles constituyen núcleos recubiertos con láminas de Fe-Mn generando grandes oncoides (SANDOVAL; CHECA, 2002; SANDOVAL, 2016). Una discontinuidad con costra ferruginosa asociada existe en la parte superior del Calloviense Inferior donde aparecen concreciones nodulares de Fe-Mn del tamaño de $\mathrm{cm}$ a dm, las cuales contienen bioclastos reelaborados, especialmente ammonites, y litoclastos. El Jurásico Medio finaliza en una capa decimétrica de calizas nodulosas rojas en donde continúan existiendo concreciones de Fe-Mn reelaboradas. Los bivalvos de concha fina son los principales componentes de las microfacies del Jurásico Medio, siendo especialmente abundantes en el intervalo Bajociense Superior-Calloviense. El paso Jurásico Medio-Jurásico Superior coincide con un cambio profundo en la litología, en las asociaciones de ammonoideos y, especialmente, en las microfacies. Es destacable el reemplazamiento de los bivalvos de concha fina (Bositra), que dominaron el Jurásico Medio, por foraminíferos planctónicos (Globuligerina) que dominarán todo el Oxfordiense. 
El Jurásico Superior comienza con calizas nodulosas, margas rojas con nódulos calcáreos y calizas nodulosas margosas $(\sim 11 \mathrm{~m})$ de edad Oxfordiense-Kimmeridgiense Inferior. Los ammonites, abundantes y bien preservados, son los macrofósiles dominantes, pero también aparecen belemnites, equinodermos, corales aislados y bivalvos. Las microfacies son wackestones de foraminíferos planctónicos (Globuligerina) con Saccocoma, Globochaete, escasos bivalvos de concha fina, foraminíferos bentónicos, radiolarios y ammonites juveniles. Conforme se sube en la sección, se observa una disminución en tamaño y abundancia de foraminíferos planctónicos, paralela con un aumento en radiolarios. Existen abundantes trazas fósiles como Thalassinoides, Chondrites y Planolites (CARACUEL; OLÓRIZ; RODRÍGUEZ-TOVAR, 2000), las cuales también tienen interés patrimonial. Estudios que actualmente se están llevando a cabo muestran que los eventos bióticos están ligados a cambios paleoceanográficos y, posiblemente, climáticos.

EL resto del Jurásico Superior, Kimmeridgiense Superior-Tithoniense ( $\sim 35$ $\mathrm{m}$ de espesor), está constituido por calizas bien estratificadas, de carácter noduloso, rojas a gris-crema, en su parte inferior, y solo parcialmente nodulosas de colores grises a rosa en la parte superior, donde aparecen pequeñas intercalaciones margosas. Todo el intervalo contiene ammonites y algunos belemnites. Entre los microfósiles observables en lámina delgada destacan, según los niveles, Saccocómidos, Globochaete y Calpionélidos. El interés patrimonial de este tramo radica en su buena exposición y estratificación, así como en los fósiles de ammonites que aparecen en algunos niveles (SEYFRIED, 1978), los cuales aún no han sido estudiados en detalle.

En sierra de Lúgar y en otras áreas próximas como en sierra de Corque o sierra de Quípar, los niveles con mayor contenido en ammonites están prácticamente expoliados por coleccionistas y comerciantes de fósiles, por lo que sería conveniente aplicar una protección especial. En áreas próximas a sierras de Lúgar y Corque, materiales equivalentes a los existentes en este tramo se explotan como rocas ornamentales. Sería conveniente proteger estas secciones con fin de que no acaben convirtiéndose en canteras para explotaciones similares.

En conclusión, el Jurásico de sierra de Lúgar tiene gran interés patrimonial en los siguientes apartados: a) tiene excelente exposición permitiendo una perfecta observación y el levantamiento detallado de secciones estratigráficas; b) contiene abundantes macrofósiles, muchos de ellos observables a simple vista en el campo; c) los fósiles tienen gran valor bioestratigráfico lo que admite mejorar la escala cronoestratigráfica; d) los buenos afloramientos permiten además observar las diversas discontinuidades estratigráficas que existen en la Subbética y analizar las eventos ligados a las mismas; e) sierra de Lúgar es la localidad tipo de un nuevo género y una nueva espe- 
cie de ammonites, Lugariceras lugarensis (SCHLÖGL; ELMI; RAKÚS et ál., 2006); f) los análisis de isótopos estables, $\delta^{13} \mathrm{C}$ y $\delta^{16} \mathrm{O}$, muy bien registrados, permiten mejorar las escalas de estratigrafía isotópica; g) la presencia de materiales que conservan la señal paleomagnética permite correlacionar los datos paleomagnéticos con la escala cronoestratigráfica; h) especial interés tiene la correlación entre la abundancia relativa de bivalvos pelágicos (Bositra) y de foraminíferos planctónicos (conoglobigerínidos).

\section{Sección del Barranco de Agua Larga (Jaén)}

La sección de barranco de Agua Larga, ubicada en el sector central del Subbético Medio, aflora a lo largo del arroyo de ese nombre, a $500 \mathrm{~m}$ al NW del Cortijo Alorí, cerca del pueblo de Campillo de Arenas, provincia de Jaén. En esta sección afloran materiales que abarcan todo el Jurásico, pero sólo el intervalo Aaleniense-Bajociense Inferior muestra especial interés desde el punto de vista patrimonial. Desde el último cuarto del siglo pasado, este intervalo ha sido objeto de estudio bajo diferentes enfoques (SANDOVAL, 1983; LINARES; SANDOVAL, 1990, 1996; SANDOVAL; CHANDLER, 2000; O'DOGHERTY; SANDOVAL; BARTOLINI et ál., 2006; SANDOVAL; HENRIQUES; LINARES, 2000; SANDOVAL; O'DOGHERTY; BILL et ál., 2011; SILVA; CANALES; SANDOVAL et ál., 2017; AGUADO, O'DOGHERTY; SANDOVAL, 2017). Agua Larga es, sin ningún tipo de dudas, la sección más completa y más desarrollada de Aaleniense marino de todo el Tetis occidental y probablemente de todo el mundo. Están representados los límites inferior y superior del Aaleniense y todas las biozonas (zonas y subzonas de ammonites) del mismo. También en Agua Larga está representado y ha sido bien estudiado todo el Bajociense Inferior.

El intervalo Aaleniense Inferior-Bajociense basal ( $125 \mathrm{~m}$ de espesor) se compone de una alternancia rítmica de margocalizas micríticas y margas grises (mudstones y wackestones con radiolarios, algunos bivalvos de concha fina y foraminíferos bentónicos). Las trazas fósiles, especialmente Zoophycos y Chondrites, son localmente abundantes. Los ammonites son altamente representativos. En el Aaleniense inferior (zona de Opalinum) se encuentran Leioceras lineatum, L. bifidatum, L. crassicostatum, Tmetoceras scissum, Erycites fallifax, Vacekia stephensi, etc., las cuales proporcionan una bioestratigrafía precisa.

El Aaleniense Medio destaca la abundancia y buena preservación de los radiolarios. Los estratos margosos, muy oscuros, predominan sobre los calcáreos. Los ammonites son relativamente abundantes, bien conservados y diversificados apareciendo grafoceratinos, tmetocerátidos, erycítidos Lytoceratida y Phylloceratida. Las zonas estándar de ammonites de Murchisonae y Bradfordensis, están bien representadas y sus límites son fácilmente determinables. El Aaleniense Superior tiene litología y microfacies similares a la de capas subyacentes. En su parte inferior, las calizas 

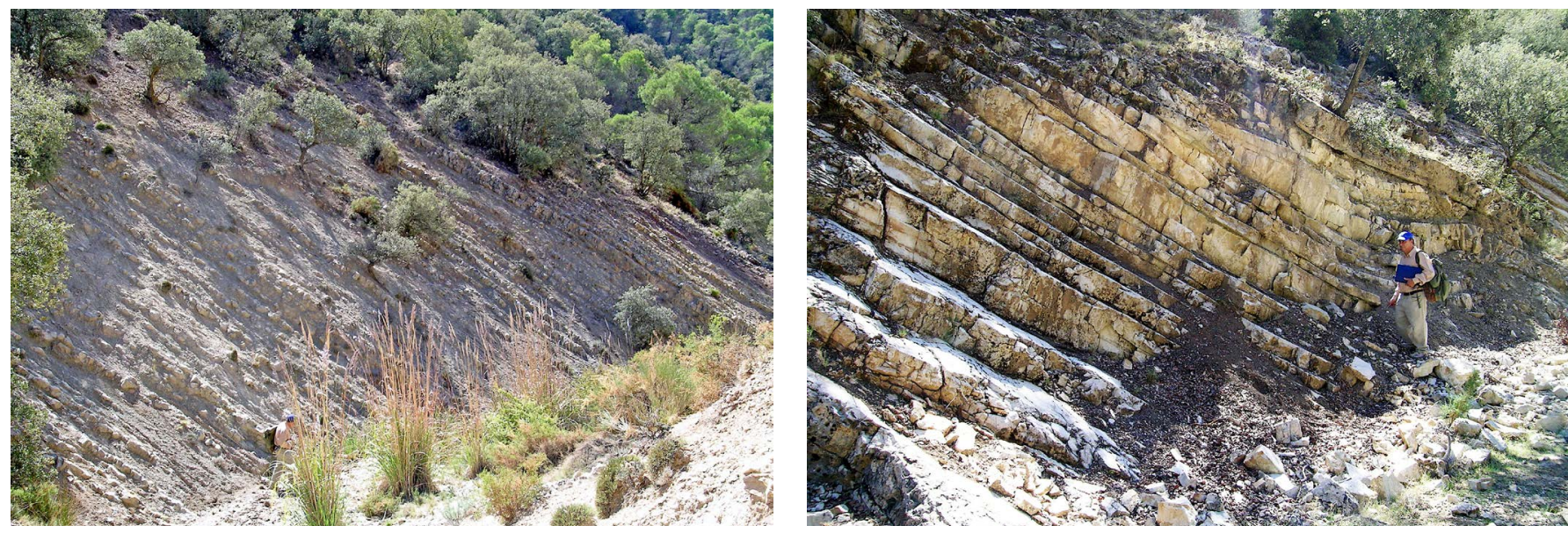

Sección de Agua Larga. A la izquierda, corte del límite Aaleniense/Bajociense; a derecha, corte del Bajociense inferior | fotos Luis O’Dogherty y José Sandoval margosas predominan sobre las margas, y los fósiles de ammonites son significativos, pero no abundantes. En el Aaleniense terminal, los depósitos margosos predominan sobre los margocalizos. Estos presentan abundantes ammonites, bien preservados y diversificados, con grafoceratinos y erycítidos (Haplopleuroceras) como elementos dominantes. Otros ammonites como grammoceratinos, hammatocerátidos, sonnínidos, otoítidos, strigocerátidos, haplocerátidos, Phylloceratina y Lytoceratina son más escasos. En el estrato JAQ1.(-49) de Linares y Sandoval (1990) se estableció el límite inferior del Bajociense, el cual viene marcado por los primeros registros de los géneros de ammonites Hyperlioceras y Reynesella.

La parte inferior del Bajociense presenta caracteres muy similares a las capas subyacentes con estratos margosos que generalmente tienen mayor espesor que los margocalizos. Las trazas fósiles (Zoophycos) son comunes. Las asociaciones de ammonites están dominadas por grafoceratinos y erycítidos (Haplopleuroceras), muy abundantes en la base y más escasos, hasta desaparecer, conforme se avanza en la sección. Otros ammonites como sonnínidos, haplocerátidos, otoítidos, Phylloceratida y Lytoceratida también pueden ser relativamente comunes. De la parte inferior de este tramo proceden los holotipos de dos nuevas especies de ammonites: Haplopleuroceras mouterdei (LINARES; SANDOVAL, 1996) y Riccardiceras westermanni (SANDOVAL; LINARES; HENRIQUES, 2000). Consecuentemente esta sección representa la localidad tipo y en ella se sitúa el estratotipo de estas dos especies. La ritmita de margocalizas-margas es coronada por un tramo $(\sim 6,5$ $\mathrm{m}$ de espesor) de calizas nodulosas o parcialmente nodulosas rojas o grises con pequeñas intercalaciones margosas. La parte inferior del tramo contiene ammonites (Witchellia y Labyrinthoceras dietzei) pertenecientes a la Zona de Laeviuscula (SANDOVAL, 1983; SANDOVAL; CHANDLER, 2015). La parte superior, con ammonites menos significativos (Sonninites, Bradfordia, Phylloceratida y Lytoceratida) se corresponde con la base de la Zona de 
Propinquans (SANDOVAL, 1983; O'DOGHERTY; SANDOVAL; BARTOLINI et ál., 2006; AGUADO; O'DOGHERTY; SANDOVAL, 2017). El resto del Bajociense Inferior ( $39 \mathrm{~m}$ de espesor) está compuesto por margas y margocalizas de color gris-claro que pasan progresivamente a calizas casi blancas con abundantes nódulos de sílex (SANDOVAL, 1983; O'DOGHERTY; SANDOVAL; BARTOLINI et ál., 2006; AGUADO; O'DOGHERTY; SANDO VAL, 2017). Las microfacies más representativas son mudstones o packstones con radiolarios y bivalvos de concha fina (Bositra). La presencia de Zoophycos es un carácter típico de todo el tramo. Las asociaciones de ammonites, no abundantes, pero bien preservados, están dominadas por Phylloceratida, sonnínidos, otoítidos y estefanocerátidos, pero otros grupos como esfaerocerátidos, estrigocerátidos, bradfordiinos y Lytoceratida pueden ser también comunes. Estos ammonites permiten diferenciar las zonas de Propinquans y de Humphriesianum del Bajociense Inferior (SANDOVAL, 1983; O'DOGHERTY; SANDOVAL; BARTOLINI et ál., 2006; AGUADO; O'DOGHERTY; SANDOVAL, 2017). El Jurásico de la sección de Larga continua con una colada de rocas subvolcánicas, margas silíceas y pelitas silíceas rojas del Bajociense Superior-Oxfordiense.

La excelente exposición de la sección, buena conservación de sus microfósiles (foraminíferos bentónicos y radiolarios) y nanofósiles calcáreos, así como la buena señal isotópica, hace de esta sección un lugar adecuado para la realización de estudios sobre estos grupos de microorganismos y sobre estratigrafía isotópica (O'DOGHERTY; SANDOVAL; BARTOLINI et ál., 2006; SANDOVAL; O'DOGHERTY; BILL et ál., 2011; SILVA; CANALES; SANDOVAL et ál., 2017; AGUADO; O'DOGHERTY; SANDOVAL, 2017).

En la reunión del BWG (Bajocian Working Group) que tuvo lugar en 1988 en Piobbico (Las Marcas, Italia), la sección de Agua Larga fue propuesta como candidata a estratotipo de límite del Bajociense (LINARES; SANDOVAL, 1990). Después de una larga discusión en disputa con las secciones de la Bahía de Bearreraig (Isla de Skye, Escocia), de Digne (Bajos Alpes, Sureste de Francia) y de Cabo Mondego (Portugal), esta última fue elegida como estratotipo (PAVIA y ENAY, 1997) del Bajociense. No obstante, la sección de Agua Larga mostró tener ammonites tan abundantes y significativos como Cabo Mondego y, posiblemente, mejor registro estratigráfico, sin lagunas estratigráficas aparentes en el Aaleniense y Bajociense Inferior.

Se puede concluir que Aaleniense-Bajociense Inferior del Barranco de Agua Larga tiene interés patrimonial en lo siguiente: a) tiene excelente exposición permitiendo una perfecta observación y el levantamiento detallado de secciones estratigráficas; b) abundancia de macrofósiles y de microfósiles con gran significado bioestratigráfico y medioambiental; c) la sección es la localidad tipo de dos especies de ammonites (Haplopleuroceras mouterdei LINARES y SANDOVAL, 1996 y Riccardiceras westermanni SANDOVAL; 
LINARES; HENRIQUES, 2000); d) los análisis de isótopos estables, $\delta^{13} \mathrm{C}$ y $\delta^{16} \mathrm{O}$, bien registrados, permiten mejorar las escalas de estratigrafía isotópica y su correlación con la escala cronoestratigráfica; e) la comparación de abundancia y diversidad de nanofósiles calcáreos y radiolarios con los cambios isotópicos permite comprobar la respuesta de estos organismos a cambios medioambientales.

\section{Sección del pantano de Cúber (Mallorca)}

La Serra de Tramuntana o Sierra Norte de Mallorca se extiende a lo largo de unos $90 \mathrm{~km}$, con anchura máxima de $15 \mathrm{~km}$, lo que supone casi un $30 \%$ del territorio de la isla. Varios picos superan los $1.000 \mathrm{~m}$ de altura, destacando el Puig Major (1.443). La Serra de Tramuntana fue declarada, en todo su conjunto, Patrimonio Mundial por la UNESCO en el año 2010, en la categoría de paisaje cultural. Gran parte de la superficie de Serra de Tramuntana está constituida por afloramientos jurásicos.

Dentro del Jurásico de la Sierra de Tramuntana existen diferentes áreas con interés paleontológico patrimonial. Quizá la más interesante, tanto por exposición, cantidad y preservación de macrofósiles como por su fácil acceso, sea el área de Pantano de Cúber. Los mejores afloramientos para levantar la sección están localizados cerca del embalse Cúber, entre los puntos kilométricos 33 y 35 de la carretera Ma10 y a ambos lados de la misma. Los primeros estudios geológicos de la Sierra Norte de Mallorca datan del siglo XIX (LA MARMORA, 1835; HAINE, 1855; HERMITE, 1879; NOLAN, 1893, etc.). En ellos se hace referencia a macrofósiles (ammonites, belemnites y braquiópodos) del Jurásico de Mallorca, muchos de los cuales proceden del área del pantano de Cúber. Fue Fallot en 1922 quien, en su tesis doctoral, dio a conocer por primera vez listas detalladas de fósiles de la Sierra Norte de Mallorca, indicando las localidades de procedencia, entre las que aparece la zona donde se encuentra el pantano de Cúber. De gran interés para el estudio de los fósiles de Mallorca son los trabajos, especialmente sobre micropaleontología, de Guillermo Colom, entre los que se encuentran algunos del Jurásico del área de Cúber (COLOM, 1970, etc.).

En la sección de Cúber, como en toda la Sierra de Tramuntana, los materiales jurásicos muestran muchos caracteres comunes con los del Subbético Externo (OLÓRIZ; LINARES; GOY et ál., 2002). El intervalo HettangiensePliensbachiense está formado por sedimentos carbonatados de plataforma marina de energía baja o media, pero también presenta algunos niveles de depósitos característicos de alta energía. En este intervalo, sin apenas interés paleontológico, salvo por los foraminíferos bentónicos y algunos niveles con laminaciones estromatolíticas, se diferencian tres formaciones (ÁLVARO; BARNOLAS; CABRA et ál., 1989): a) formación Mal Pass, brechas calcáreas y dolomías masivas ( $150 \mathrm{~m}$ de espesor) con laminaciones estromatolíticas, típicas de sedimentos de plataforma poco profunda (Hettangiense); 


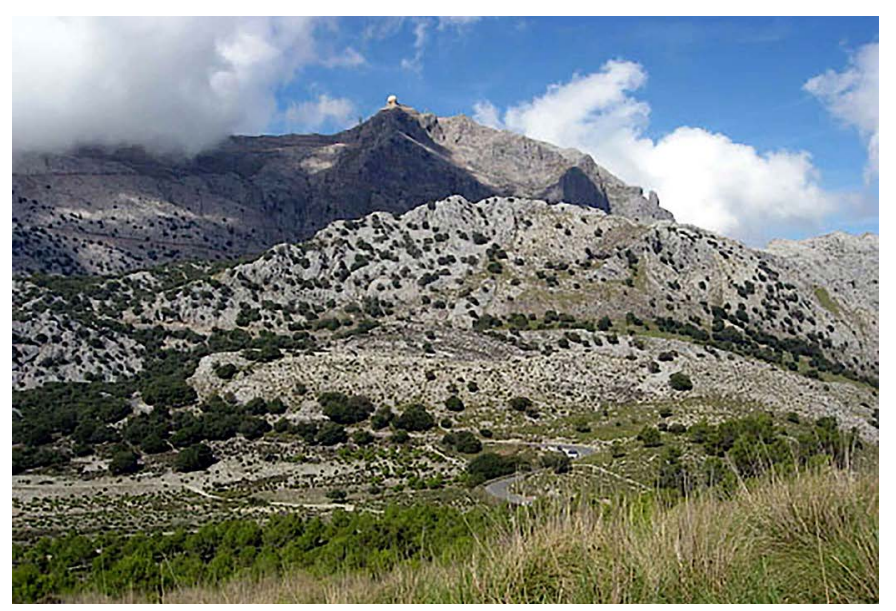

b) formación Sóller ( $200 \mathrm{~m}$ espesor), de calizas de plataforma poco profunda, bien estratificadas que en su parte superior pueden cambiar progresivamente a margas ocre o calizas margosas ( $\sim 30 \mathrm{~m}$ de espesor) con fauna nerítica (Sinemuriense-Pliensbachiense Inferior); éstas son seguidas por microconglomerados y areniscas silíceas (miembro Es Raco), un nivel guía en toda la isla (ÁLVARO; BARNOLAS; CABRA et ál., 1989; BARÓN; FORNÓS; GELABERT et ál., 2004); c) formación El Cosconal; calizas grises ( $\sim 50 \mathrm{~m}$ de espesor) con abundantes crinoideos, donde, localmente, aparecen belemnites y ammonites (Pliensbachiense Superior). Esta formación está tapizada por un "hard ground" con costras limoníticas y una discontinuidad con hiato asociado, con abundantes macrofósiles (ammonites, belemnites, etc.) de gran interés paleontológico. El hiato separa al Pliensbachiense del Toarciense Medio o Superior y marca un cambio profundo en la sedimentación de carbonatos de plataforma a una ritmita de margas hemipelágicas y de calizas margosas.

En el intervalo Toarciense-Jurásico Medio predominan los sedimentos pelágicos, con margas y calizas margosas que alternan con calizas con sílex y calizas nodulosas en su parte superior, donde también aparecen algunos niveles radiolaríticos (ÁLVARO; BARNOLAS; CABRA et ál., 1989; SANDOVAL, 1994; OLÓRIZ; LINARES; GOY et ál., 2002; BARÓN; FORNÓS; GELABERT et ál., 2004; BARNOLAS; LLAVE, 2012). En toda la Sierra de Tramuntana, y por tanto en la sección de Cúber, se diferencian las formaciones Gorg Blau, Cúber, y Puig d'en Paré. La formación Gorg Blau ( $25 \mathrm{~m}$ de espesor) es una unidad compleja cuyo límite basal es el nivel con costras de Fe-Mn y abundantes ammonites del Toarciense. Este nivel pasa gradualmente a calizas nodulosas rojas o grises, a ritmitas de margas y margocalizas grises o blancas y, finalmente, calizas parcialmente nodulosas. Los fósiles son abundantes, destacando ammonites que datan el intervalo Toarciense-Bajociense Inferior, foraminíferos bentónicos,
Sección de Cúber. A la izquierda, vista general, a la José Sandoval en el corte del Bajociense inferior | fotos Luis O'Dogherty y José Sandoval 
radiolarios y bivalvos de concha fina (ÁLVARO; BARNOLAS; CABRA et ál., 1989; GOY; URETA, 1988; SANDOVAL, 1994; OLÓRIZ; LINARES; GOY et ál., 2002).

Sobre la Fm Gorg Blau existen alternancias de margas y margocalizas con niveles que contienen nódulos de sílex ( $-50 \mathrm{~m}$ de espesor) de la Fm Cúber (ÁLVARO; BARNOLAS; CABRA et ál., 1989; OLÓRIZ; LINARES; GOY et ál., 2002; BARNOLAS; LLAVE, 2012), las cuales contienen trazas fósiles (Zoophycos y Chondrites). Los ammonites, abundantes, bien preservados y representativos, permiten diferenciar las biozonas del Bajociense de Discites, Laeviuscula, Propinquans, Humphriesianum, Niortense y Garantiana (SANDOVAL, 1994).

El intervalo Bajociense Terminal-Calloviense constituye la formación Puig d'en Paré ( $10 \mathrm{~m}$ espesor), en la que se pueden diferenciar dos tramos. En el inferior dominan las calizas nodulosas con microfacies de bivalvos de concha fina (Bositra) y con abundantes ammonites del intervalo Bajociense Superior-Bathoniense Medio (SANDOVAL, 1994). La parte superior, después de una pequeña discontinuidad, está constituida por unos $125 \mathrm{~cm}$, donde alternan niveles con bivalvos de concha fina y Clobochaete, en cuya base se han reconocido ammonites (Macrocephalites gracilis) del Calloviense Inferior (SANDOVAL, 1994; OLÓRIZ; LINARES; GOY et ál., 2002), y niveles silíceos con abundantes radiolarios muy bien conservados (CARACUEL; EL KADIRY; OLÓRIZ, 1995). Sobre estos niveles existe una discontinuidad que abarca parte del Calloviense y el Oxfordiense Inferior (OLÓRIZ; LINARES; GOY et ál., 2002; BARÓN; FORNÓS; GELABERT et ál., 2004; BARNOLAS; LLAVE, 2012).

El Jurásico Superior continua con la formación Alfabia ( 20 m de espesor), la cual está formada por calizas nodulosas, alternantes con margas grises en la parte inferior, y por niveles de calizas tableadas en la parte superior. En algunos niveles aparece sílex formando nódulos o bandas continuas. Las microfacies son ricas en radiolarios, protoglobigerinas y Saccocoma (CARACUEL, 1996; CARACUEL; EL KADIRY; OLÓRIZ., 1995; CARACUEL; OLÓRIZ, 1998; OLÓRIZ; LINARES; GOY et ál., 2002; BARÓN, FORNÓ; GELABERT et ál., 2004; BARNOLAS; LLAVE, 2012). Los ammonoideos son relativamente abundantes y característicos, lo que permitió reconocer todas las zonas de ammonites del intervalo Oxfordiense Medio-Kimmeridgiense (CARACUEL, 1996; CARACUEL; OLÓRIZ, 1998).

En el Tithoniense se reconocen dos formaciones bien diferentes entre sí. La inferior, Fm Aumedrá ( $35 \mathrm{~m}$ ), está constituida por calizas tableadas de color gris claro $u$ ocre muy pobres en macrofósiles, aunque aparecen algunos ammonites mal preservados del Tithoniense basal (CARACUEL; OLÓRIZ, 1998; OLÓRIZ; LINARES; GOY et ál., 2002; BARÓN; FORNÓS; GELABERT 
et ál., 2004). Las microfacies presentan Globochaete, Saccocoma y radiolarios como elementos más comunes. El resto del Tithoniense constituye la parte inferior $(\sim 7 \mathrm{~m})$ de la formación son Torreles. La parte inferior son unos $2 \mathrm{~m}$ de calizas nodulosas grises alternando con niveles bioclásticos resedimentados. El resto de la formación son calizas nodulosas rojas que alternan con pequeñas capas margosas donde ocasionalmente aparecen niveles turbidíticos/tempestíticos distales. Las microfacies son wackestones o mudstones con abundantes calpionélidos, radiolarios, Saccocoma y Globochaete junto a otros componentes minoritarios. Los ammonites, abundantes, a veces, y bien conservados, y los calpionélidos permiten buenas dataciones (OLÓRIZ; CARACUEL; MARQUES et ál., 1995; CARACUEL, 1996; CARACUEL; OLÓRIZ, 1998) reconociéndose todas las biozonas de ammonites del subpiso.

En resumen, el área de Cúber tiene gran interés patrimonial para el Jurásico marino por: a) constituye la zona con mejores secciones estratigráficas del Jurásico en la Sierra de Tramuntana; b) varios niveles tienen macrofósiles (especialmente ammonites) abundantes y bien preservados; c) es la localidad tipo de la formación Cúber; c) presenta intervalos con gran potencial para el estudio de microfósiles (foraminíferos bentónicos y planctónicos, radiolarios y calpionélidos); d) en algunos intervalos de la sección se han realizado estudios de estratigrafía isotópica con excelentes resultados (COIMBRA; OLÓRIZ, 2012); e) cabe resaltar que este área se encuentra enmarcada en una zona declarada Patrimonio Mundial por la UNESCO y por tanto goza de especial protección.

\section{Sección de Fuentelsaz (Guadalajara)}

La sección de Fuentelsaz está ubicada a $500 \mathrm{~m}$ al norte del pueblo de Fuentelsaz, noreste de la provincia de Guadalajara, sector central de la rama castellana de la Cordillera Ibérica; unos $30 \mathrm{~km}$ al norte de Molina de Aragón. La sección tiene un interés patrimonial particular porque en ella se estableció el estratotipo de límite (Global Boundary Stratotype Section and Point, GSSP) del piso Aaleniense, el cual marca, a su vez, el límite entre el Jurásico Inferior y el Jurásico Medio. La posición del límite coincide con los horizontes de primera aparición de las especies de ammonites Leioceras opalinum, L. lineatum y $L$. cf. costosum.

Las primeras referencias a la sección de Fuentelsaz son de Goy y ComasReginfo en el mapa geológico de 1983. Posteriormente, y hasta la definición del estratotipo de límite por Cresta, Goy, Ureta et ál. (2001), la sección ha sido objeto de numerosos estudios llevados a cabo por el equipo de investigadores del Jurásico de la Universidad Complutense de Madrid, casi todos ellos bajo el enfoque de mostrar el interés de la sección de Fuentelsaz como futuro GSSP del piso Aaleniense (ver referencias en CRESTA; GOY; URETA et ál., 2001). 
Desde 1991 los miembros del grupo de trabajo del Aaleniense (AWG, por sus siglas en inglés Aalenian Working Group) se reunieron tres veces (1991, 1994, 1996) para debatir la clave bioestratigráfica que define el límite inferior del Aaleniense y para desarrollar una propuesta común para el GSSP de este piso del Jurásico Medio. El trabajo se concentró en las secciones de Fuentelsaz (Guadalajara, España) y de Wittnau (Baden-Württemberg, Alemania) ya que, desde un principio, no se presentaron más propuestas. Las reuniones de trabajo del AWG tuvieron lugar en: Portree, Isla de Skye, Escocia, año 1991; Marrakech, Marruecos, año 1994 y Nuévalos (España) y Friburgo (Alemania), año 1996. En esta ocasión, los miembros del AWG visitaron las dos secciones candidatas y dedicaron dos días de campo para verificar y profundizar los datos estratigráficos recogidos de las secciones de Fuentelsaz y Wittnau. A esta reunión asistieron treinta y dos investigadores y los siguientes países estuvieron representados: Argelia, Canadá, Francia, Alemania, Gran Bretaña, Italia, Portugal, España y Suiza. La discusión sobre GSSP tuvo lugar en Friburgo el 25 de septiembre con la asistencia de 26 miembros del AWG.

La votación dentro del grupo de trabajo del Aaleniense (AWG) tuvo lugar en 1997 y en ella participaron 31 miembros del AWG de los 46 con derecho a voto. El resultado fue el siguiente: 9 (30\%) votaron por Wittnau, 18 (60\%) lo hicieron por Fuentelsaz, 4 (10\%) se abstuvieron. La resolución para definir el GSSP del piso Aaleniense en Fuentelsaz se presentó durante la reunión del ISJS (International Subcomisión on Jurassic Stratigraphy) que tuvo lugar en Canadá en 1998. Finalmente, en julio de 2016, con la asistencia del presidente de la "International Union of Geological Sciences (IUGS)", del Director del Instituto Geominero de España, de los miembros del equipo investigador responsable de los trabajos de investigación del estratotipo, liderados por M. S. Ureta y A. Goy, y de diversas autoridades locales y autonómicas, tuvo lugar el acto de clavar el Golden Spike en la base del estrato FZ106 de la sección de Fuentelsaz como indicador del límite inferior del Aaleniense.

En Fuentelsalz, el Toarciense terminal y el Aaleniense Inferior muestran un desarrollo de espesor significativo en comparación con otras áreas de la Cordillera Ibérica; además, la sección contiene asociaciones fósiles de ammonites muy diversificadas y bien conservadas (CRESTA; GOY; URETA et ál., 2001). Las litologías del Aaleniense terminal (zona de Aalensis) y Aaleniense Inferior (zona de Opalinum) son bastante uniformes, y consisten en ritmitas de margas y calizas que contienen ammonites en casi todos los estratos calizos, así como en muchos de los estratos de margas. Aparte de ammonites existe un número considerable de fósiles pertenecientes a otros grupos de macroorganismos (braquiópodos, bivalvos) y microorganismos bentónicos (foraminíferos, ostrácodos) y planctónicos (nanofósiles calcáreos y palinomorfos) (CRESTA; GOY; URETA et ál., 2001). 


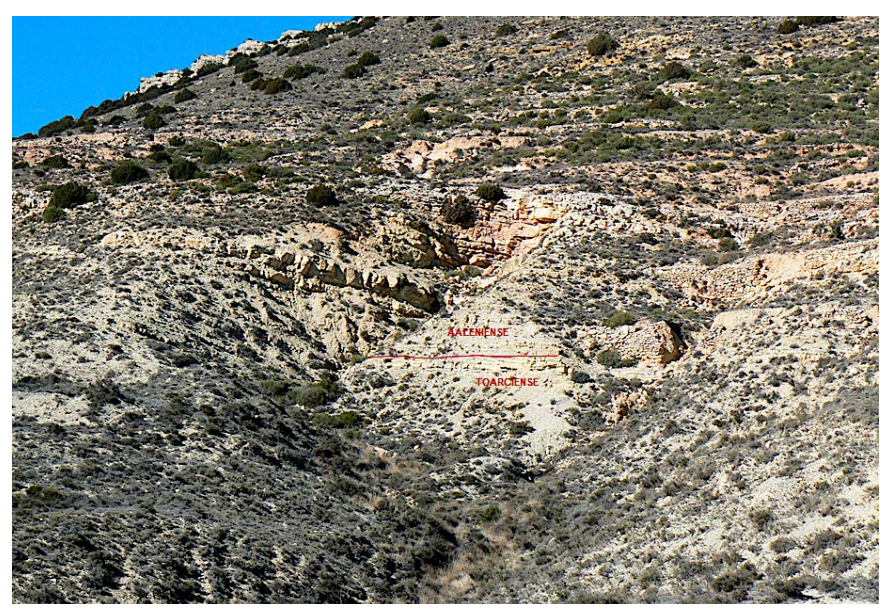

El Toarciense terminal (zona de Aalensis) tiene $11 \mathrm{~m}$ de espesor divididos en 38 niveles que contienen ammonites pertenecientes, fundamentalmente, a los grammoceratinos (Pleydellia falcifer, $P$. buckmani y $P$. leura) y hammatoceratinos (Bredyia subinsignis, $B$. sp.). Los Lytoceratida aparecen esporádicamente. La zona se caracteriza básicamente por la sucesión de especies del género Pleydellia (CRESTA; GOY; URETA et ál., 2001). El Aaleniense Inferior (Zona Opalinum) tiene un mínimo de 23,8 m de espesor. Como previamente se ha indicado, el límite inferior de esta zona coincide con los primeros registros del género Leioceras. El límite inferior del Aaleniense Medio (zona de Murchisonae) no se puede identificar porque los niveles superiores del Aaleniense Inferior (subzona Bifidatum) están cubiertos con sedimentos terrígenos del Cretácico. En la zona de Opalinum se han reconocido 34 niveles que contienen frecuentes ammonites (leioceratinos, hammatoceratinos y grammoceratinos). Esta zona se caracteriza básicamente por la sucesión de las especies del género Leioceras (CRESTA; GOY; URETA et ál., 2001). Aparte de los ammonites, otros grupos de fósiles son también abundantes y diversificados.

Entre los macrofósiles destacan los braquiópodos, los cuales existen tanto en Toarciense terminal como en el Aaleniense Inferior, pero los únicos bioeventos detectables próximos al límite son la extinción de una especie justo en la base de la Subzona de Buckmani y la aparición de otra especie en el último estrato del Toarciense (García-Joral en CRESTA; GOY; URETA et ál., 2001). Los Bivalvos, aunque aparecen en varios niveles, no son muy abundantes y no muestran ningún bioevento significativo cerca del límite Toarciense Aaleniense (Bernard en CRESTA; GOY; URETA et ál., 2001).

Los Ostrácodos, bien conservados e irregularmente distribuidos, muestran una importante renovación con la desaparición de 12 especies cerca del límite (Árias en CRESTA; GOY; URETA et ál., 2001). Los Foraminíferos bentónicos
Sección de Fuentelsaz, a la izquierda, vista general; a la derecha, detalle del estratotipo del límite Toarciense/Aaleniense | fotos Marisol Ureta 
están presentes en todos los estratos, siendo abundantes, diversificados y presentando buen estado de preservación. Se detecta una renovación importante con la extinción de una especie en la última Subzona del Toarciense y siete horizontes de primera aparición de especies en la proximidad del límite Toarciense-Aaleniense (Canales y Herrero en CRESTA; GOY; URETA et ál., 2001). Los palinomorfos están en general bien conservados y son similares a lo largo de la transición Toarciense-Aaleniense. A partir de la parte superior del Aaleniense Inferior están peor conservados y muestran una disminución progresiva de la diversidad (Barrón en CRESTA; GOY; URETA et ál., 2001). Los nanofósiles calcáreos, aunque siempre abundantes, muestran una disminución general en abundancia, diversidad y preservación a través de la transición Toarciense-Aaleniense. Los eventos más significativos que tienen lugar cerca del límite son la primera aparición de Watznaueria contracta en la base de la Subzona Buckmani y la primera aparición de Hexalithus magharensis en la base del Aaleniense (Perilli en CRESTA; GOY; URETA et ál., 2001).

La sección del Fuentelsaz también reúne condiciones óptimas para analizar eventos no bióticos, pero de gran interés en la definición del estratotipo como son geoquímica y mineralogía (García-Romero en CRESTA; GOY; URETA et ál., 2001), análisis isotópicos del $\delta^{13} \mathrm{C}$ y del $\delta^{16} \mathrm{O}$ (González en CRESTA; GOY; URETA et ál., 2001) y la magnetoestratigrafía (Villalaín en CRESTA; GOY; URETA et ál., 2001).

Concluyendo, la sección de Fuentelsaz es de gran interés patrimonial por: a) haber sido elegida estratotipo de límite del piso Aaleniense; b) al ser el Aaleniense el piso más antiguo del Jurásico Medio, Fuentelsaz es también la localidad tipo de este subperiodo; c) la sección tiene excelente exposición para muestreos y tiene fácil acceso; d) la sección de Fuentelsaz tiene registro continuo de varios grupos de macrofósiles y microfósiles abundantes y bien preservados; e) es la localidad tipo y en ella está el estrato típico de una nueva especie de ammonites, Bredyia fuentelsazensis (MARTÍNEZ, 1992).

\section{YACIMIENTOS MESOZOICOS (CRETÁCICOS)}

Lucas Mallada, considerado por muchos como el fundador de la paleontología española, señalaba a finales del siglo XIX que "no hay sistema en España que alcance, ni con mucho, la importancia paleontológica que el cretáceo". La afirmación puede parecer hoy exagerada y, probablemente, sesgada por el conocimiento que en la época se tenía de la geología española. En cualquier caso, sí son muy abundantes los afloramientos de materiales cretácicos con un gran interés patrimonial, bien desde el punto de vista paleontológico, estratigráfico, sedimentológico, geomorfológico o tectónico. Para este capítulo hemos elegido cinco secciones que tienen o pueden tener 
un papel crucial en la definición de límites cronoestratigráficos. Tres de ellas (Puerto Escaño, Cañada Luenga y Río Argos) están situadas en la Cordillera Bética, otra en el Pirineo (Organyà) y la última en el área vasco-cantábrica (Olazagutía).

\section{Sección de Puerto Escaño (Córdoba)}

La sección de Puerto Escaño se localiza muy cerca de la localidad de Carcabuey, en el corazón del Parque Natural de las Sierras Subbéticas cordobesas. Ya en la década de los 80 del siglo XIX, Lucas Mallada y el francés Wilfrid Kilian pusieron de manifiesto la gran riqueza fosilífera de las sucesiones sedimentarias del Jurásico y Cretácico de la zona meridional de la provincia de Córdoba. Pero es a partir del último tercio del siglo pasado cuando se emprende su estudio detallado, habiéndose publicado desde entonces decenas de trabajos en los que se abordan aspectos muy diversos de esos materiales.

En concreto, en la sección de Puerto Escaño a la que nos referimos en este apartado se puede observar un registro excepcional de los sedimentos situados alrededor del límite Jurásico-Cretácico. La sucesión, que alcanza unos 7,5 metros de potencia, comprende todo el Titoniense Superior (Jurásico Terminal) y la parte baja del Berriasiense (Cretácico basal). Las facies son de tipo Ammonitico Rosso y similares, variando entre bancos de calizas bien estratificadas y capas de calizas margosas con aspecto nodu-

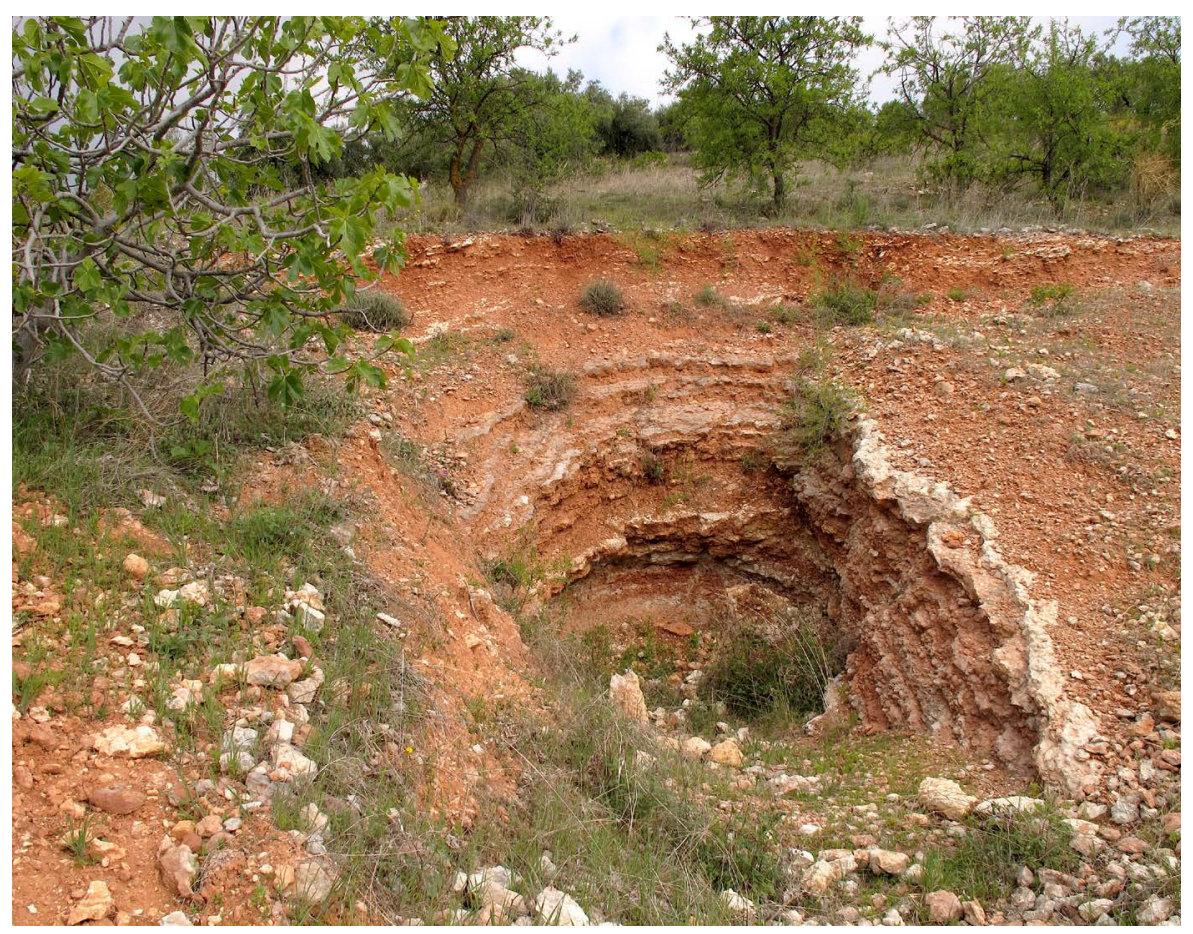


loso. Generalmente se interpreta que este tipo de materiales se depositó en ambientes marinos distales correspondientes a umbrales o bloques elevados. La sección de Puerto Escaño ha sido estudiada en profundidad, conociéndose en detalle sus aspectos litológicos, bioestratigráficos (ammonites, calpionélidos y nanofósiles calcáreos), magnetoestratigráficos y quimioestratigráficos. Se pueden consultar las referencias correspondientes en Pruner, Houša, Olóriz et ál. (2010) y Svobodová y Košták (2016).

Muchos autores han considerado esta sección como la más idónea para ser estratotipo global del límite Jurásico-Cretácico (OGG; HINNOV, 2012). Sin embargo, se está lejos de llegar a una resolución definitiva ya que existe un intenso debate en el seno del grupo de trabajo de la Subcomisión Internacional de Estratigrafía del Cretácico encargado de esta cuestión. Debido a circunstancias diversas, se han barajado varios eventos como posibles marcadores del límite, incluyendo, entre otros, bioeventos de ammonites (primeras apariciones de Berriasella jacobi y Pseudosubplanites grandis), de calpionélidos (proliferación de Calpionella alpìna), de nanofósiles calcáreos (primeras apariciones de Nannoconus steinmanni minor y de Nannoconus kamptneri minor) o cambios en la polaridad magnética (bases de los crones M19n.1r, M19n.2n y M18.r).

En Puerto Escaño se han registrado la mayor parte de esos eventos y, de hecho, los datos proporcionados por esta sección desempeñan un papel principal en todas las discusiones en torno al límite Jurásico-Cretácico. No obstante, son varias las secciones, en diferentes continentes, que están siendo consideradas como posibles candidatas a estratotipo de dicho límite. La decisión no se tomará hasta que se haya fijado el evento marcador del límite. La sección cordobesa presenta el inconveniente de que las facies de Ammonitico Rosso incluyen frecuentes superficies de omisión, aunque en este caso las pequeñas discontinuidades parecen estar siempre por debajo del nivel de resolución bioestratigráfica. Por el contrario, la posibilidad de integración de métodos estratigráficos muy diversos es su principal baza para esa designación.

\section{Sección de Cañada Luenga (Murcia)}

Los sedimentos de la parte más inferior del Cretácico subbético afloran con una muy buena exposición al sur de Cehegín (Murcia), entre la Sierra de Quípar y la Peña Rubia. Estos materiales, muy ricos en fósiles, ya atrajeron la atención de los pioneros de la geología en la región, como el francés René Nicklès y el español Daniel Jiménez de Cisneros, a finales del siglo XIX y principios del XX. Más tarde, desde mediados del siglo pasado, han sido numerosos los estudios paleontológicos, estratigráficos y sedimentológicos publicados sobre el Cretácico inferior de esa zona. Particular interés presentan varias secciones que permiten el análisis detallado del límite Berriasiense-Valanginiense. En concreto una de ellas, la sección de Cañada 
Luenga, ha sido seleccionada como candidata para estratotipo global de dicho límite.

La sección de Cañada Luenga está situada en el barranco del mismo nombre, unos tres kilómetros al suroeste de Cehegín. Ha sido estudiada en detalle en diversos trabajos, pudiendo destacarse los de Allemann, Grünn y Wiedmann (1975); Ogg, Steiner, Company et ál. (1988); y Aguado; Company y Tavera (2000). El espesor de la sección es de unos 14 metros. En la base hay un intervalo de calizas margosas nodulosas rojas y grises con abundantes fragmentos de crinoides. Estos niveles corresponden al techo de la formación Tollo y muestran evidencias claras de una baja tasa de sedimentación, con frecuentes interrupciones en el depósito, incluyendo superficies de omisión y corrosión de la parte superior de los fósiles. El resto de la sucesión está constituido por una alternancia rítmica de margas y margocalizas, características de la formación Miravetes. El medio de depósito corresponde a un umbral pelágico con variaciones en la tasa de subsidencia.

Los macrofósiles (mayoritariamente ammonites, acompañados de belemnites, bivalvos, gasterópodos, braquiópodos y equinodermos) son abundantes y están excelentemente conservados. También los microfósiles (calpionélidos y nanofósiles calcáreos) muestran una buena preservación. El evento que define el límite Berriasiense-Valanginiense es la aparición del calpionélido Calpionellites darderi, que se registra $6,15 \mathrm{~m}$ por encima de la base de la sección. Este evento coincide también con una renovación importante en la fauna de ammonites, con la extinción de varias especies características de la parte terminal del Berriasiense (como Berriasella calisto, Fauriella

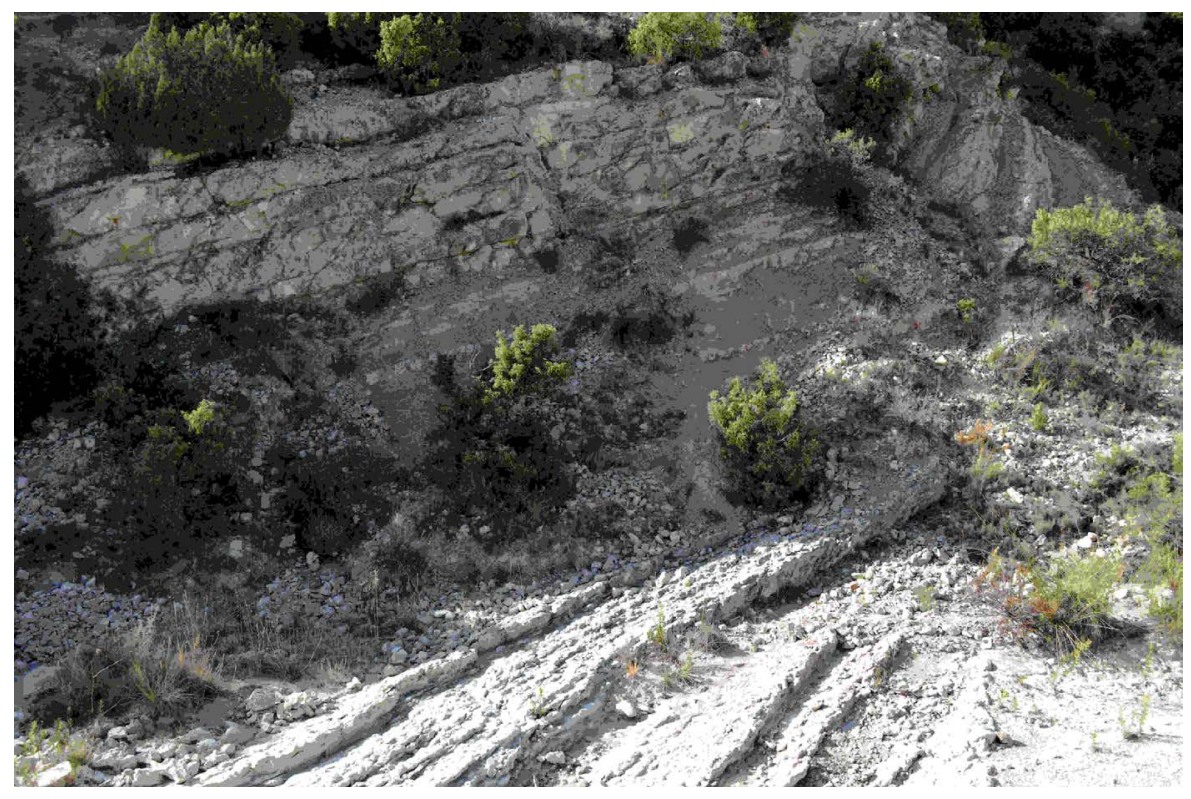


boissieri, Tirnovella alpillensis, Erdenella paquieri y "Thurmanniceras" otopeta) y la aparición de otras nuevas ("Thurmanniceras" pertransiens, "Thurmanniceras" gratianopolitense, Neocomites premolicus, Kilianella roubaudiana y Sarasinella eucyrta).

El excepcional registro paleontológico que presenta esta sección, junto con el hecho de que sea la única a nivel mundial en la que se ha podido establecer una calibración directa de la bioestratigrafía de ammonites con la escala magnetoestratigráfica, ha motivado, como comentábamos anteriormente, que haya sido seleccionada por el grupo de trabajo del Valanginiense de la Subcomisión Internacional de Estratigrafía del Cretácico como una de las dos candidatas para convertirse en estratotipo global del límite Berriasiense-Valanginiense (OGG; HINNOV, 2012).

La otra se localiza cerca de Montbrun-les-Bains, en el sureste de Francia. En la actualidad se están llevando a cabo estudios complementarios en ambas secciones con vistas a la preparación de las propuestas formales para la discusión y decisión definitiva.

\section{Sección del río Argos (Murcia)}

Esta sección, candidata a estratotipo global del límite HauterivienseBarremiense, forma parte de los magníficos afloramientos del Cretácico inferior que atraviesa el río Argos cerca de Caravaca de la Cruz (Murcia) y que han merecido estar catalogados como área de interés geológico en el PGOU de ese municipio. Esos afloramientos fueron dados a conocer por Jiménez de Cisneros en los primeros años del siglo XX y estudiados en mayor detalle por el holandés Gijsbrecht W. van Veen en su tesis a finales de los 60.

La sección se sitúa en el margen derecho del río, unos ocho km al oeste de Caravaca. Tiene un espesor cercano a los $40 \mathrm{~m}$ y la sucesión litológica está formada por una monótona alternancia de margas y margocalizas pertenecientes a la formación Miravetes y depositadas en un ambiente marino distal, de muy baja energía y relativamente profundo. Constituye un extraordinario registro, tanto estratigráfico (sedimentación continua sin indicios de condensación o interrupción) como paleontológico (ammonites, foraminíferos, nanofósiles calcáreos, dinoflagelados, etc.), del intervalo situado en torno al límite Hauteriviense-Barremiense. Ello explica que haya sido objeto de numerosos trabajos en los que se han analizado diversos aspectos paleontológicos, bioestratigráficos, quimioestratigráficos, paleooceanográficos, astrocronológicos, etc, entre los que podemos citar los de Hoedemaeker (1994); Company, Aguado, Sandoval et ál. (2005); Martinez, Pellenard, Deconinck et ál. (2012), y Aguado, Company, O’Dogherty et ál. (2014).

El bioevento que marca el límite Hauteriviense-Barremiense (la primera aparición del ammonites Taveraidiscus hugii) se localiza 23 metros por encima 


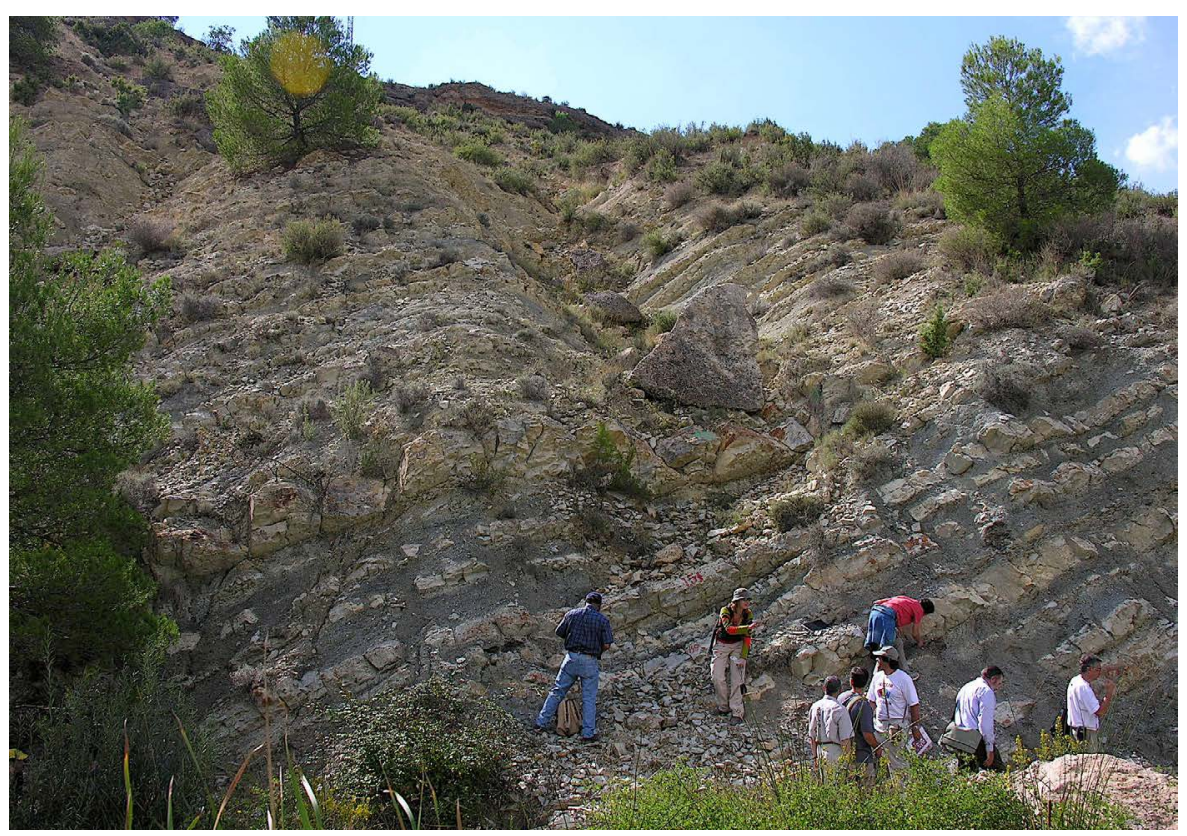

de la base de la sección. Además, se reconocen otros muchos bioeventos secundarios a lo largo del intervalo estudiado que amplían el potencial de correlación del límite estratigráfico y lo enmarcan dentro de la zona NC5 de nanofósiles calcáreos y de la zona de Hedbergella semielongata de foraminíferos planctónicos. El análisis astrocronológico ha permitido datar la base del Barremiense en $-126,02 \pm 1.0$ millones de años. Por otra parte, en la parte baja de la sección se puede observar un excelente registro del Nivel Faraoni, un evento anóxico de corta duración que tuvo lugar al final del Hauteriviense y que ha sido detectado en todo el ámbito mediterráneo.

La sección del río Argos está considerada como la más apropiada para el estudio del límite Hauteriviense-Barremiense y, de hecho, es la única candidata para convertirse en estratotipo global de dicho límite (OGG; HINNOV, 2012). Actualmente, un amplio equipo científico multidisciplinario internacional está ultimando los detalles para presentar la propuesta formal a la Subcomisión Internacional de Estratigrafía del Cretácico (COMPANY; AGUADO; BAUDIN et ál., 2017).

\section{Sección de Organyà (Lérida)}

En los alrededores de la localidad de Organyà, en el Prepirineo leridano, aflora una imponente secuencia de sedimentos del Cretácico inferior que alcanza casi 5.000 metros de espesor. Los primeros datos sobre estos materiales fueron publicados en los años 70 del siglo XIX por el ingeniero y geólogo Luis Mariano Vidal. Desde entonces, y hasta nuestros días, han sido innumerables las publicaciones en las que se han estudiado la paleontolo-
Sección del río Argos (límite HauterivienseBarremiense). Vista general | foto Miguel Company 
gía, estratigrafía, sedimentología o evolución tectónica de esos afloramientos (GARCÍA SENZ, 2002; SÁNCHEZ-HERNáNDEZ; MAURRASSE, 2014).

Entre toda la secuencia estratigráfica de la cuenca de Organyà destaca especialmente, por su interés geológico y patrimonial, el intervalo estratigráfico de edad Barremiense-Aptiense inferior. El tramo inferior de ese intervalo (Barremiense-Aptiense basal) corresponde a la formación Prada, constituida por calizas de facies urgoniana, con rudistas, orbitolínidos y otros foraminíferos bentónicos, y algas dasicladáceas y carofitas, depositadas en una plataforma somera con amplia variedad de ambientes. Hacia la parta alta se observan algunas pasadas margosas con fauna de ammonites, equínidos, gasterópodos y foraminíferos planctónicos, que sugieren una clara influencia hemipelágica. La Formación Prada, con un espesor total de unos 1.200 metros, aflora espectacularmente en el Congost dels Tres Ponts, cañón abierto por el río Segre inmediatamente al norte de Organyà.

El tramo superior del intervalo antes mencionado, que corresponde al resto del Aptiense inferior, está formado por las margas y margocalizas de la formación Cabó. Alcanza un espesor máximo cercano a los 950 metros y su contenido fósil incluye ammonites, equínidos, ostrácodos y foraminíferos planctónicos y bentónicos, que indican un ambiente de depósito relativamente profundo. Los mejores afloramientos de esta formación se localizan en el valle del río Cabó, al oeste de Organyà.

La caracterización del límite Barremiense-Aptiense es un tema debatido en la actualidad. La propuesta provisional del grupo de trabajo sugería la base del cron magnético M0 como evento marcador y la sección de Gorgo a Cerbara (Italia central) como estratotipo global de dicho límite. No obstante, un número cada vez mayor de investigadores plantea serias objeciones a esta propuesta (FRAU; BULOT; DELANOY et ál., en prensa). De hecho, el grupo se está replanteando en la actualidad la propuesta original. En este sentido, alguno de los espléndidos afloramientos del intervalo alrededor del límite BarremienseAptiense en la cuenca de Organyà (techo de la formación Prada y base de la formación Cabó), con un buen registro paleontológico (ammonites, foraminíferos planctónicos y nanofósiles calcáreos) (MORENO-BEDMAR, 2010), quimioestratigráfico (SÁNCHEZ-HERNÁNDEZ; MAURRASSE, 2014) y magnetoestratigráfico (GONG; DEKKERS; DINARÉS-TURELL et ál., 2008), puede constituir una muy sólida alternativa.

\section{Sección de Olazagutía (Navarra)}

En esta sección fue definido el estratotipo global del límite ConiacienseSantoniense. Se localiza en la Cantera de Egibil (o Cantera de Margas), un kilómetro al sur del núcleo urbano de Olazagutía, en la comarca de La Barranca, en el noroeste de Navarra, muy cerca de los confines con Álava y Guipúzcoa. 

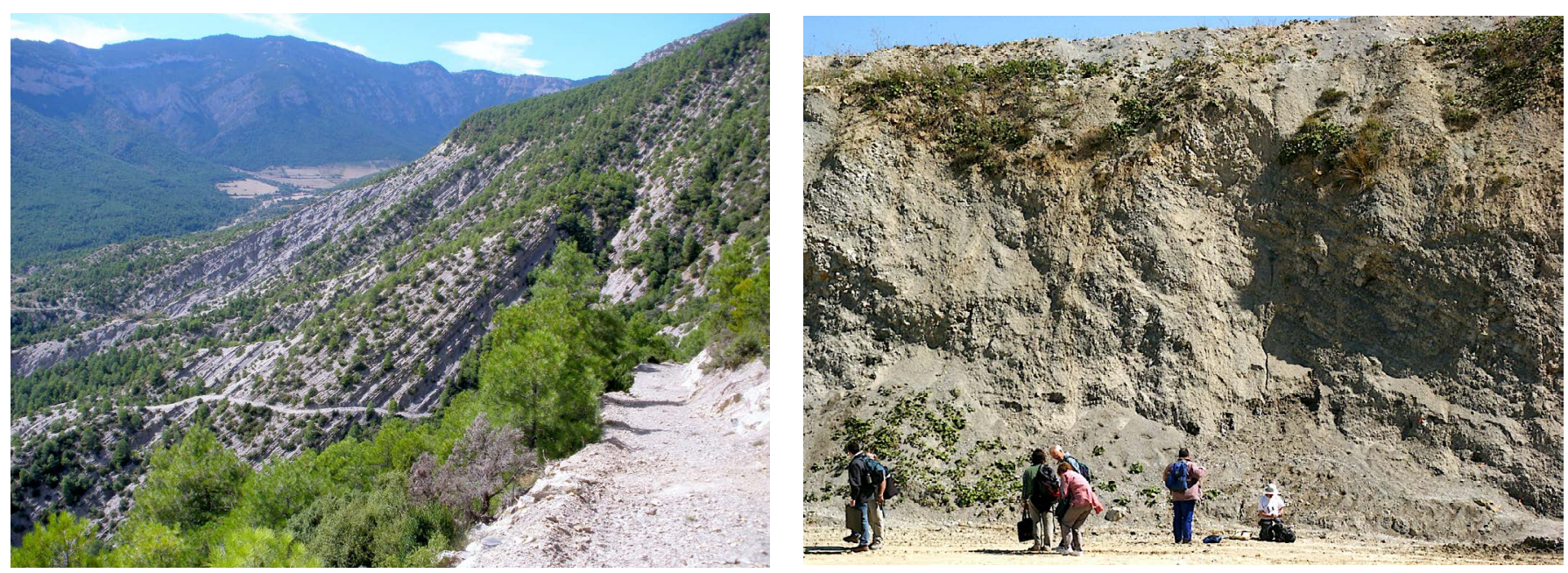

A la izquierda, sección de Organyà. Afloramiento de los materiales en torno al límite BarremienseAptiense en la Vall de Cabó | foto Josep A. Moreno

Las primeras noticias sobre la existencia de sedimentos del Cretácico superior en el corredor de La Barranca se remontan a la segunda mitad del siglo XIX y se deben a los franceses Verneuil, Collomb y Triger y al español Lucas Mallada. Sin embargo, no es hasta mediados del pasado siglo cuando se abordan trabajos más detallados. En concreto, las primeras publicaciones sobre bioestratigrafía y paleontología de la sección de Olazagutía datan de los años setenta. Rápidamente, esta localidad se convirtió en un referente para el estudio del Coniaciense superior y el Santoniense de forma que, en las conclusiones del I Simposio Internacional sobre los límites de los pisos del Cretácico que tuvo lugar en Copenhague en 1983, ya se contemplaba la sección de la cantera de Olazagutía como una de las posibles para llegar a ser estratotipo del límite Coniaciense-Santoniense, a la vez que se barajaban diversos bioeventos como posibles marcadores de dicho límite. Más tarde, en la segunda edición del mismo simposio celebrada en Bruselas en 1995, ya se seleccionó la primera aparición del bivalvo Platyceramus undulatoplicatus como bioevento definitorio del límite y se señalaban tres secciones como candidatas a estratotipos globales. Junto a la sección de Olazagutía figuraban también la de Seaford Head en Inglaterra y la de Ten Mile Creek en Texas (LAMOLDA; HANCOCK, 1996).

En los años siguientes se llevaron a cabo numerosos estudios sobre estas tres secciones, que sirvieron de base para las discusiones de los miembros del grupo de trabajo del Santonienese de la Subcomisión de Estratigrafía del Cretácico, quienes finalmente, en 2007, escogieron la sección de Olazagutía como estratotipo global para la base del Santoniense. Esta decisión fue posteriormente aprobada por la Subcomisión del Cretácico y por la Comisión Internacional de Estratigrafía y ratificada definitivamente, en 2013, por la Unión Internacional de Ciencias Geológicas (LAMOLDA; PAUL; PERYT et ál., 2014).
A la derecha, sección de Olazagutía (tránsito Coniaciense-Santoniense). Vista general | foto Eustoquio Molina 
En la sección de Olazagutía se exponen unos 160 metros de sedimentos que cubren el intervalo estratigráfico entre el Coniaciense medio y el Santoniense medio. La parte inferior está constituida por una alternancia de margas y margas arcillosas del Miembro de la Barranca, mientras que la parte superior corresponde a margocalizas de la formación Olazagutía, sedimentos todos ellos depositados en un ambiente pelágico. Los macrofósiles son relativamente abundantes, especialmente los bivalvos inocerámidos y los equínidos irregulares, siendo más escasos los ammonites y los restos de espongiarios. En cuanto a los microfósiles, tanto los foraminíferos planctónicos como los nanofósiles calcáreos presentan una buena preservación. A lo largo de la sección se registra un buen número de bioeventos de estos grupos de organismos. El marcador primario del límite ConiacienseSantoniense, primera aparición de Platyceramus undulatoplicatus, se localiza 94.4 metros por encima de la base de la sección.

\section{YACIMIENTOS CENOZOICOS (PALEÓGENO)}

El límite Cretácico/Paleógeno (K/Pg), más conocido popularmente como límite Cretácico/Terciario $(\mathrm{K} / \mathrm{T})$, está muy bien representado en la Península Ibérica y el estudio de varios cortes ha permitido poder detallar el evento de la quinta gran extinción en masa y definir el límite K/Pg en el nivel con las evidencias del impacto de un gran meteorito. Asimismo, el límite Paleoceno/Eoceno (P/E) está bien representado en varios cortes que han permitido reconocer el evento de extinción de los foraminíferos bentónicos batiales y abisales. Además, se han definido varios estratotipos de límite: Daniense/Selandiense, Selandiense/Thanetiense e Ypresiense/ Luteciense. A continuación describimos aquellos cortes que son de mayor interés patrimonial.

\section{Sección de Caravaca (Murcia)}

El corte de Caravaca, situado en el barranco del Gredero a $3 \mathrm{~km}$ al sur de Caravaca, es el más relevante de los cortes marinos del límite $\mathrm{K} / \mathrm{Pg}$, cuyo valor patrimonial y conservación fueron puestos de manifiesto por Molina (2004). Fue descubierto a mediados del siglo XX por varios geólogos franceses que describieron una serie completa del tránsito Cretácico-Terciario en la zona Este de las Cordilleras Béticas. Los microfósiles fueron preliminarmente estudiados por otros investigadores extranjeros, principalmente alemanes y holandeses, que establecieron la bioestratigrafía en las provincias de Murcia y Alicante. El holandés Jan Smit realizó la tesis doctoral en esta región, estudiando el Cretácico Superior y Paleógeno muy detalladamente con foraminíferos planctónicos en el barranco del Gredero, lo que le permitió definir una biozona de pocos centímetros justo en el límite $\mathrm{K} / \mathrm{Pg}$ (SMIT, 1979). Este mismo año un equipo americano, liderado por el físico premio Nobel Louis Álvarez y su hijo geólogo Walter, comunicó en un con- 


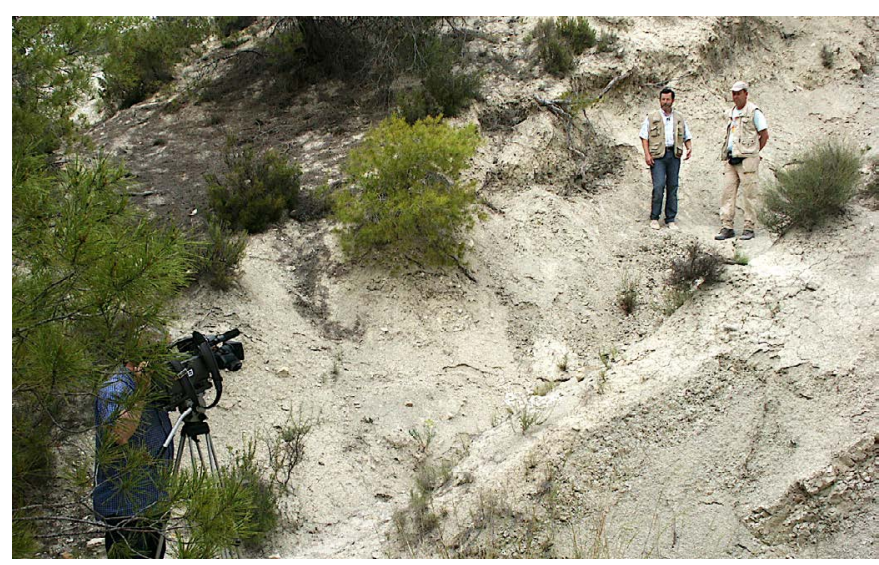

greso el hallazgo de un exceso anómalo de iridio en Gubbio (Italia). Esta era la principal evidencia del impacto de un enorme meteorito que habría extinguido a los dinosaurios y otros muchos animales y plantas en el límite $\mathrm{K} / \mathrm{T}$. Inmediatamente Jan Smit se percató de que la capa de arcilla oscura del barranco del Gredero era correlacionable a la que había localizado el equipo de Álvarez en Italia, pero la capa española era más potente y estaba mejor conservada. Se apresuró a enviar muestras para analizar el iridio y encontraron la misma anomalía que los americanos. Rápidamente escribieron un artículo (SMIT; HERTOGEN, 1980) que enviaron a la revista Nature y que se publicó un mes antes que el de los americanos en 1980 en la revista Science. Sin embargo, la prioridad corresponde al equipo americano que había comunicado la teoría impactista en un congreso el año anterior. Desde entonces ambos equipos han colaborado buscando otras evidencias de impacto y por esto Walter Álvarez ha considerado a Jan Smit como codescubridor de la teoría impactista.

El evento del límite K/Pg está representado por una arcilla oscura en cuya base tiene un nivel milimétrico rojo amarillento que contiene las evidencias de impacto meteorítico. Además del iridio se encontraron microesferas de sanidina, que fueron interpretadas como microtectitas, así como otras evidencias de impacto. Sin embargo, el mayor interés paleontológico del corte de Caravaca radica en que permite estudiar muy detalladamente los microfósiles planctónicos, ya que la facies es de tipo margoso y se pueden estudiar por la técnica del levigado, lo cual no es posible en la mayor parte del corte de Gubbio. El estudio de alta resolución con muestreos centimétricos de Smit (1982) sugería que se extinguieron casi todos los globotruncánidos en coincidencia con el nivel de las evidencias de impacto; solo sobreviviría Guembelitria cretacea y posiblemente Globotruncanella monmouthensis y Globigerinelloides messinae. Este patrón súbito de extinción fue cuestionado por Gerta Keller, que realizó estudios menos detallados en este mismo corte y en El Kef (Túnez), presentando un patrón aparentemente gradual. Así surgió
Sección de Caravaca. A la izquierda, Jan Smit y Eustoquio Molina filmando para TVE en el líminte Cretácido/Paleógeno; a la derecha, detalle del límite $\mathrm{K} / \mathrm{Pg}$ entre las dos monedas | fotos Eustoquio Molina 
una fuerte controversia, en la que Canudo, Keller y Molina (1991) estudiaron el corte de Caravaca sin llegar a solucionar la controversia. Ahora bien, otros estudios sugerían que el patrón gradual podría ser un artefacto de la metodología empleada: búsqueda insuficiente en las muestras superiores del Cretácico y reelaboración alocrónica en la base del Terciario. Para resolver este problema el equipo de la Universidad de Zaragoza realizó dos tesis doctorales (ARENILLAS, 1996 y ARZ, 1996) y se publicaron diversos artículos (COCCIONI; FABBRUCCI; GALEOTTI, 1993; ARENILLAS; MOLINA, 1997; KAIHO; LAMOLDA, 1999; ARZ; ARENILLAS; MOLINA, 2000; ARENILLAS; ARZ; MOLINA, 2000; MOLINA; ALEGRET; ARENILLAS et ál., 2001) que pusieron de manifiesto un patrón de extinción en masa súbito que afectaría a más del $90 \%$ de las especies y que fue la mayor crisis de la historia de los foraminíferos planctónicos.

El mismo patrón de extinción se ha observado en el corte de Agost (Alicante), que ha sido objeto también de múltiples estudios y publicaciones, las cuales se encuentran referenciadas en Molina, Alegret, Arenillas et ál. (2005).

El corte de Caravaca fue considerado como candidato para la definición de los límites K/Pg y Paleoceno/Eoceno (P/E). Esto propició que ambos límites en el corte del barranco del Gredero fueran estudiados muy detalladamente, si bien los estratotipos fueron finalmente definidos respectivamente en El Kef (Túnez) y en Dababiya (Egipto), el corte de Caravaca fue posteriormente considerado "paraestratotipo" auxiliar para el límite K/Pg (MOLINA; ALEGRET; ARENILLAS et ál., 2009). El límite P/E muestra un estrato calcarenítico con abundantes macroforaminíferos y un intervalo oscuro arcilloso mucho más potente que el del K/Pg y situado unos $120 \mathrm{~m}$ más arriba. El estrato calcarenítico es de tipo turbidítico y produjo un hiato de 0,7 Ma (MOLINA; CANUDO; MARTÍNEZ-RUIZ et ál., 1994) lo que supuso un serio inconveniente para que fuera definido el estratotipo en este corte (MOLINA, 1994). Diversos estudios (CANUDO; KELLER; MOLINA et ál., 1995; ANGORI; MONECHI, 1995; ARENILLAS; MOLINA, 1997; MOLINA; ALEGRET; ARENILLAS et ál., 2001) han permitido saber lo que ocurrió en el evento hace $55 \mathrm{Ma}$, así los cambios isotópicos indican un gran aumento de temperatura y un descenso de la productividad oceánica, que tuvieron como consecuencia la extinción de más de la mitad de las especies de foraminíferos bentónicos de los fondos batiales y abisales. Además, el estudio de los ostrácodos permitió definir una especie nueva Trachyleberidea marginata Guernet y Molina (1997). Recientemente, ha sido estudiado el evento micropaleontológico del Daniense terminal (ALEGRET; ORTIZ; ARREGUÍN-RODRÍGUEZ et ál., 2016).

\section{Sección de Zumaya (Guipúzcoa)}

El corte de Zumaya, Zumaia en euskera, es el que presenta mejor exposición debido a estar situado en la costa vasca (provincia de Guipúzcoa) y ser limpiado por el oleaje. La bioestratigrafía con foraminíferos fue estable- 
cida por Hillebrandt (1965) que mostraba una serie potente y continua desde el límite K/Pg al Eoceno inferior. La parte más interesante es el Paleógeno Inferior que se extiende desde Punta Aitzgorri, donde aflora el límite K/Pg, hasta Punta Mariantón donde aflora el Ypresiense (MOLINA; ARENILLAS, 1998). Si bien por debajo aflora una potente serie del Cretácico Superior, desde el Santoniense, y por encima llega en localidades cercanas hasta el Eoceno Medio y Superior. Al tratarse de una serie flysch con abundantes ichnofósiles atrajo la atención de los especialistas (HANISCH, 1972; CRIMES, 1973; entre otros).

El corte de Zumaya es muy conocido, además de por su excelente exposición, por el límite $\mathrm{K} / \mathrm{Pg}$, ya que fue propuesto como candidato para la definición del estratotipo de límite, en las votaciones quedó en segunda posición con el $29 \%$ de los votos y posteriormente fue designado como corte "paraestratotípico" auxiliar (MOLINA; ALEGRET; ARENILLAS et ál., 2009). El patrón de extinción del Cretácico terminal también fue controvertido, ya que los ammonites parecían extinguirse gradualmente. En una excursión al corte el alemán Josh Wiedmann ofreció una botella de whisky a quien encontrara
Sección de Zumaya. De izquierda a derecha y de arriba abajo: geólogos muestreando el límite Cretácico/Paleógeno; Eustoquio Molina apoyado en el estratotipo del límite Daniense/Selandiense; acto de definición del estratotipo del límite Selandiense/ Thanetiense; Carolina Náñez sentada en el límite Paleoceno/Eoceno | fotos Eustoquio Molina
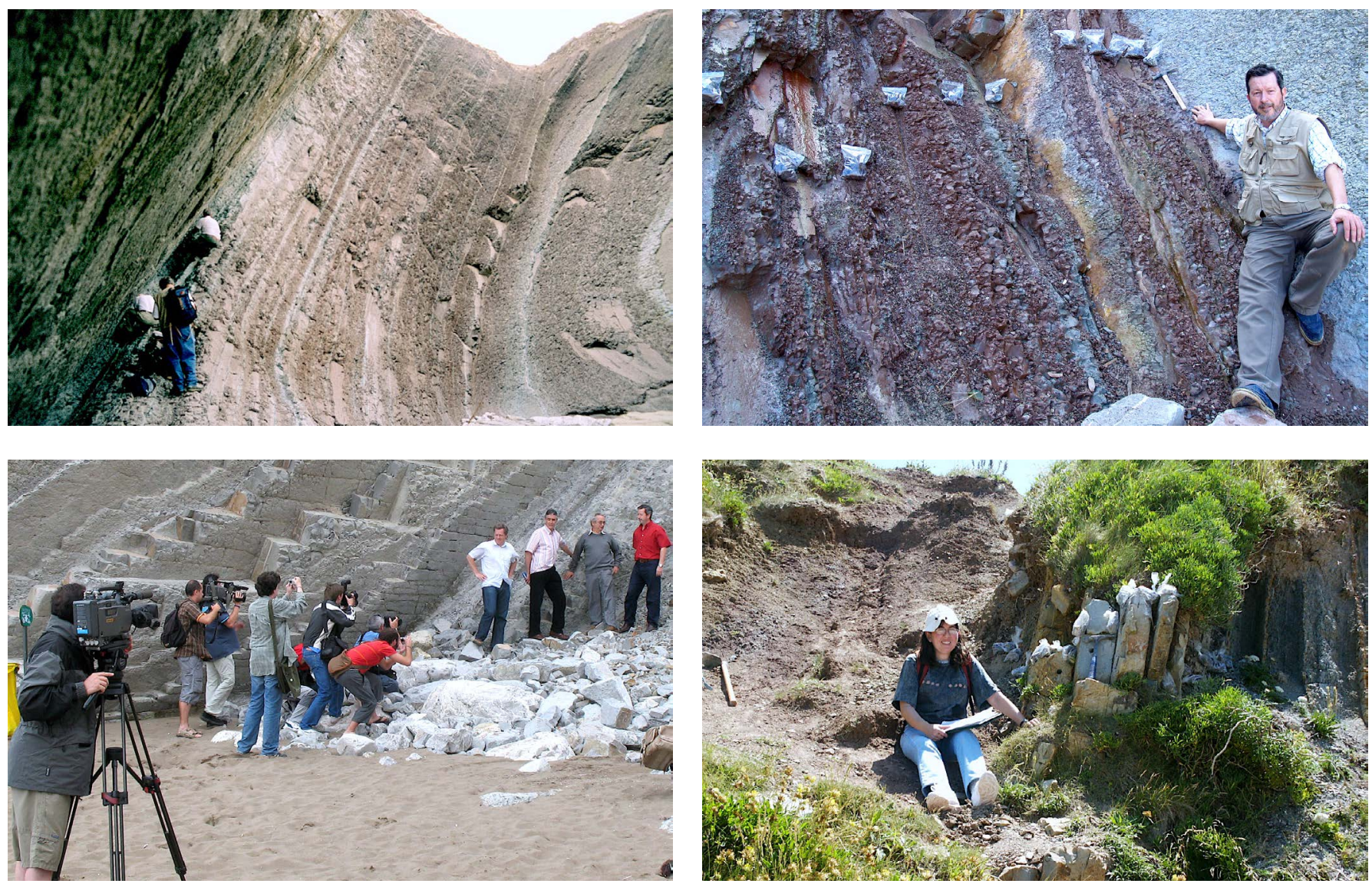
un ejemplar en el Cretácico terminal; como había muchos participantes buscando pronto apareció un ammonites, demostrando que sus estudios estaban afectados por el efecto Signor-Lipps. Poco después el americano Peter Ward muestreó intensamente este y otros cortes de la costa vasca, y encontró que los ammonites se extinguían en el nivel con las evidencias de impacto del límite K/Pg (WARD; WIEDMANN; MOUNT, 1986; WARD; KENNEDY, 1993). La extinción de los foraminíferos planctónicos también generó una polémica parecida y similar a la ya explicada para el corte de Caravaca. Se dudaba de la supervivencia o reelaboración de algunas especies, pero pronto quedó bien documentado que la extinción fue súbita, que algunas especies sobrevivieron y que el evento de extinción coincide exactamente con el nivel que contiene las evidencias de impacto meteorítico (APELLANIZ; BACETA; BERNAOLA-BILBAO et ál., 1997; ARENILLAS; ARZ; MOLINA, 1998; ARZ; ARENILLAS; MOLINA, 1999).

Los aspectos patrimoniales más relevantes del corte de Zumaya consisten en la definición de los estratotipos de límite del Daniense/Selandiense (D/S) y Selandiense/Thanetiense (S/T) por Schmitz, Pujalte, Molina et ál. (2011). Este corte es el que mejor representa todo el Paleoceno, ya que su límite inferior fue candidato para la definición del límite $\mathrm{K} / \mathrm{Pg}$ y el superior también fue candidato para la definición del límite Paleoceno/Eoceno (P/E). La base del Selandiense se localiza en la base de la formación Itzurum en la playa del mismo nombre, también denominada de San Telmo, a $49 \mathrm{~m}$ sobre el límite $\mathrm{K} /$ Pg (SCHMITZ; MOLINA; VON SALIS, 1998; ARENILLAS; MOLINA; ORTIZ et ál., 2008; BERNAOLA; MARTÍN-RUBIO; BACETA, 2009). EI Selandiense es la parte más hemipelágica del corte y está constituido principalmente por margas que se encuentran sobre las margocalizas y calizas rojas alternantes del Daniense. El mejor criterio de correlación global para la base del Selandiense es la segunda radiación de nanofósiles calcáreos del grupo de los fasciculítidos, que tienen su primera aparición unos pocos decímetros sobre la base, concretamente Fasciculithus tympaniformis, que es la especie marcadora para la Zona NP5 y aparece 1,1 m sobre la base del Selandiense. La base del Thanetiense se sitúa en el mismo corte a $78 \mathrm{~m}$ sobre el límite $\mathrm{K} / \mathrm{Pg}$. Se definió a 2,8 m sobre la base de un distintivo intervalo arcilloso asociado con el evento biótico del Paleoceno medio. El nannofósil calcáreo Heliolithus kleinpelli, especie que marca la base de la Zona NP6, aparece 6,5 m sobre la base del Thanetiense (SCHMITZ; PUJALTE; MOLINA et ál., 2011).

El corte de Zumaya presenta un intervalo arcilloso rojo de varios metros de potencia que representan el evento del límite Paleoceno/Eoceno. En este evento se registra la extinción en masa de la mitad de los foraminíferos bentónicos de medios batiales y abisales (CANUDO; KELLER; MOLINA et ál., 1995; SCHMITZ; ASARO; MOLINA et ál., 1997). Este evento de extinción se correlaciona con la parte media de la Biozona de Morozovella velascoensis, que coincide con la base de la Subzona de Acarinina sibaiyaensis 
(ARENILLAS; MOLINA, 2000), en la que se produce un brusco incremento de los acarinínidos debido al aumento global de temperatura. Este corte fue propuesto para definir el estratotipo del límite P/E, que finalmente fue definido en Dababiya (Egipto), pero puede ser un excelente candidato como "paraestratotipo" auxiliar (MOLINA, 1994).

\section{El llerdiense: secciones de Tremp (Lérida) y Campo (Huesca)}

Los cortes de Tremp y Campo en el Prepirineo central son muy interesantes por haber definido en ellos el estratotipo y el paraestratotipo del piso llerdiense, dado su excelente registro fósil. En este sentido, el llerdiense es uno de los pisos marinos que tiene un registro fósil mejor conservado, bien expuesto y de una gran diversidad. El estratotipo del llerdiense se sitúa en la provincia de Lérida y el corte tipo en Tremp, desde el pueblo de Claret al puerto de Montllovar. La Formación Ager tiene $830 \mathrm{~m}$ de potencia y es una megasecuencia transgresiva-regresiva de sedimentos marinos poco profundos. El llerdiense fue propuesto como nuevo piso por Hottinger y Schaub en 1960 (Eclogae geologicae Helvetiae) derivando del nombre latino de Lérida. El estratotipo fue designado por Schaub en 1969 (Mém. B.R.G.M.), además indicó que el corte de Campo podría ser el paraestratotipo y en 1974 fue ratificado en una reunión en París. Sin embargo, por diversas razones de política científica no ha sido aceptado como piso estándar, pero su utilidad es grande como piso regional. Ambos cortes son muy ricos en macroforaminíferos, principalmente alveolínidos y nunmulítidos, que permitieron hacer relevantes biozonaciones (HOTTINGER, 1960; SCHAUB, 1981). Posteriormente fueron estudiados otros grupos de microfósiles, principalmente foraminíferos planctónicos, dinoflagelados, nanofósiles, ostrácodos y carofitas, que han permitido la correlación y establecer uno de los mejores ejemplos de bioestratigrafía integrada (HILLEBRANDT, 1965; MOLINA; CANUDO; GUERNET et ál., 1992; MOLINA; ANGORI; ARENILLAS et ál., 2003, entre otros).

\section{Sección de Arguis (Huesca)}

El corte de Arguis está situado en el Prepirineo de la provincia de Huesca, presenta sus mejores afloramientos en la antigua carretera desde un kilómetro al sur del embalse de Arguis hasta el puerto de Monrepós. En 1907 taxones de este corte fueron citados por Lucas Mallada en su explicación del mapa geológico de España y en 1910 por Marius Dalloni en su Étude géologique des Pyrénées de l'Aragon. Posteriormente, Hottinger (1960) estudió las alveolinas y Schaub (1981) los nunmulites y asilinas del Paleógeno. Este corte es complementario de los de Tremp y Campo, ya que en Arguis existe un hiato y no aflora el llerdiense. La excelente exposición y potencia del Eoceno medio y superior ha permitido realizar detallados estudios geológicos y micropaleontológicos (CANUDO; MOLINA; RIVELINE et ál., 1988; entre otros). Su mayor interés es de tipo didáctico, ya que permite conocer la geología de un sector clave del Prepirineo y observar su excelente registro 
Sección de Campo (paraestratotipo del llerdiense) parte inferior | foto Eustoquio Molina

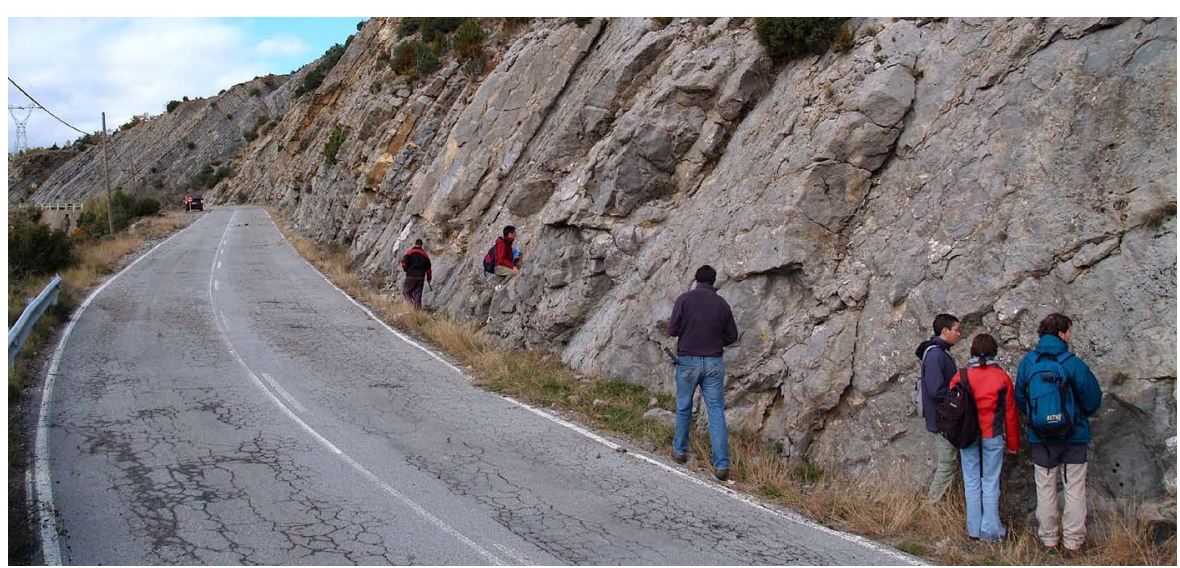

fósil. En este sentido se han organizado numerosas excursiones, tanto de congresos como de alumnos, y se han publicado guías explicativas, sobre todo para observar los abundantes microfósiles, especialmente macroforaminíferos, con la ayuda de una lupa (MOLINA, 1986a; MOLINA; ALEGRET; SERRA-KIEL, 2013).

\section{Sección de Gorrondatxe (Vizcaya)}

El corte de Gorrondatxe se localiza al noroeste de la ciudad de Bilbao y es parte de una potente serie flysch de $2300 \mathrm{~m}$, desde el Ypresiense inferior hasta el Luteciense superior, que aflora en la costa vasca desde Sopelana a Punta Galea. En el acantilado de la playa de Gorrondatxe afloran 700 m, predominantemente margosos con estratos calcareníticos intercalados del tránsito Ypresiense-Luteciense, que fueron muy detalladamente estudiados para la definición del estratotipo de la base del Luteciense (ORUE-ETXEBARRIA; APELLANIZ, 1985; PAYROS; ORUE-ETXEBARRIA; BERNAOLA et ál., 2009; entre otros). El GSSP de la base del piso Luteciense se ha definido en un nivel margoso oscuro que coincide con la primera aparición del nanofósil calcáreo Blackites inflatus, en la mitad de la polaridad del Cron C21r, a aproximadamente $47,8 \mathrm{Ma}$, y ha sido interpretada como el máximo transgresivo de una secuencia deposicional global (MOLINA; ALEGRET; APELLANIZ et ál., 2011).

\section{Sección de Fuente Caldera (Granada)}

El corte de Fuente Caldera se encuentra en el sector central Subbético de las cordilleras Béticas al norte de la provincia de Granada. Concretamente, en el barranco del Gavilán aflora muy bien una serie completa y potente del Paleógeno, excepto el Eoceno medio que es muy margoso y se encuentra cultivado. A partir del Eoceno superior existen intercalaciones calcareníticas que facilitan la exposición hasta casi el límite Oligoceno/Mioceno. La facies y sucesión estratigráfica fue descrita y datada por Comas, Martínez-Gallego y Molina (1985). 


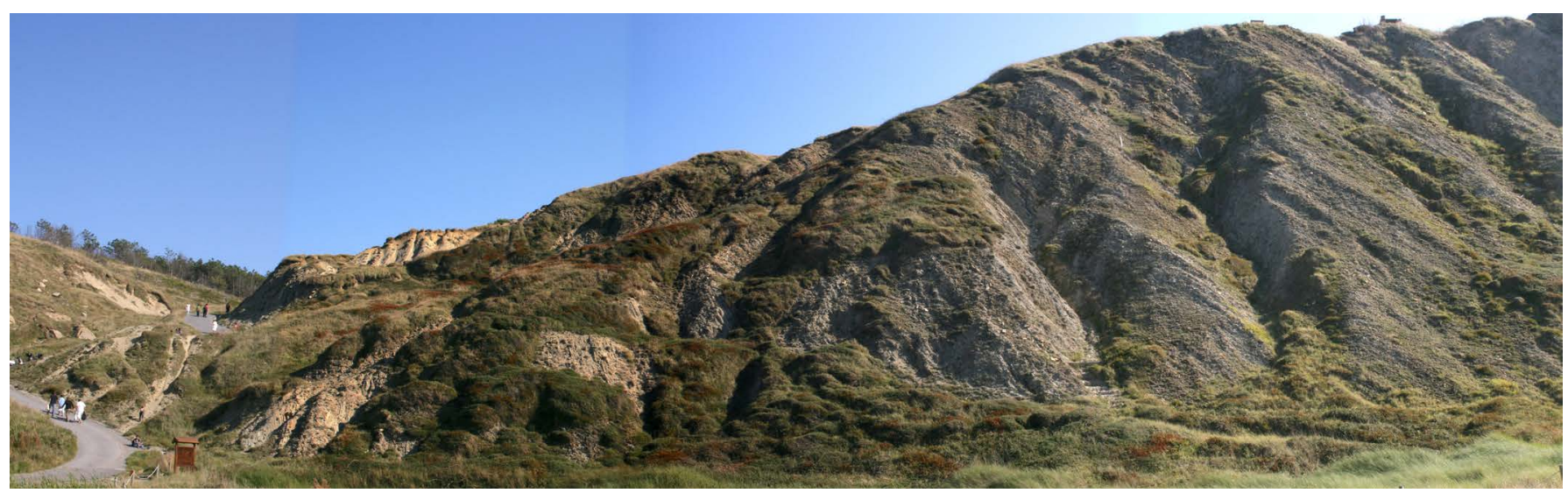

Posteriormente, el corte fue propuesto como candidato para la definición del límite Eoceno/Oligoceno (MOLINA, 1986b), ya que era el corte conocido más expandido del tránsito, al existir un intervalo entre las extinciones de las Turborotalias carenadas y las Hantkeninas, foraminíferos planctónicos que se pensaba se extinguían al mismo tiempo, pero el GSSP fue finalmente definido en Massignano (Italia). Dado el excelente registro con muchos microfósiles, e incluso evidencias de impacto meteorítico (espinelas de niquel), ha sido objeto de varias publicaciones (ROBIN; MOLINA, 2006; ALEGRET; CRUZ; FENERO et ál., 2008; FENERO; THOMAS; ALEGRET et ál., 2012).

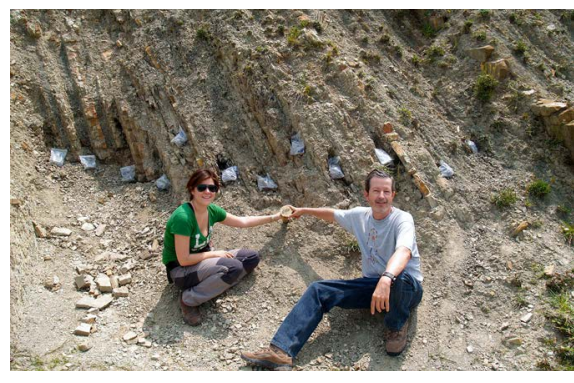

Arriba, sección de Gorrondatxe; abajo, agarrados al clavo dorado que marca el estratotipo del límite Ypresiense/Luteciense | fotos Eustoquio Molina

\section{YACIMIENTOS CENOZOICOS (NEÓGENO)}

Los yacimientos más interesantes para el patrimonio geológico y paleontológico se encuentran en la Cuenca de Sorbas y Níjar-Almería, que son dos pequeñas cuencas intramontañosas situadas en la provincia de Almería y delimitadas por la sierra de los Filabres, sierra Alhamilla, sierra Cabrera y el complejo volcánico del Cabo de Gata. Aunque existen informes internos de geólogos holandeses anteriores, las primeras publicaciones sobre la estratigrafía de la cuenca de Sorbas las encontramos en el mapa geológico de España del IGME (1975) y en Dronkert (1976). Además, existen otros yacimientos interesantes en la cuenca del Guadalquivir, en la costa de Málaga y en la provincia de Granada.

\section{Sección del Navazuelo (Granada)}

El corte del Navazuelo está situado en el término municipal de Guadahortuna (Granada) y aflora $2 \mathrm{~km}$ al este del cortijo El Navazuelo. Tiene una potencia de $250 \mathrm{~m}$ desde el Rupeliense (Oligoceno inferior) al Aquitaniense (Mioceno inferior). Debido a su excelente exposición y potencia fue propuesto para definir el límite Oligoceno/Mioceno (GONZÁLEZ DONOSO; MOLINA, 197778), en caso de que no fuera aceptada se proponía como hipoestratotipo, fue 
visitado por los miembros de la International Commission on Stratigraphy, pero el límite fue finalmente definido en Italia. Este límite constituye la base del Aquitaniense, del Mioceno y del Neógeno. Los foraminíferos plantónicos de esta sección fueron estudiados en detalle por Molina en su tesis doctoral, defendida en 1979 y publicada al año siguiente. Esta sección es la localidad tipo de la especie Protentella navazuelensis (MOLINA, 1980).

\section{Secciones de Sorbas y Níjar (Almería)}

La sección de los Molinos del río Aguas se localiza a unos $8 \mathrm{~km}$ al SE de Sorbas (Almería), en las proximidades de la carretera regional A1102, en la orilla izquierda del río Aguas. La sección comienza con unos depósitos de calcarenitas que se depositaron en ambientes marinos someros. Son muy ricos en algas rodofíceas, equinodermos, briozoos y moluscos. Esta unidad transgresiva pasa a las margas del miembro Abad, definiéndose el límite Tortoniense-Messiniense muy cerca de la base (SIERRO; FLORES; CIVIS et ál., 1993). La sucesión de margas del miembro Abad muestra una ciclicidad sedimentaria de origen astronómico, generada por cambios climáticos inducidos por variaciones cíclicas en la precesión del eje de la Tierra (SIERRO; FLORES; ZAMARREÑO et ál., 1999). Esta ciclicidad se manifiesta por la alternancia de margas grises con niveles compactos ricos en ópalo, que originalmente fueron niveles diatomíticos. En la parte superior de la sección aparecen también niveles de sapropeles, que se forman con una periodicidad de 21.000 años, cada vez que la Tierra pasa por el perihelio durante el verano del Hemisferio norte (SIERRO; FLORES; ZAMARREÑO et ál., 1999). La sección ha sido propuesta como serie de referencia global para la Escala astronómica de polaridad magnética para el periodo Messiniense (KRIJGSMAN; HILGEN; RAFFI et ál., 1999; SIERRO; HILGEN; KRIJGSMAN et ál., 2001). Estas margas son muy ricas en microfósiles, sobre todo foraminíferos, nanofósiles y diatomeas, cuyas asociaciones también muestran claras variaciones cíclicas asociadas a los cambios paleoceanográficos del Mediterráneo (SIERRO; FLORES; FRANCES et ál., 2003; PÉREZ-FOLGADO; SIERRO; BARCENA et ál., 2003; FLORES; SIERRO; FILIPPELLI et ál., 2005). Destaca la presencia de diatomitas en la parte superior junto con niveles de Neopycnodonta. Termina la sección con el depósito del miembro Yesares, formado por capas de yeso de gran espesor, que representan el inicio de la crisis de salinidad del Messiniense, cuando se redujo la conexión del Mediterráneo con el Atlántico. A lo largo del río Aguas puede verse una de las mejores secciones del miembro Yesares con la exposición de unos 12 niveles de yeso alternando con niveles de margas carbonatadas laminadas (DRONKERT, 1976; KRIJGSMAN; FORTUIN; HILGEN et ál., 2001).

A lo largo de los márgenes de estas cuencas destacan por su espectacularidad importantes afloramientos de arrecifes de coral de edad Messiniense, en los que se pueden observar en algunas ocasiones las facies de lagoon, 

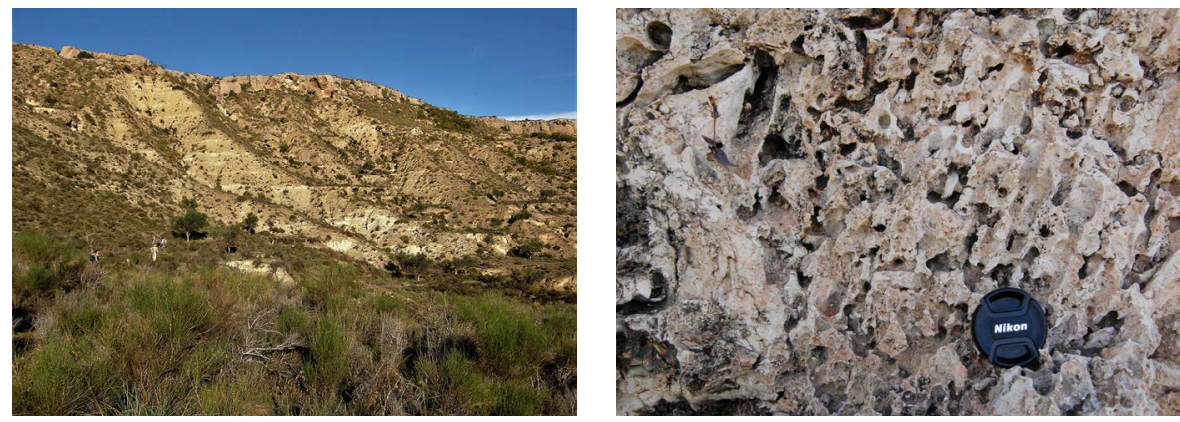

el frente arrecifal y el talud. Estos arrecifes están formados por grandes colonias de Porites incrustados por estromatolitos y, en ocasiones, aparecen domos de trombolitos y altas concentraciones de oolitos. Los principales arrecifes en la cuenca de Sorbas se encuentran en las secciones de Cariatiz y rambla de Gochar, mientras que en la cuenca de Níjar destaca la singularidad del atolón fósil del Hoyazo o los parches arrecifales de la mesa de Roldán (BRAGA; AGUIRRE, 2001; BRAGA; MARTÍN, 1996; BRAGA; MARTÍN; RIDING, 1995, 1996; MARTÍN; BRAGA; RIDING, 1993; RIDING; BRAGA; MARTÍN, 1991).

Los afloramientos Messinienses de las cuencas de Sorbas y Níjar son en la actualidad series de referencia para entender los escenarios que se sucedieron durante uno de los episodios mas dramáticos de la historia del Mediterráneo. Entre 5,97 y 5,33 millones de años se produjo la llamada crisis de salinidad del Messiniense, la conexión con el Atlántico se vio fuertemente restringida y las altas tasas de evaporación y escasos aportes de agua dulce desencadenaron una subida importante de la salinidad del Mediterráneo, precipitándose capas de sal de mas de $1 \mathrm{~km}$ de espesor en los fondos abisales y grandes capas de yeso en las cuencas marginales, como las de Sorbas y Níjar. Aunque el Mediterráneo nunca llegó a desecarse, sí se produjo probablemente un significativo descenso del nivel del mar.

\section{Sección de la Casa del Pino (Huelva)}

Esta sección está situada en la provincia de Huelva, a lo largo de la carretera A 5001 que une las localidades de Niebla y Bonares, en las proximidades de esta última localidad. La sección, que aflora en los taludes de la carretera, comienza con un nivel de arenas finas muy glauconíticas que se corresponde con el límite Mioceno-Plioceno (VAN DEN BERG; SIERRO; HILGEN et ál., 2015). Sobre este nivel aparecen las denominadas arenas de Huelva con la presencia de varios niveles alternantes de alta y baja concentración de fósiles de moluscos, fundamentalmente. Aparece una gran diversidad de especies de bivalvos, gasterópodos, escafópodos, así como dientes de seláceos, rayas, algunos restos de ballenas y frecuentes trazas fósiles. Ha sido ampliamente estudiada por varios investigadores (ANDRÉS, 1982;

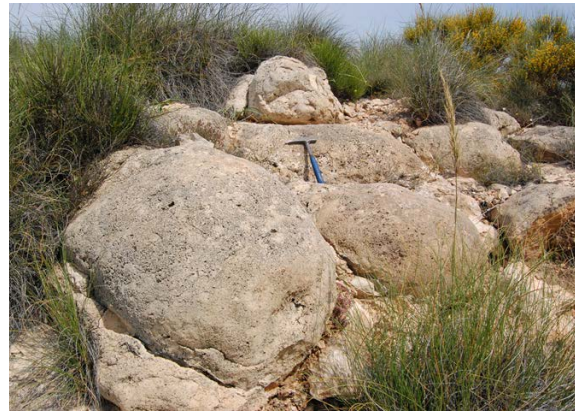

De izquierda a derecha: Sección del río Aguas; Detalles de Porites en la cuenca de Sorbas; detalle de Trombolitos en la cuenca de Níjar | fotos Francisco J. Sierro 


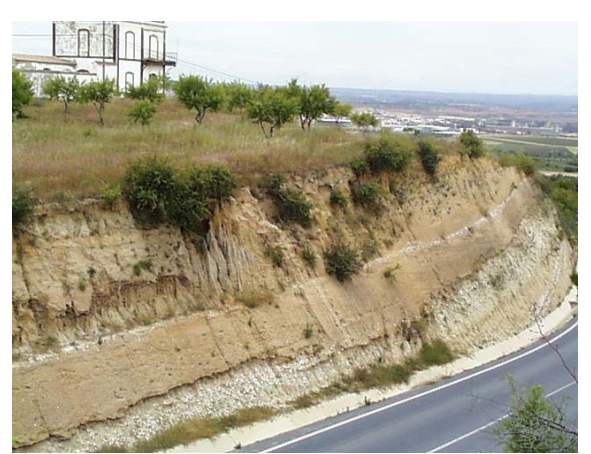

A la izquierda, sección de la Casa del Pino; a la derecha, detalles de acumulación de bivalvos | fotos José Ángel González Delgado y Francisco J. Sierro
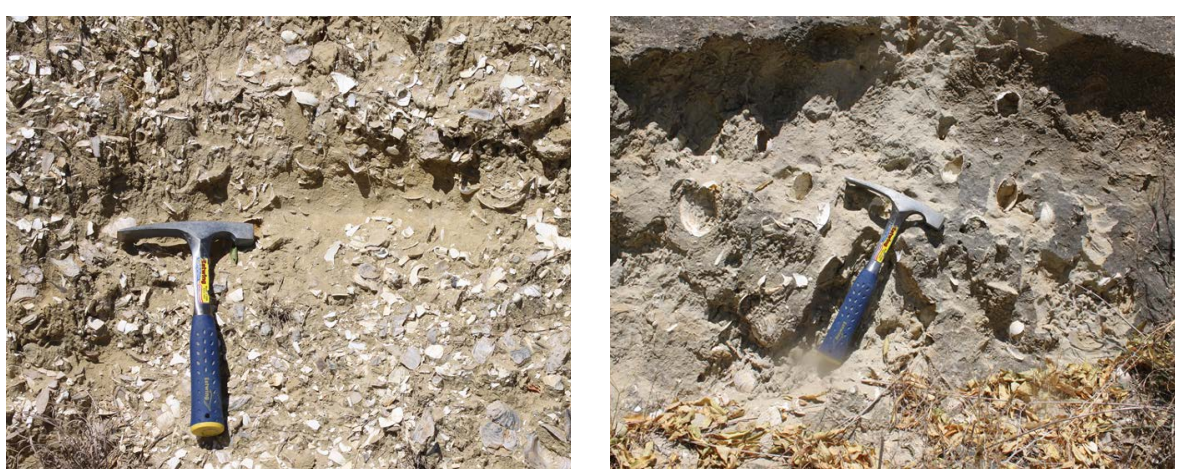

GONZÁLEZ-DELGADO, 1983; GONZÁLEZ DELGADO; ANDRES; SIERRO, 1995; GONZÁLEZ-DELGADO; MARTÍNEZ-GRAÑA; CIVIS et ál., 2015; MAYORAL, 1986; ESPERANTE; MUÑIZ; NICK, 2009; GARCÍA; ANTUNES; CÁCERES-BALBINO et ál., 2009). Se han identificado alrededor de 450 especies de moluscos fósiles, muchos de ellos excelentemente preservados. El ambiente se ha interpretado como un área de plataforma donde los moluscos vivirían en la zona por debajo del nivel de base de las olas de buen tiempo, aunque el fondo marino habría sido barrido por tormentas que desenterrarían los bivalvos infaunales y los depositarían en capas de acumulación de conchas (GONZÁLEZ DELGADO; ANDRES; SIERRO, 1995).

El Andaluciense: las secciones de Carmona y arroyo Galapagar (Sevilla) Como ya hemos indicado anteriormente el Mioceno terminal, el Messiniense, fue un periodo extraordinariamente dramático para la fauna y flora marina del Mediterráneo, debido al fuerte incremento de la salinidad y al depósito de grandes capas de sal y yeso. Por este motivo Enrico Perconig, director del Equipo de micropaleontología de la empresa Nacional Adaro (ENADIMSA), propuso en 1964 en el CMNS (Committee on Mediterranean Neogene Stratigraphy) de Berna las secciones de Carmona y arroyo Galapagar, en la provincia de Sevilla, como estratotipo de un nuevo piso en la escala geológica de tiempo que denominó Andaluciense. El Messiniense representa el periodo comprendido entre el Tortoniense y el Plioceno, su estratotipo estaba formado por capas de evaporitas sin ningún tipo de fósiles y, por tanto, difícil de correlacionar a escala global. Por ello, Perconig propone el Andaluciense como un estratotipo alternativo al Messiniense, pero en aguas del Atlántico. La propuesta fue apasionadamente debatida en varios congresos internacionales del CMNS de Berna en 1964 (PERCONIG, 1966), en Bolonia en 1967 (PERCONIG, 1968), en el CMNS de Lyon en 1971 o en el XIII Coloquio europeo de Micropaleontología que tuvo lugar en Madrid en 1973 (PERCONIG; GRANADOS, 1973). El estratotipo incluía la sección de Carmona y la sección de arroyo Galapagar, situada a lo largo del citado arroyo, al norte del cruce con la carretera A436 en las proximidades de Villanueva del Río (Sevilla). En el Arroyo Galapagar se observan unos depósitos de arenas siliciclásticas 
transgresivas sobre el basamento Paleozoico, sobre las que se apoyan arcillas hemipelágicas con abundantes foraminíferos planctónicos, que corresponden al momento en que la Meseta Ibérica se hunde como respuesta a la sobrecarga de los materiales béticos. El límite Tortoniense-Messiniense fue localizado en los primeros metros de estas arcillas (SIERRO; FLORES; CIVIS et ál., 1993). Esta unidad arcillosa se extiende entre al arroyo Galapagar y la sección de Carmona, alcanza más de $700 \mathrm{~m}$ de espesor y efectivamente es de edad Messiniense, pero está cubierta por los depósitos cuaternarios superficiales del río Gudalquivir, aflorando sólamente los últimos metros de la unidad en la sección de Carmona. En esta localidad, sobre las arcillas, se apoya una calcarenita, conocida como caliza tosca, que forma la base sobre la que se sustenta la ciudad de Carmona. El corte se sitúa enfrente de la antigua fábrica del anisado en la carretera de Carmona a El Viso.

Los encendidos debates internacionales, especialmente en Berna, Bolonia, Lyon y Málaga, se centraron fundamentalmente en analizar la conveniencia del Andaluciense como estratotipo alternativo al Messiniense, siendo los micropaleontólogos italianos los que fueron más críticos, al considerar que algunos de los microfósiles encontrados en Carmona eran en realidad de edad Pliocena y no Messiniense (CITA, 1973). Esta idea fue ampliamente rebatida por los geólogos de ENADIMSA (Empresa Nacional Adaro de Investigaciones Mineras S. A.) (BAENA PÉREZ; CABAÑAS LOZANO; CRESPO ZAMORANO et ál., 1974) que mantuvieron el Andaluciense en el punto de mira de micropaleontólogos de todo el mundo (BERGGREN; HAQ, 1976). Aunque hoy la edad Messiniense de las arcillas de Carmona no deja lugar a dudas (SIERRO; GONZÁLEZ-DELGADO; DABRIO, et ál., 1996), el Andaluciense no fue aceptado como nuevo estratotipo por la comunidad internacional. Desde nuestro punto de vista el principal problema del estratotipo Andaluciense, que efectivamente es equivalente al Messiniense, es su continuidad ya que la mayor parte de las arcillas están cubiertas por el Cuaternario entre el arroyo Galapagar y Carmona.

\section{Secciones de Estepona y San Pedro de Alcántara (Málaga)}

Estos yacimientos aparecen en las arenas fosilíferas del Plioceno inferior de la zona costera de Málaga. El Plioceno marino aparece discordante sobre distintas unidades béticas como consecuencia del ascenso relativo del nivel del mar después de la crisis de salinidad del Messiniense. Los niveles transgresivos de la base son facies más conglomeráticas que pasan a arenas masivas bioturbadas que contienen gran cantidad de bivalvos, gasterópodos y escafópodos bien conservados (GUERRA-MERCHÁN, 1997; GUERRA-MERCHÁN; PALMQVIST; LOZANO FRANCISCO, 1996; VERAPELÁEZ; LOZANO-FRANCISCO; MUÑIZ SOLÍS et ál., 1995). Los principales yacimientos son los de Padrón, Velerín, Guadalmansa y Parque Antena, especialmente por la conservación de los fósiles (VERA-PELÁEZ; LOZANOFRANCISCO; MUÑIZ SOLíS et ál., 1995) 


\section{CONCLUSIONES}

Los yacimientos marinos aquí descritos y figurados son los más relevantes patrimonialmente de los que se encuentran en España (Península lbérica e islas Baleares). Todos merecen la protección para su conservación y el interés es muy variado.

Entre los yacimientos paleozoicos destaca el de Murero (Zaragoza) por su potente serie del Cámbrico inferior y medio, en cuya base aparece una fauna primordial muy bien conservada y a techo del Cambrio inferior un evento de extinción en masa. La sección del valle del Río Luna (León) también presenta la fauna primordial, es mucho más potente que Murero y presenta un buen registro fósil hasta el Devónico. La sección de Arnao (Asturias) se ha calificado como un auténtico museo paleontológico del Devónico debido a la riqueza de fósiles arrecifales y de plataforma. En la sección de Checa (Guadalajara) existen unos depósitos glaciomarinos del Ordovícico y Silúrico, que constituyen un rico yacimiento paleontológico incluido en el Geoparque de Molina y Alto Tajo. En el Geoparque de la Sierra Norte de Sevilla, existe unos depósitos del Ordovícico y Devónico en el sinclinal del Valle, que han permitido una bioestratigrafía muy detallada; así como un yacimiento en el Cerro del Hierro con una espectacular karstificación intracámbrica. Las secciones de Demués y las Llacerías (Asturias) también presentan un registro muy bueno de distintos fósiles del Carbonífero.

Entre los yacimientos mesozoicos, en el Jurásico destacan varias secciones. La sección de Sierra de Lúgar (Murcia) que tiene una excelente exposición y un excelente registro fósil que han permitido una bioestratigrafía muy detallada de todo el Jurásico. La sección del barranco de Agua Larga (Jaén) del intervalo Aaleniense-Bajociense inferior también tiene un excelente registro fósil que ha permitido precisar la datación y la reconstrucción paleoambiental. La seción del área del pantano de Cúber (Mallorca) también tiene un excelente registro fósil del Jurásico por lo que ha sido declarada Patrimonio Mundial por la UNESCO. La sección de Fuentelsaz (Guadalajara) fue elegida para definir el estratotipo de límite de la base del Aaleniense y también es la localidad tipo de una especie de ammonites. En el Cretácico también destacan varias secciones. La sección de Puerto Escaño tiene un registro excepcional del límite Jurásico/Cretácico por lo que ha sido propuesta para definir en ella el límite inferior del Berriasiense. La sección de Cañada Luenga (Murcia) también ha sido propuesta para definir el estratotipo de límite de la base del Valanginiense. La sección del Río Argos (Murcia) está propuesta para definir en ella el estratotipo del límite Barremiense. La sección de Organyà (Lérida) presenta un excelente registro del Barremiense-Aptiense y ha sido propuesta como candidata para definir el límite inferior del Aptiense. La sección de Olazagutía (Navarra) tiene un magnífico registro del Coniaciense-Santoniense y ha permitido definir en ella el estratotipo de límite de la base del Santoniense. 
Entre los yacimientos Cenozoicos, en el Paleógeno destacan varias secciones. La sección de Caravaca (Murcia), junto con el cercano corte de Agost (Alicante), fue muy relevante para la propuesta de la teoría impactista del límite $\mathrm{K} / \mathrm{Pg}$ y fue propuesto como estratotipo de límite para el limite $\mathrm{K} / \mathrm{Pg}$ y el límite Paleoceno/Eoceno. La sección de Zumaya (Guipúzcoa) también fue candidata para la definición de los dos límites citados y, dado su registro tan completo del Paleoceno, permitió definir en ella los límites Daniense/ Selandiense y Selandiense/Thanetiense. Las secciones de Tremp (Lérida) y Campo (Huesca) sirvieron para la definición del estratotipo del piso llerdiense, la primera como estratotipo y la segunda como paraestratotipo. La sección de Arguis (Huesca) presenta un excelente desarrollo y exposición que ha permitido relevantes estudios geológicos y micropaleontológicos. La sección de Gorrondatxe (Vizcaya) ha servido para la definición en ella del límite Ypresiense/Luteciense. La sección de Fuente Caldera (Granada) tiene un excelente registro y desarrollo por lo que fue candidata para la definción del límite Eoceno/Oligoceno. En el Neógeno también destacan varias secciones. La sección del Navazuelo (Granada) fue propuesta para definir el límite Oligoceno/Mioceno. La sección de los Molinos del Río Aguas (Almería) ha sido propuesta como serie de referencia global para la Escala astronómica de polaridad magnética para el periodo Messiniense y en los márgenes de la cuenca de Sorbas y Níjar hay espectaculares afloramientos arrecifales. La sección de la casa del Pino (Huelva) presenta un excelente registro fósil de moluscos. Las secciones de Carmona y arroyo Galapagar (Sevilla) sirvieron para proponer el piso Andaluciense. Las secciones de Estepona y San Pedro de Alcántara (Málaga) también presentan un excelente registro de moluscos y una conservación excepcional.

\section{Agradecimientos}

Nuestro agradecimiento a la Dra. M. Soledad Ureta, Universidad Complutense de Madrid, por su lectura crítica del texto de la sección de Fuentelsalz y por las fotos de campo de dicha sección, así como a Bienvenido Martínez Navarro, Universidad Rovira i Virgili de Tarragona, por sus excelentes sugerencias y correcciones que han permitido mejorar el manuscrito. Trabajo parciamente financiado por los proyectos CGL2014-52546-P, CGL2014-58794P y CGL2015-68459-P. 


\section{BIBLIOGRAFÍA}

- AgUADO, R.; COMPANY, M.; O'DOGHERTY, L. et ál. (2014) Late Hauterivian-early Barremian calcareous nannofossil biostratigraphy, palaeoceanography, and stable isotope record in the Subbetic domain (southern Spain). Cretaceous Research, vol. 49, 2014, pp. 105-124

- AguAdO, R.; COMPANY, M.; TAVERA, J. M. (2000) The Berriasian/Valanginian boundary in the Mediterranean region: new data from the Caravaca and Cehegín sections, SE Spain. Cretaceous Research, vol. 21, 2000, pp. 1-21

- AGUADO, R.; O'DOGHERTY, L.; SANDOVAL, J. (2017) Calcareous nannofossil assemblage turnover in response to the Early Bajocian (Middle Jurassic) palaeoenvironmental changes in the Subbetic Basin. Palaeogeography, Palaeoclimatology, Palaeoecology, vol. 472, 2017, pp. 128145

- ALEGRET, L.; CRUZ, L.; FENERO, R. et ál. (2008) Effects of the Oligocene climatic events on the foraminiferal record from Fuente Caldera section (Spain, western Tethys). Palaeogeography, Palaeoclimatology, Palaeoecology, vol. 269, pp. 94-102

- ALEGRET, L.; ORTIZ, S.; ARREGUÍN-RODRÍGUEZ, G. J. et ál. (2016) Microfossil turnover across the uppermost Danian at Caravaca, Spain: Paleoenvironmental inferences and identification of the latest Danian event. Palaeogeography, Palaeoclimatology, Palaeoecology, vol. 463, 2016, pp. 45-59

- ALLEMANN, F.; GRÜNN, W.; WIEDMANN, J. (1975) The Berriasian of Caravaca (Prov. of Murcia) in the subbetic zone of Spain and its importance for defining this stage and the Jurassic-Cretaceous boundary. Mémoires du Bureau de Recherches Géologiques et Minières, vol. 86, 1975, pp. 14-22

- Álvaro, M.; BARNOLAS, A.; CABRA, A. et ál. (1989) El Jurásico de Mallorca (Islas Baleares). Cuadernos de Geología Ibérica, vol. 13, 1989, pp. 67-120

- ANDRÉS, I. (1982) Estudio malacológico (Clase Bivalvia) del Plioceno marino de Bonares (Huelva). Tesis doctoral inédita, Universidad de Salamanca, 1982, 410 p.

- ANGORI, E.; MONECHI, S. (1995) High-resolution calcareous nannofossil biostratigraphy across the Paleocene/Eocene boundary at Caravaca (southem Spain). Israel Journal of Earth Sciences, vol. 44, 1995, pp. 197-206

- APELLANiZ, E.; BACETA, J. I.; BERNAOLA-BILBAO, G. et ál. (1997) Analysis of uppermost Cretaceous-lowermost Tertiary hemipelagic successions in the Basque Country (Western Pyrenees): evidence for a sudden extinction of more than half planktic foraminifer species at the KIT boundary. Bulletin de la Société Géologique de France, vol. 168, 1997, pp. 783-793
- ARBIZU, M.; MÉNDEZ-BEDIA, I. (2006) El Patrimonio Natural y Cultural de Castrillón (Asturias): Geología, fósiles e historia minera. Trabajos de Geología, vol. 26, 2006, pp. 73-91

- ARBIZU, M.; MÉNDEZ-BEDIA, I.; SOTO, F. (1995) Fossil communities in the Aguión Formation (Lower Devonian) of the Arnao Platform. Geobios, vol. 28, 1995, pp. 567-571

- ARENILLAS, I.; ARZ, J. A.; MOLINA, E. (1998) El límite Cretácico/Terciario de Zumaya, Osinaga y Músquiz (Pirineos): control bioestratigráfico y cuantitativo de hiatos con foraminíferos planctónicos. Revista de la Sociedad Geológica de España, vol. 11, 1998, pp. 127-138

- ARENILLAS, I.; MOLINA, E. (2000) Reconstrucción paleoambiental con foraminíferos planctónicos y cronoestratigrafía del tránsito Paleoceno-Eoceno de Zumaya (Guipúzcoa). Revista Española de Micropaleontología, vol. 32,2000 , pp. $283-300$

- ARENILLAS, I.; MOLINA, E.; ORTIZ, S. et ál. (2008) Foraminiferal and $\partial 13 \mathrm{C}$ isotopic event-stratigraphy across the Danian-Selandian transition at Zumaya (northern Spain): chronostratigraphic implications. Terra Nova, vol. 20, 2008, pp. 38-44

- ARENILLAS, J.; ARZ, J. A.; MOLINA, E. (2000) Spanish and Tunisian Cretaceous-Tertiary boundary sections: a planktic foraminiferal biostratigraphic comparison and evolutive events. GFF, vol. 122, 2000, pp. 11-12

- ARENILLAS, I.; MOLINA, E. (1997) Análisis cuantitativo de los foraminíferos planctónicos del Paleoceno de Caravaca (Cordilleras Béticas): cronoestratigrafía, bioestratigrafía y evolución de las asociaciones. Revista Española de Paleontología, vol. 12, 1997, pp. 207-232

- ARZ, J. A.; ARENILLAS, I.; MOLINA, E. (1999) Extinción de foraminíferos planctónicos en el tránsito CretácicoTerciario de Zumaya (Guipúzcoa): ¿supervivencia o reelaboración? Revista Española de Micropaleontología, vol. 31, 1999, pp. 297-304

- ARZ, J. A.; ARENILLAS, I.; MOLINA, E. et ál. (2000) La estabilidad evolutiva de Jos foraminíferos planctónicos en el Maastrichtiense Superior y su extinción en el límite Cretácico/Terciario de Caravaca, España. Revista Geológica de Chile, vol. 27, 2000, pp. 27-47

- BAENA PÉREZ, J.; CABAÑAS LOZANO, I.; CRESPO ZAMORANO, A. et ál. (1974) El Andaluciense como unidad cronoestratigráfica adecuada para el área Mediterránea. Revista Española de Micropaleontología, vol. 9, 1974, pp. 259-288

- BAEZA-CARRATALÁ, J. (2008) Patrimonio paleontológico en la colección Jiménez de Cisneros y su aplicación al estudio de los braquiópodos del Jurásico inferior en la 
Cordillera Bética oriental (provincias de Alicante y norte de Murcia). Tesis doctoral, Universidad de Alicante, $905 \mathrm{p}$.

- BAEZA-CARRATALÁ, J.; gARCíA-JORAL, F.; SANDOVAL, J. (2014) Bajocian-Early Bathonian (Jurassic) brachiopods from the Subbetic domain (Betic Cordillera, SE Spain): Taxonomy and palaeogeographic implications. Neues Jahrbuch für Geologie und Paläontologie, Abhandlungen, vol. 274, 2014, pp. 1-24

- BARNOLAS, A. E.; LLAVE, E. (2012) Contourites, turbidites and mass wasting deposits in the Middle and Upper Jurassic of the Majorca Island (Spain). Geo-Temas, vol. 13, 2012, pp. 1-4

- BARÓN, A.; FORNÓS, J. J.; GELABERT, B. et ál. (2004) Baleares. En VERA, J. A. (ed.) Geología de España. Madrid: SGE-IGME, 2004, pp. 450-664

- BERGgREN, W. A.; HAQ, B. U. (1976) The Andalusian stage (Late Miocene): biostratigraphy, biochronology and paleoecology. Palaeogeography, Palaeoclimatology, Palaeoecology, vol. 20, 1976, pp 67-129

- BERNAOLA, G.; MARTÍN-RUBIO, M.; BACETA, J. I. (2009) New high resolution calcareous nannofossil analysis across de the Danian/Selandian transition at the Zumaia section: comparison with South Tethys and Danish sections. Geologica Acta, vol. 7, 2009, pp. 79-92

- BRAGA, J. C. (1983) Ammonites del Domeriense de la Zona Subbética (Cordilleras Béticas, Sur de España). Granada: Secretariado de Publicaciones, Universidad de Granada, 1983, 410 p. (Tesis doctoral)

- BRAGA, J. C.; AGUIRRE, J. (2001) Coralline algal assemblages in upper Neogene reef and temperate carbonates in Southern Spain. Palaeogeography Palaeoclimatology Palaeoecology, vol. 175, n. ${ }^{\circ} 1-4,2001$, pp. 27-41

- BRAGA, J. C.; MARTÍN, J. M.; RIDING, R. (1995) Controls on microbial dome fabric development along a carbonate-siliciclastic shelf-basin transcect, Miocene, SE Spain. Palaios, vol. 10, n. ${ }^{\circ} 4,1995$, pp. 347-361

- BRAGA, J. C.; MARTíN, J. M. (1996) Geometries of reef advance to relative sea-level changes in a Messinian (uppermost Miocene) fringing reef (Cariatiz reef, Sorbas basin, SE Spain). Sedimentary Geology, vol. 107, 1996, pp. 61-81

- BRAGA, J. C.; MARTÍN, J. M.; RIDING, R. (1996) Internal structure of segment reefs: Halimeda algal mounds in the Mediterranean Miocene. Geology, vol. 24, 1996, pp. 35-38

- CANTABRANA CORTÉS, P.; NÚÑEZ-LAHUERTA, C.; GÁMEZ VINTANED, J. A. et ál. (2014) El centro de interpretación de la explosión de la vida en el Cámbrico de Miñera de Luna (León). Naturaleza Aragonesa, vol. 31, 2014, pp. 67-71

- CANUDO, J. I.; MOLINA, E.; RIVELINE, J. et ál. (1988) Les événements biostratigraphiques de la zone prépyreneéenne d'Aragón (Espagne), de l'Éocène moyen á l'Oligocène inferieur. Revue de Micropaléontologíe, vol. 31, 1998, pp. $15-29$

- CANUDO, J. I.; KELLER G.; MOLINA E. (1991) Cretaceous/Tertiary boundary extinction pattern and faunal tumover at Agost and Caravaca, S.E. Spain. Marine Micropaleontology, vol. 17, 1991, pp. 319-341

- CANUDO, J. I.; KELLER, G.; MOLINA, E. et ál. (1995) Planktic foraminiferal turnover and $\partial 13 \mathrm{C}$ isotopes across the Paleocene-Eocene transition at Caravaca and Zumaya, Spain. Palaeogeography, Palaeoclimarology, Palaeoecology, vol. 114, 1995, pp. 75-100

- CARACUEL, J. E. (1996) Asociaciones de megainvertebrados, evolución sedimentaria e interpretaciones ecoestratigráficas en umbrales epioceánicos de Tethys Occidental (Jurásico superior). Unversidad de Granada, 1996, 474 p. (Tesis doctoral)

- CARACUEL, J. E.; EL KADIRI, K.; OLÓRIZ, F. (1995) Faciès radiolaritiques et discontinuités à la limite DoggerMalm dans la Formation "Puig d'en Paré" (Sierra Norte, Majorque). Geobios, vol. 28, 1995, pp. 675-681

- CARACUEL, J. E.; OLÓRIZ, F. (1998) Revisión estratigráfica del Jurásico superior de la Sierra Norte (Mallorca). Revista de la Sociedad Geológica de España, vol. 11, 1998, pp. 345-353

- CARACUEL, J. E.; OLÓRIZ, F.; RODRÍGUEZ-TOVAR, F. J. (2000) Oxfordian Biostratigraphy from the Lugar Section (External Subbetic, Southern Spain). GeoResarch Forum, vol. 6, 2000, pp. 55-64

- CITA, M. B. (1973) Pliocene Biostratigraphy and Chronostratigraphy. En RYAN, W. B. F. et ál. Initial Reports of the Deep Sea Drilling Project, Volume XIII, Washington (U.S. Government Printing Office), pp. 1343-1379

- COCCIONI, R.; FABBRUCCI, L.; GALEOTTI, S. (1993) Terminal cretaceous deep-water benthic foraminiferal decimation, survivorship and recovery al Caravaca (SE Spain). Paleopelagos, vol. 3, 1993, pp. 3-24

- COIMBRA, R.; OLÓRIZ, F. (2012) Geochemical evidence for sediment provenance in mudstones and fossilpoor wackestones (Upper Jurassic, Majorca Island). Terra Nova, vol. 24, 2012, pp. 437-445

- COLOM, G. (1970) Estudio litológico y micropaleontológico del Lías de la Sierra Norte y porción central de la isla de Mallorca. Memorias Real Academia de Ciencias de Madrid, 24, 1970, 87 p. 
- cOMAs, M. C.; MARTíNEZ-GALlEgo, J.; MOLINA, E. (1985) Litofacies y sucesión estratigráfica del Eoceno y Oligoceno al norte del Cerro Mencal (Zona subbetica, Provincia de Granada). Cuadernos de Geología, vol. 12, 1985, pp. 145-155

- COMPANY, M.; AGUADO, R.; BAUDIN, F. et ál. (2017) The Barremian GSSP-state of the art. Berichte der Geologischen Bundesanstalt, Wien, vol. 120, 2017, p. 54

- COMPANY, M.; AGUADO, R.; SANDOVAL, J. et ál. (2005) Biotic changes linked to a minor anoxic event (Faraoni Level, latest Hauterivian, Early Cretaceous). Palaeogeography, Palaeoclimatology, Palaeoecology, vol. 224, n. ${ }^{\circ} 1-3,2005$, pp. 186-199

- CRESTA, S.; GOY, A.; URETA, S. et ál. (2001) The Global Boundary Stratotype Section and Point (GSSP) of the Toarcian-Aalenian Boundary (Lower-Middle Jurassic). Episodes, vol. 24, 2001, pp. 166-175

- CRIMES, T. P. (1973) From limestones to distal turbidites: a facies and trace fossil analysis in the Zumaya flysch (Paleocene-Eocene), nonh-Spain. Sedimentology, vol. 20, 1973, pp. 105- 131

- DABRIO, C. J.; ESTEBAN, M.; MARTIN, J. M. (1981) The coral-reef of Nijar, Messinian (Uppermost Miocene), Almeria Province, SE Spain. Journal of Sedimentary Petrology, vol. 51, n. ${ }^{\circ} 2,1981$, pp. 521-539

- DE VERNEUIL, E. (1862) Descubrimiento de la fauna primordial en Zaragoza. Revista minera, vol. 13, 1862, pp. $1-479$

- DRONKERT, H. (1976) Late Miocene evaporites in the Sorbas basin and adjoining áreas. Mem. Soc. Geol. Ital., vol. 16, 1976, pp. 341-362

- ESPERANTE, R.; MUÑIZ, F.; NICK, K. E. (2009) Taphonomy of a mysticeti whale in the Lower Pliocene Huelva Sands Formation (southern Spain). Geologica Acta, vol. 7, 2009, pp. 489-505

- FALlOT, P. (1922) Étude Géologique de la Sierra de Majorque. Paris: Librerie polytechnique Ch. Béranger, 1922, $481 \mathrm{p}$.

- FALLOT, P. (1945) Estudios geológicos en la zona subbética entre Alicante y el Río Guadiana Menor. Consejo Superior de Investigaciones Científicas, Instituto de Inves tigaciones Geológicas, 1945, 719 p.

- FENERO, R.; THOMAS, E.; ALEGRET, L. et ál. (2012) Oligocene benthic foraminifera from the Fuente Caldera section (Spain, Western Tethys: taxonomy and paleoenvironmental inferences). Journal of Foraminiferal Research, vol. 42, 2012, pp. 286-304

- FLORES, J. A.; SIERRO, F. J.; FILIPPELLI, G. M. et ál. (2005) Surface water dynamics and phytoplankton communities during deposition of cyclic late Messinian sapropel sequences in the western Mediterranean. Marine Micropaleontology, vol. 56, 2005, pp. 50-79

- FRAU, C.; BULOT, L. G.; DELANOY, G. etál. (en prensa) The Aptian GSSP candidate at Gorgo a Cerbara (Central Italy): an alternative interpretation of the bio-, litho- and chemostratigraphic markers. Newsletter on Stratigraphy <https://doi.org/10.1127/ nos/2017/0422> [Consulta: 19/12/2017]

- GARCÍA-CORTÉS, A. (ed.) (2008) Contextos geológicos españoles: una aproximación al patrimonio geológico español de relevancia internacional. Instituto Geológico y Minero de España, 2008, 235 p.

- GARCíA SENZ, J. (2002) Cuencas extensivas del Cretácico inferior en los Pirineos centrales, formación y subsecuente inversión. Tesis doctoral inédita, Universitat de Barcelona, 2002

- GARcíA, E. X. M.; ANTUNES, M. T.; CÁCERESBALBINO, A. et ál. (2009) Los tiburones Lamniformes (Chondrichthyes, Galeomorphii) del Plioceno inferior de la formación Arenas de Huelva, suroeste de la cuenca de Guadalquivir, España. Revista Mexicana de las Ciencias Geológicas, vol. 26, n. ${ }^{\circ}$ 3, 2009

- GÓMEZ DE LLARENA, J.; POU, J. (1914) Excursión geológica a Navas de Estena (montes de Toledo). Boletín de la Real Sociedad Española de Historia Natural, vol. 14 1914, pp. 385-388

- GONG, Z.; DEKKERS, M. J.; DINARÉS-TURELL, J. et ál. (2008) Remagnetization mechanism of Lower Cretaceous rocks from the Organyà basin (Pyrenees, Spain). Studia Geophysica et Geodaetica, vol. 52, 2008, pp. 187-210

- GONZÁleZ DELGADO, J. A. (1983) Estudio de los Gasterópodos del Plioceno de Huelva. Tesis doctoral inédita. Universidad de Salamanca, $474 \mathrm{p}$.

- GONZÁlEZ DELGADO, J. A.; ANDRES, I.; SIERRO, F. J. (1995) Late neogene molluscan faunas from the Northeast Atlantic (Portugal, Spain, Morocco). Geobios, vol. 28, n. ${ }^{\circ} 4,1995$, pp. 459-471

- GONZÁlEZ DONOSO, J. M.; MOLINA, E. (1977-1978) El corte del Navazuelo (Cordilleras Béticas, Provincia de Granada). Posible hipoestratotipo del límite Oligoceno/ Mioceno. Cuadernos de Geología, vol. 8-9, 1977-1978, pp. 225-240

- GONZÁLEZ-DELGADO, J. A.; MARTÍNEZ-GRAÑA, A. M.; CIVIS, J. et ál. (2015) Virtual 3D tour of the Neogene palaeontological heritage of Huelva (Guadalquivir Basin, Spain). Environmental Earth Sciences, vol. 73, 2015, pp. 4609-4618

- GOZALO, R.; LIÑÁN, E.; DIES, M. E. (2003) Intraspecific dimorphism in an evolutionary series of paradoxidids from 
the Middle Cambrian of Murero, Spain. En LANE, P. D; SIVETER, D. J.; FORTEY, R. A. (ed.) Trilobites and their relavies (proceedings of Oxford conference. Special Papers in Palaeontology), vol. 70, 2003, pp. 141-156

- GUERNET, C.; MOLINA, E. (1997) Les Ostracodes et le passage Paléocene-Éocene dans les Cordilleres Bétiques (coupe de Caravaca, Espagne). Geobios, vol. 30, 1997, pp. 31-43

- GUERRA-MERCHÁN, A. (1997) Registro sedimentario de la transgression plioceno al sur de Sierra Bermeja (Cordillera Bética, Mediterráneo occidental). Cuadernos de Geología Ibérica, vol. 22, 1997, pp. 103-120

- GUERRA-MERCHÁN, A.; PALMQVIST, P.; LOZANO FRANCISCO, M. D. C. (1996) Análisis sedimentológico y paleoecológico del yacimiento plioceno de Parque Antena (Estepona, Málaga). Revista Española de Paleontología, vol. 11, 1996, pp. 226-234

- GUTIÉRREZ MARCO, J. C.; RÁBANO, I.; LIÑÁN, E. et ál. (2008) Las sucesiones estratigráficas del Paleozoico inferior y medio. En Contextos geológicos españoles: una aproximación al patrimonio geológico español de relevancia internacional. Instituto Geológico y Minero de España, Madrid, 2008, pp. 31-43

- GUTIÉRREZ MARCO, J. C.; RABANO, I.; BARRÓN, E. (2011) Geodiversidad en el Parque Nacional de Cabañeros (Ciudad Real-Toledo): la ruta del Boquerón de Estena. Madrid: Real Sociedad Española de Historia Natural, 2011, $26 \mathrm{p}$.

- GUTIÉRREZ-MARCO, J. C.; SAN JOSÉ LANCHA, M. A. (DE); PIEREN, A. P. et ál. (2007) La sucesión paleozoica del Parque Nacional de Cabañeros (Ciudad Real-Toledo). Cuadernos del Museo Geominero, vol. 8, pp. 417-434

- HAINE, J. (1855) Notice sur la géologie de l'ile de Majorque. Bulletin de la Societé géologique de France, vol. 2, 1855, pp. 734-752

- HANISCH, J. (1972) Venicale veneilung der ichnofossilien im Tertiar-flysch von Zumaya (N. Spanien). Neues Jarbuch fur Geologie und Paläontologie, Mh., vol. 9, 1972, pp. 511526

- HeRMite, H. (1879) Études géologiques sur les lles Baléares. Prémiere partie. Majorque et Minorque. Tesis, Paris, $362 \mathrm{p}$.

- HILLEBRANDT, A. VON (1965) ForaminiferenStrarigraphie im Alt- tertiar von Zumaya (Prov. Guipuzcoa, NW Spanien) und ein Vergleoch mit anderen TethysGebietsn. Bayerische Akademie der Wissenschaften, vol. 123, 1965, 62 p.

- HOEDEMAEKER, P. J. (1994) Ammonite distribution around the Hauterivian-Barremian boundary along the Río
Argos (Caravaca, SE Spain). Géologie Alpine, Mémoires hors série, vol. 20, 1994, pp. 219-277

- HOTTINGER, L. (1960) Recherches sur les Alvéolines du Paléocène et de l'Eocene. Mémoires Suisses de Paléontologie, 75-76, 1960, $236 \mathrm{p}$.

- KAIHO, K.; LAMOLDA, M. (1999) Catastrophic extinction of planktonic foraminifera at the Cretaceous-Tertiary boundary evidenced by stable isotopes and foraminiferal abundance at Caravaca, Spain. Geology, vol. 27(4), 1999, pp. 355-358

- KRIJGSMAN, W.; FORTUIN, A. R.; HILGEN, F. J. et ál. (2001) Astrochronology for the Messinian Sorbas basin (SE Spain) and orbital (precessional) forcing for evaporite cyclicity. Sedimentary Geology, vol. 140, 2001, pp. 43-60

- KRIJGSMAN, W.; HILGEN, F.; RAFFI, I. et ál. (1999) Chronology, causes and progression of the Messinian salinity crisis. Nature, vol. 400, n. ${ }^{\circ} 6745,1999$, pp. 652-655

- LA MARMORA, A. DE (1835) Observations géologiques sur les deux iles Baléares. Memorias Academia Scienze Torino, vol. 38, 1835, pp. 1-51

- LAMOLDA, M. A.; HANCOCK, J. M. (1996) The Santonian Stage and substages. Bulletin de l'Institut Royal des Sciences Naturelles de Belgique, Sciences de la Terre, vol. 66, 1996, pp. 95-102

- LAMOldA, M. A.; PAUL, C. R. C.; PERYT, D. et ál. (2014) The Global Boundary Stratotype and Section Point (GSSP) for the base of the Santonian Stage, "Cantera de Margas", Olazagutia, northern Spain. Episodes, vol. 37, 2014, pp. 2-13

- LINARES, A.; SANDOVAL, J. (1990) The lower boundary of the Bajocian in the "Barranco de Agua Larga" section, (Subbetic Domain, Southern Spain). Memorie descrittive Carta Geologica D' Italia, vol. 40, 1990, pp. 13-22

- LINARES, A.; SANDOVAL, J. (1996) The genus Haplopleuroceras (Erycitidae, Ammonitina) in the Betic Cordillera, Southern Spain. Geobios, vol. 29, 1996, pp. 287-305

- LIÑÁN, E.; GOZALO, R.; DIES ÁlVAREZ, M. E. et ál. (2008) Fouth International Trilobite Conference, Trilo 08. Toledo, Spain, 2008. Post-Conference Field Trip. Lower and Middle Cambrian trilobites of selected localities in Cadenas Ibéricas (NE, Spain), 2008, $52 \mathrm{p}$.

- LIÑÁN, E.; GOZALO, R. (1986) Trilobites del Cámbrico Inferior y medio de Murero (Cordillera Ibérica). Memorias del Museo Paleontológico de la Universidad de Zaragoza, vol. 2, 1986, pp. 1-104

- MARQUíNEZ, J.; MÉNDEZ, C. A.; MENÉNDEZALVAREZ, J. R. et ál. (1982) Datos bioestratigráficos de la sucesión carbonífera (Tumesiense-Kasi- moviense) de las 
Llacerias, Picos de Europa, Norte de España. Trabajos de Geología, vol. 12, 1982, pp. 187-193

- MARTÍN, J. M.; BRAGA, J. C.; RIDING, R. (1993) Siliciclastic stromatolites and thrombolites, Late Miocene, SE Spain. Journal of Sedimentary Petrology, vol. 63, n. ${ }^{\circ}$, 1993, pp. 131-139

- MARTínEZ, G. (1992) Hammatoceratinae (Ammonitina) del Toarciense superior y Aaleniense en la Cordillera Ibérica. Colección Tesis Doctorales n. ${ }^{\circ} 374 / 92$, Universidad Complutense de Madrid, 1992, 331 p.

- MARTíneZ, M.; PELLENARD, P.; DECONINCK; J. F. et ál. (2012) An orbital floating time scale of the Hauterivian/ Barremian GSSP from a magnetic susceptibility signal (Río Argos, Spain). Cretaceous Research, vol. 36, 2012, pp. 106-115

- MAYORAL, E. (1986) Tafonomía y paleoecología del Plioceno de Huelva-Bonares. Tesis doctoral inédita, Universidad de Sevilla, 1986, 599 p.

- MAYORAL, E.; LIÑÁN, E.; GÁMEZ VINTANED, J. A. et ál. (2008) El Cámbrico inferior del Cerro del Hierro (Sevilla). Propuesta de itinerario paleontológico. En CUENCA BONILLA, I.; MENOR CAMPILLO, A. (coord.) Investigación científica y conservación en el Parque Natural Sierra Norte de Sevilla. Sevilla: Consejería de Medio Ambiente, Junta de Andalucía, 2008, pp. 27-43

- MIRAS, A. (1990) Geoquímica y mineralizaciones de los depósitos de barita de Badajoz y Sevilla. Tesis doctoral inédita. Universidad de Sevilla, 481 p.

- MOLINA, E. (1980) Oligoceno-Mioceno inferior por medio de foraminíferos planctónicos en el sector central de las Cordilleras Béticas (España). Tesis doctoral. Publicación Universidades de Granada y Zaragoza, 1980, 342 p.

- MOLINA, E. (1986a) Excursión al Cretácico Superior y Paleógeno del Prepirineo Oscense en el sector de Arguis. Memorias de las I Jornadas de Paleontología. Zaragoza, 1986, pp. 235-247

- MOLINA, E. (1986b) Description and biostratigraphy of the main reference section of the Eocene/Oligocene boundary in Spain: Fuente Caldera section. En POMEROL, CH.; PREMOLI-SILVA, I. (ed.) Terminal Eocene Events. Elsevier, 1986, pp. 53-63

- MOLINA, E. (1994) Paleocene sections in Spain: chronostratigraphical problems and possibilities. GFF, vol. 116,1994 , pp. 58-60

- MOLINA, E. (2004) Eventos de extinción del CretácicoTerciario: valor patrimonial y conservación del barranco del Gredero (Caravaca, Murcia). En GUILLÉN MONDÉJAR, F.; DEL RAMO, A. (ed.) El patrimonio geológico: cultura, turismo y medio ambiente. Actas de la $V$ Reunión de la Comisión de Patrimônio Geológico de la Sociedad Geológica de España. Murcia: Universidad de Murcia, 2004, pp. 41-49

- MOLINA, E.; ARENILLAS, I. (1998) The Paleogene of the Zumaya section. En LAMOLDA, M. A. (ed.) Libro guía del $24^{\circ}$ Coloquio Europeo de Micropaleontología, 1998, pp. 93-97

- MOLINA, E.; ALEGRET, L.; ARENILLAS, I. et ál. (2009) The Global Boundary Stratotype Section and Point for the base of the Danian Stage (Paleocene, Paleogene, "Tertiary", Cenozoic): auxiliary sections and correlation. Episodes, vol. 32, 2009, pp. 84-95

- MOLINA, E.; ALEGRET, L.; ARENILLAS, I. et ál. (2001) Field-trip guide to the Agost and Caravaca sections (Betic Cordillera, Spain). En MARTíNEZ RUIZ, F. C.; MOLINA, E.; RODRÍGUEZ TOVAR, F. J. (ed). 6th Impact Markers in the Stratigraphic Record. Granada. 2001, 72 p.

- MOLINA, E.; ANGORI, E.; ARENILLAS, I. et ál. (2003) Correlation between the Paleocene/Eocene boundary and the Ilerdian at Campo, Spain. Revue de Micropaléontologie, vol. 46, 2003, pp. 95-109

- MOLINA, E.; CANUDO, J. I.; GUERNET, C. et ál. (1992) The stratotypic ilerdian revisited: integrated stratigraphy across the Paleocene/Eocene boundary. Revue de Micropaléontologie, vol. 35, 1992, pp. 143-156

- MOLINA, E.; CANUDO, J. I.; MARTÍNEZ-RUIZ, F. et ál. (1994) Integrated stratigraphy across the Paleocene/ Eocene boundary at Caravaca, southern Spain. Eclogae geologicae Helvetiae, vol. 87, 1994, pp. 47-61

- MOLINA, E.; ALEGRET, L.; APELLANIZ, E. et ál. (2011) The Global Standard Stratotype-section and Point (GSSP) for the base of the Lutetian Stage at the Gorrondatxe section, Spain. Episodes, vol. 34, 2011, pp. 86-108

- MOLINA, E.; ALEGRET, L.; ARENILLAS, I. et ál. (2005) The Cretaceous/Paleogene boundary at the Agost section revisited: paleoenvironmental reconstruction and mass extinction pattern. Journal of Iberian Geology, vol. 31, 2005, pp. $135-148$

- MOLINA, E.; ALEGRET, L.; SERRA-KIEL, J. (2013) LoS microfósiles del Prepirineo de Arguis (Huesca): breve guía para observarlos y reconocerlos. Naturaleza Aragonesa, vol. 30, 2013, pp. 4-12

- MONDÉJAR A.; DEL RAMO (ed.) (2004) El patrimonio geológico: cultura, turismo y medio ambiente. Actas de la $\checkmark$ Reunión de la Comisión de Patrimônio Geológico de la Sociedad Geológica de España. Murcia: Universidad de Murcia, 2004, pp. 41-49

- MORENO-BEDMAR, J. A. (2010) Ammonits de l'Aptià inferior de la Península Ibèrica. Biostatigrafia $i$ aportacions 
a l'estudi del Oceanic Anoxic Event 1a. Tesis doctoral inédita. Universitat de Barcelona, 2010. <http://hdl. handle. net/2445/34792> [Consulta 19/12/2017]

- NOLAN, H. (1893) Sur les terrains triasique et jurasique des iles Baléares. Comptes Rendus de l'Académie des sciences de Paris, vol. 117, 1893, pp. 821-823

- O'DOGHERTY, L.; SANDOVAL, J.; BARTOLINI, A. et ál. (2006) Carbon-isotope stratigraphy and ammonite faunal turnover for the Middle Jurassic in the Southern Iberian palaeomargin. Palaeogeography, Palaeoclimatology, Palaeoecology, vol. 239, 2006, pp. 311-333

- OGG, J. G.; HINNOV, L. A. (2012) Cretaceous. En GRADSTEIN, F. M.; OGG, J. G.; SCHMITZ, M. et ál. (ed.) The Geologic Time Scale 2012. Amsterdam: Elsevier, 2012, pp. $793-853$

- OGG, J. G.; STEINER, M. B.; COMPANY, M. et ál. (1988) Magnetostratigraphy across the Berriasian-Valanginian stage boundary (Early Cretaceous), at Cehegin (Murcia Province, southern Spain). Earth and Planetary Science Letters, vol. 87, 1988, pp. 205-215

- OLÓRIZ, F.; CARACUEL, J.; MARQUES, B. et ál. (1995) Asociaciones de Tintinnoides en facies Ammonitico Rosso de la Sierra Norte (Mallorca). Revista Española de Paleontología, número homenaje al Dr. Guillermo Colom, 1995, pp. 77-93

- OLÓRIZ, F.; LINARES, A.; GOY, A. et ál. (2002) Jurassic in the Betic Cordillera and Balearic Island. En GIBBONS, W.; MORENO, T. (ed.), The Geology of Spain. The Geological Society. London, 2002, pp. 235-253

- ORUE-ETXEBARRIA, X.; APELLANIZ, E. (1985) Estudio del límite Cuisiense-Luteciense en la Costa Vizcaina por medio de foraminíferos planctónicos. Newsletters on Stratigraphy, vol. 15(1), 1985, pp. 1-12

- OSETE, C. (1999) Estudio magnetoestratigráfico en las Cordilleras Béticas. Límites Bajociense-Bathoniense y Toarciense-Aaleniense. Tesis de diplomatura. Universidad Complutense de Madrid, $112 \mathrm{p}$.

- PAVIA, G.; ENAY, R. (1997) Definition of the AalenianBajocian Stage boundary. Episodes, vol. 20, 1997, pp. 16-20

- PAYRos, A.; ORUE-ETXEBARRIA, X.; BERNAOLA, G. et ál. (2009) Characterization and astronomically calibrated age of the first ocurrence of Turborotalia frontosa in the Gorrondatxe section, a prospective Lutetian GSSP: implications for the Eocene time scale. Lethaia, vol. 42, 2009, pp. 255-264

- PERCONIG, E. (1966) Sul l'esistenza del Miocene superiore in facies marine nella Spagna meridionale. Proceedings of the Third Session in Berne (1964). Com. Med. Neogene Stratigraphy. I.U.G.S., pp. 288-302
- PERCONIG, E. (1968) Biostratigrafía della sezione di Carmona (Andalusia, Spagna) in base ai foraminiferi planctonici. CMNS Proc., IV Session, Bologna, 1967. Giornale di Geologia, vol. 35, 1968, 191 p.

- PERCONIG, E.; GRANADOS, L. F. (1973) El estratotipo del Andaluciense. Guidebook to XIII Coloquio Europeo de Micropaleontologia, España, Sept. 1973, C.N.G. Madrid: Enadimsa, 1973, pp. 225-246

- PÉREZ-FOLGADO, M.; SIERRO, F. J.; BARCENA, M. A. et ál. (2003) Western versus eastern Mediterranean paleoceano graphic response to astronomical forcing: a high-resolution microplankton study of precessioncontrolled sedimentary cycles during the Messinian. Palaeogeography Palaeoclimatology Palaeoecology, vol. 190, 2003, pp. 317-334

- PRUNER, P.; HOUŠA, V.; OLÓRIZ, F. et ál. (2010) High-resolution magnetostratigraphy and biostratigraphic zonation of the Jurassic/Cretaceous boundary strata in the Puerto Escaño section (southern Spain). Cretaceous Research, vol. 31, abril 2010, pp. 192-206

- RIDING, R.; BRAGA, J. C.; MARTÍN, J. M. (1991) Oolite stromatolites and thrombolites, Miocene, Spain: analogues of Recent giant Bahamian examples. Sedimentary Geology, vol. 71, n. ${ }^{\circ} 3,1991$, pp. 121-127

- ROBIN, E.; MOLINA, E. (2006) Chronostratigraphy, composition and source of Ni-rich spinel in the late Eocene Fuente Caldera section (Spain): one impact or more? Meteoritics and Planetary Science, vol. 41, 2006, pp. 12311248

- ROMERO, G.; SANDOVAL, J.; CARACUEL, J. E. et ál. (2004) Jurassic Paleontological heritage of Murcia (Betic Cordillera, South-Eastern Spain). Rivista Italiana di Paleontologia e Startigrafia, vol. 110, 2004, pp. 417-426

- SAN JOSÉ LANCHA, M. A. de; GUTIÉRREZ MARCO, J. C.; RÁBANO, I. (1997) Geología y Paleontología del Parque Nacional de Cabañeros (Ciudad Real). En GARCíA CANSECO, V. (coord.) El Parque Nacional de Cabañeros y sus pueblos. Ed. Eco-hábitat, 1997, pp. 51-76

- SÁNCHEZ DE POSADA, L. C, VILLA, E., MARTíNEZ CHACÓN, M. L et ál. (1999) Contenido paleontológico y edad de la sucesión de Demués (Carbonífero, Zona Cantábrica). Trabajos de geología, vol. 21, 1999, pp. 339352

- SÁNCHEZ DE POSADA, L. C.; MARTÍNEZ CHACÓN, E.; VILLA, E. et ál. (2002) The Carboniferous succession of the Asturian-Leonese Domain. An overview. Cuadernos del Museo Geominero, vol. 1, 2002, pp. 61-91

- SÁNCHEZ-HERNANDEZ, Y.; MAURRASSE, F. J. (2014) Geochemical characterization and redox signals from 
the latest Barremian to the earliest Aptian in a restricted marine basin: El Pui section, Organyà Basin, south-central Pyrenees. Chemical Geology, vol. 372, 2014, pp. 12-31

- SANDOVAL, J. (1983) Bioestratigrafía y Paleontología (Stephanocerataceae y Perisphinctaceae) del Bajocense y Bathonense de las Cordilleras Béticas. Tesis Doctoral, Universidad de Granada. Secretariado de Publicaciones, Universidad de Granada, 613 p.

- SANDOVAL, J. (1994) The Bajocian stage in the Island of Majorca: Biostratigraphy and ammonite assemblages. Miscellania del Servizio Geológico Nazionale, vol. 5, 1994 pp. 203-215

- SANDOVAL, J. (2016) Ammonite assemblages and chronostratigraphy of the uppermost Bajocian-Callovian (Middle Jurassic) of the Murcia Region (Betic Cordillera, south-eastern Spain). Proceedings of the Geologists' Association, vol. 127, 2016, pp. 230-246

- SANDOVAL, J.; O’DOGHERTY, L.; BILL, M. et ál. (2011) Estratigrafía isotópica del Bajociense Superior-Calloviense (Jurásico) en sierras de Lúgar y Corque: Subbético externo, Región de Murcia. Paleontologia i Evolución, M. E., 2011, pp. 349-353

- SANDOVAL, J.; CHANDLER, R. B. (2000) The Sonniniid ammonite Euhoploceras from the Middle Jurassic of southwest England and southern Spain. Palaeontology, vol. 43, 2000, pp. 495-532

- SANDOVAL, J.; CHANDLER, R. B. (2015) Labyrinthoceras and Frogdenites (Sphaeroceratidae, Ammonitina) from Western Tethys: The origin of the Sphaeroceratidae. Geobios, vol. 48, 2015, pp. 39-56

- SANDOVAL, J.; CHECA, A. (2002) Taphonomy of cephalopods concentrations in the Jurassic of the Subbetic. En DE RENZI, M. et ál. (ed.) Currents Topics on Taphonomy and Fossilization. Ayuntamiento de Valencia, 2002, pp. 223-230.

- SANDOVAL, J.; LINARES, A.; HENRIQUES, M. H. (2000) The Middle Jurassic genus Riccardiceras (Otoitidae, Ammonitina) in the westernmost Tethys: Betic Cordillera and Lusitanian Basin. Revue de Paleobiologie, vol. 8, 2000, pp. 29-44

- SCHAUB, H. (1981) Nummulites et Assilines de la Téthys Paléogène. Taxonomie, hylogénèse et biostratigrafíe. Mémories Suisses de Paléontologíe, vol. 104-106, 1981, $236 \mathrm{p}$.

- SCHLÖGL, J.; ELMI, S.; RAKÚS, M. et ál. (2006) Specialization and iterative evolution of some Western Tethyan Bathonian ammonites [Benatinites (B.) nov. B. (Lugariceras) nov. and Hemigarantia. Geobios, vol. 39, 2006, pp. 113-124
- SCHMITZ, B.; ASARO, F.; MOLINA, E. et ál. (1997) Highresolution iridium, $\partial 13 \mathrm{C}, \partial 18 \mathrm{O}$, foraminifera and nannofossil profiles across the latest Paleocene benthic extinction event at Zumaya, Spain. Palaeogeography, Palaeoclimatology, Palaeoecology, vol. 133, 1997, pp. 49-68

- SCHMITZ, B.; MOLINA, E.; VON SALIS, K. (1998) The Zumaya section in Spain: a posible global stratoype section for the Selandian and Thanetian Stages. Newsletters on Stratigraphy, vol. 36, 1998, pp. 35-42

- SCHMITZ, B.; PUJALTE, V.; MOLINA, E. et ál. (2011) The Global Stratotype Section and Points for the bases of the Selandian (Middle Paleocene) and Thanetian (Upper Paleocene) stages at Zumaia, Spain. Episodes, vol. 34, 2011, pp. 220-243

- SEYFRIED, H. (1978) Der subbetische Jura von Murcia (Südost-Spanien). Geologisches Jahrbuch, vol. 29, 1978, pp. 3-201

- SIERRO, F. J.; FLORES, J. A.; CIVIS, J. et ál. (1993) Late Miocene Globorotaliid event-stratigraphy and biogeography in the NE Atlantic and Mediterranean. Marine Micropaleontology, vol. 21, 1993, pp. 143-168

- SIERRO, F. J.; FLORES, J. A.; FRANCES, G. et ál. (2003) Orbitally-controlled oscillations in planktic communities and cyclic changes in western Mediterranean hydrography during the Messinian. Palaeogeography, Palaeoclimatology, Palaeoecology, vol. 190, 2003, pp. 289-316

- SIERRO, F. J.; FLORES, J. A.; ZAMARRENO, I. et ál. (1999) Messinian pre-evaporite sapropels and processioninduced oscillations in western Mediterranean climate. Marine Geology, vol. 153, 1999, pp. 137-146

- SIERRO, F. J.; GONZÁLEZ-DELGADO, J. A.; DABRIO, C. J. et ál. (1996) Late Neogene depositional sequences in the foreland basin of Guadalquivir (SW Spain). En FRIEND P.; DABRIO, C. J. Tertiary Basins of Spain: The stratigraphic record of crustal kinematics. Cambridge University Press, 1996, pp. 329-334

- SIERRO, F. J.; HILGEN, F. J.; KRIJGSMAN, W. et ál. (2001) The Abad composite (SE Spain): a Messinian reference section for the Mediterranean and the APTS. Palaeogeography, Palaeoclimatology, Palaeoecology, vol. 168, 2001, pp. 141-169

- SILVA S. C.; CANALES M. L; SANDOVAL, J. et ál. (2017) Paleoecological analysis based on benthic foraminifera of the Aalenian-Bajocian boundary (Middle Jurassic) in the Barranco de Agua Larga section (Betic Cordillera, SE Southern Spain). Journal of Iberian Geology, vol. 43, 2017, pp. 1-22

- SMIT, J. (1979) The Cretaceous-Tertiary transition in the Barranco del Gredero, Spain. En CHRISTENSEN W. K.; 
BIRKELUND T. (ed) Proc. C-T boundary event Symp., vol. 11, 1979, pp. 156-163.

- SMIT, J. (1982) Extinction and evolution of planktonic foraminifera afler a major impact at the Cretaceous/Tertiay boundary. Geological Society of America, Special Paper, vol. 190, 1982, pp. 329-352

- SMIT, J.; HERTOGEN J. (1980) An extraterrestrial event at the Cretaceous-Tertiary boundary. Nature, vol. 285, 1980, pp. $198-200$

- SVOBODOVÁ, A.; KOŠŤÁK, M. (2016) Calcareous nannossils of the Jurassic/Cretaceous boundary strata in the Puerto Escaño section (southern Spain) biostratigraphy and palaeoecology. Geologica Carpathica, vol. 67, 2016, pp. 223-238

- VAN DEN BERG, B. C. J.; SIERRO, F. J.; HILGEN, F. J. et ál. (2015) Astronomical tuning for the upper Messinian Spanish Atlantic margin. Disentangling basin evolution, climate cyclicity and MOW. Global and Planetary Change, vol. 135, 2015, pp. 89-103

- VERA-PELÁEZ, J.L.; LOZANO-FRANCISCO, M. C.; MUÑIZ SOLÍS, R. et ál. (1995) Estudio preliminar de la malacofauna del Plioceno de Estepona (Málaga, España). Iberus, vol. 13, 1995, pp. 93-117

- VERA, J. A.; ARIAS, C.; GARCÍA-HERNÁNDEZ, M. et ál. (2004) Cordillera Bética y Baleares: Las Zonas Externas Béticas y el Paleomargen Subdibérico. En VERA, J. A. (ed.) Geología de España. Madrid: SGE-IGME, 2004, pp. 354361

- WARD, P. D.; KENNEDY, W. J. (1993) Maastrichlian ammonites from the Biscay region (France, Spain). Memoirs of the Paleontolological Society, vol. 34, 1993, pp. 1-58

- WARD, P. D.; WIEDMANN J.; MOUNT, J. F. (1986) Maastrichtian molluscan biostratigraphy and extinction pattems in a Cretaceous/Tertiary boundary section exposed at Zumaya. Geology, vol. 14, 1986, pp. 899-903 